\title{
Advances in understanding mineral dust and boundary layer processes over the Sahara from Fennec aircraft observations
}

\author{
C. L. Ryder ${ }^{1}$, J. B. McQuaid ${ }^{2,6}$, C. Flamant ${ }^{3}$, P. D. Rosenberg ${ }^{2}$, R. Washington ${ }^{4}$, H. E. Brindley ${ }^{5}$, E. J. Highwood ${ }^{1}$, \\ J. H. Marsham ${ }^{2,6}$, D. J. Parker ${ }^{2}$, M. C. Todd ${ }^{7}$, J. R. Banks ${ }^{5}$, J. K. Brooke ${ }^{2,8}$, S. Engelstaedter ${ }^{4}$, V. Estelles ${ }^{\text {, a }}$, \\ P. Formenti ${ }^{10}$, L. Garcia-Carreras ${ }^{2}$, C. Kocha ${ }^{3}$, F. Marenco $^{8}$, H. Sodemann ${ }^{11, b}$, C. J. T. Allen ${ }^{4}$, A. Bourdon ${ }^{12}$, \\ M. Bart ${ }^{2, c}$, C. Cavazos-Guerra ${ }^{7, d}$, S. Chevaillier ${ }^{10}$, J. Crosier ${ }^{13}$, E. Darbyshire ${ }^{1,13}$, A. R. Dean ${ }^{14}$, J. R. Dorsey ${ }^{13}$, \\ J. Kent ${ }^{8}$, D. O'Sullivan ${ }^{8}$, K. Schepanski ${ }^{2, e}$, K. Szpek ${ }^{8}$, J. Trembath ${ }^{14}$, and A. Woolley ${ }^{14}$ \\ ${ }^{1}$ Department of Meteorology, University of Reading, Reading, RG6 6BB, UK \\ ${ }^{2}$ School of Earth and Environment, University of Leeds, Leeds, LS2 9JT, UK \\ ${ }^{3}$ Sorbonne Universités, UPMC, Université Paris 06, CNRS \& UVSQ, UMR 8190 LATMOS, Paris, France \\ ${ }^{4}$ School of Geography and the Environment, University of Oxford, Oxford, UK \\ ${ }^{5}$ Space and Atmospheric Physics, Department of Physics, Imperial College London, London, UK \\ ${ }^{6}$ National Centre for Atmospheric Science, University of Leeds, Leeds, LS2 9JT, UK \\ ${ }^{7}$ Department of Geography, University of Sussex, Brighton BN1 9QJ, UK \\ ${ }^{8}$ Met Office, Exeter, EX1 3PB, UK \\ ${ }^{9}$ Dept. Física Fundamental y Experimental, Electrónica y Sistemas, Universidad de La Laguna, \\ San Cristóbal de La Laguna, Spain \\ ${ }^{10}$ LISA, UMR CNRS 7583, Université Paris Est Créteil et Université Paris Diderot, \\ Institut Pierre Simon Laplace, Créteil, France \\ ${ }^{11}$ Institute for Atmospheric and Climate Science, ETH Zurich, Zurich, Switzerland \\ ${ }^{12}$ SAFIRE, UMS CNRS-CNES-Météo-France, Francazal, France \\ ${ }^{13}$ National Centre for Atmospheric Science, University of Manchester, Manchester, M13 9PL, UK \\ ${ }^{14}$ Facility for Airborne Atmospheric Measurements, Cranfield, MK43 0AL, UK \\ ${ }^{a}$ now at: Department of Earth Physics and Thermodynamics, Universitat de València, Santa Cruz de Tenerife, Spain \\ ${ }^{b}$ now at: Geophysical Institute, University of Bergen, Bergen, Norway \\ ${ }^{c}$ now at: Aeroqual Ltd, 109 Valley Road, Auckland, New Zealand \\ ${ }^{d}$ now at: Institute for Advanced Sustainability Studies (IASS), Berliner Straße 130, 14467 Potsdam, Germany \\ enow at: Leibniz Institute for Tropospheric Research, Permoserstr. 15, 04318 Leipzig, Germany
}

Correspondence to: C. L. Ryder (c.l.ryder@reading.ac.uk)

Received: 10 November 2014 - Published in Atmos. Chem. Phys. Discuss.: 7 January 2015

Revised: 15 June 2015 - Accepted: 24 June 2015 - Published: 30 July 2015

\begin{abstract}
The Fennec climate programme aims to improve understanding of the Saharan climate system through a synergy of observations and modelling. We present a description of the Fennec airborne observations during 2011 and 2012 over the remote Sahara (Mauritania and Mali) and the advances in the understanding of mineral dust and boundary layer processes they have provided. Aircraft instrumentation aboard the UK FAAM BAe146 and French SAFIRE (Service des Avions Français Instrumentés pour la Recherche en
\end{abstract}

Environnement) Falcon 20 is described, with specific focus on instrumentation specially developed for and relevant to Saharan meteorology and dust. Flight locations, aims and associated meteorology are described. Examples and applications of aircraft measurements from the Fennec flights are presented, highlighting new scientific results delivered using a synergy of different instruments and aircraft. These include (1) the first airborne measurement of dust particles sizes of up to 300 microns and associated dust fluxes in the 
Saharan atmospheric boundary layer (SABL), (2) dust uplift from the breakdown of the nocturnal low-level jet before becoming visible in SEVIRI (Spinning Enhanced Visible Infra-Red Imager) satellite imagery, (3) vertical profiles of the unique vertical structure of turbulent fluxes in the SABL, (4) in situ observations of processes in SABL clouds showing dust acting as cloud condensation nuclei $(\mathrm{CCN})$ and ice nuclei (IN) at $-15^{\circ} \mathrm{C}$, (5) dual-aircraft observations of the SABL dynamics, thermodynamics and composition in the Saharan heat low region (SHL), (6) airborne observations of a dust storm associated with a cold pool (haboob) issued from deep convection over the Atlas Mountains, (7) the first airborne chemical composition measurements of dust in the SHL region with differing composition, sources (determined using Lagrangian backward trajectory calculations) and absorption properties between 2011 and 2012, (8) coincident ozone and dust surface area measurements suggest coarser particles provide a route for ozone depletion, (9) discrepancies between airborne coarse-mode size distributions and AERONET (AERosol Robotic NETwork) sunphotometer retrievals under light dust loadings. These results provide insights into boundary layer and dust processes in the SHL region - a region of substantial global climatic importance.

\section{Background and motivation}

The Sahara desert remains one of the most data-sparse regions on the planet. During the northern summer, a vast low pressure system, the Saharan heat low (SHL), exists over the central Sahara caused by the strong solar heating and this drives major dynamical features (e.g. Lavaysse et al., 2009; Chauvin et al., 2010). Strong sensible surface fluxes generate near-surface temperatures in excess of $40{ }^{\circ} \mathrm{C}$ and a deep Saharan atmospheric boundary layer (SABL) that reaches a height of $6000 \mathrm{~m}$, generating what is commonly regarded as the world's deepest boundary layer (Tompkins et al., 2005; Cuesta et al., 2009) (Gamo, 1996 \#716). To the south of the Sahara lies the Sahel, and the SHL exerts a significant influence upon this region, in particular on the timing of the West African Monsoon (WAM) onset (Lavaysse et al., 2009; Sultan and Janicot, 2003). The prediction of the onset of the WAM has been the topic of a number of recent science programmes, (e.g. the African Monsoon Multidisciplinary Analysis (AMMA); Redelsperger et al., 2006), as it is critical to the livelihoods of the population in this region: the growing season here is short and the ground must be prepared and planted ahead of the arriving rains.

The Sahara is the largest source of mineral dust on the planet, with the highest summer dust loadings co-located with the SHL (Engelstaedter et al., 2006). Mineral dust is an important atmospheric aerosol because of its direct and indirect radiative effects (Forster et al., 2007), its contribution to atmospheric chemistry (de Reus et al., 2005), and its transport and deposition of essential nutrients to the ocean (Jickells et al., 2005). Saharan dust is known to modify hurricane activity by reducing local sea surface temperatures in the Caribbean (Dunion and Velden, 2004; Sun et al., 2009; Jenkins et al., 2008) and in the tropical Atlantic Ocean (Evan et al., 2011, 2009). Saharan dynamics, including haboobs frequently driven by moist convection (Marsham et al., 2013c), low-level jets (Washington et al., 2006) and dust devils and convective plumes (Ansmann et al., 2009), result in vast quantities of dust being lofted into the atmosphere on a very regular basis, where they are then susceptible to synoptic-scale atmospheric transport. Thus, the Saharan region plays a significant role in the weather and climate in the Northern Hemisphere (Tompkins et al., 2005; Rodwell and Jung, 2008), influencing regions far beyond its geographical boundaries.

There are considerable uncertainties in both climate and numerical weather prediction models for this region (Evan et al., 2014; Marsham et al., 2008b; Messager et al., 2010). Representation of the position and intensity of the SHL in climate models varies considerably. Identifying the cause of such discrepancies and ascertaining which representation most closely matches reality can only be addressed through observational data. The extreme nature of the Saharan climate and also the considerable uncertainties associated with mineral dust aerosols in numerical models all compound the discrepancies between models and reality (e.g. Kim et al., 2014; Huneeus et al., 2011; Evan et al., 2014). Additionally, observations of both dust chemical composition and the full size distribution in this remote region are crucial for accurately representing the radiative effect of dust (Formenti et al., 2014; Mahowald et al., 2014).

In the last decade or so, a number of field programmes have been tasked with improving the observational data set of meteorological and aerosol conditions in the wider northern African sector (Table 1 and Fig. 1). With the exception of limited measurements during AMMA (Messager et al., 2010; Cuesta et al., 2008), no previous campaign has focused on this central region of northern Africa during the summer dust season. For example, SAMUM1 was based in Morocco, while SAMUM2 observations took place at Cabo Verde (Heintzenberg, 2009; Ansmann et al., 2011). Fennec was designed to fill critical gaps in observations and understanding of the Saharan climate system.

The Fennec climate programme aims to improve the understanding of and quantify the physical processes controlling the Saharan climate system through a synergy of observational and modelling approaches in order to evaluate and attribute the cause of errors in weather and climate models for this region (Washington et al., 2012). The observational strategy is a large-scale, multi-platform approach involving ground-based measurements, airborne observations and Earth observation. Fennec is an international consortium which includes research groups from the United Kingdom, France, Germany, Switzerland and the United States of 
Table 1. Previous aircraft programmes in the region.

\begin{tabular}{lll}
\hline Campaign & Date & Reference \\
\hline JET2000 & Summer 2000 & Thorncroft et al. (2003) \\
Saharan Dust Experiment (SHADE) & Summer 2000 & Haywood et al. (2003) \\
Dust and Biomass Experiment DABEX & Winter 2006 & Haywood et al. (2008) \\
Dust Outflow and Deposition to the Ocean (DODO) & Winter/Summer 2006 & McConnell et al. (2008) \\
African Monsoon Multidisciplinary Analysis (AMMA) & 2006 & Redelsperger et al. (2006) \\
NASA AMMA (NAMMA) & Summer 2006 & Zipser et al. (2009) \\
Saharan Mineral Dust Experiment 1 (SAMUM1) & 2006 & Heintzenberg (2009) \\
Saharan Mineral Dust Experiment 2 (SAMUM2) & 2008 & Ansmann et al. (2011) \\
Geostationary Earth Radiation Budget Intercomparison of & Summer 2007 & Haywood et al. (2011a) \\
Long-wave and Short-wave radiation (GERBILS) & & \\
\hline
\end{tabular}

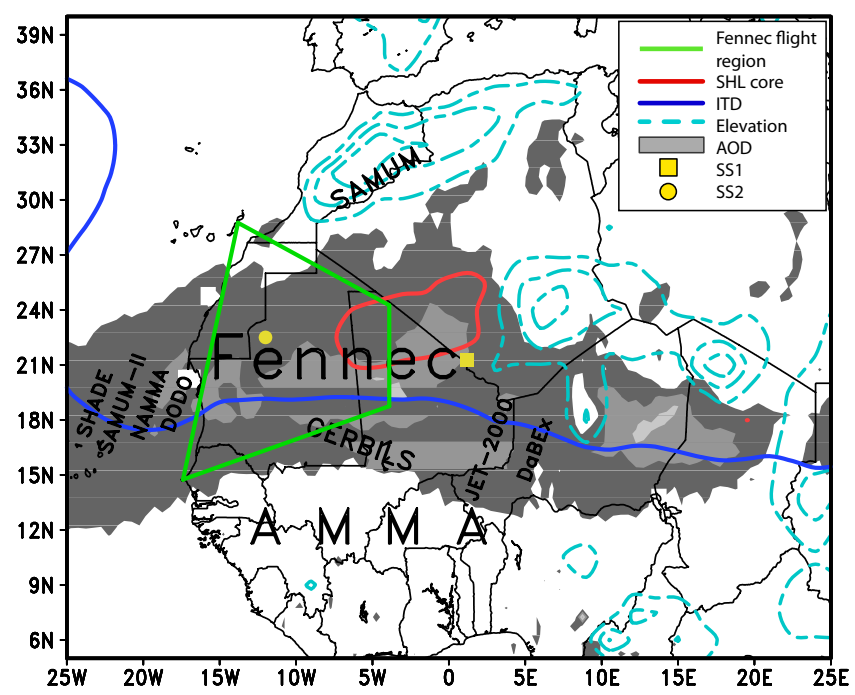

Figure 1. The Fennec domain and climatology. The figure shows mean (2000-2012) June-September aerosol optical depth (AOD) from Multi-angle Imaging SpectroRadiometer (MISR) satellite data (shaded, contour intervals are 0.4, 0.6 and 0.8) and key mean JuneSeptember circulation features derived from ERA-Interim reanalysis data (1979-2012), specifically the mean position of the Saharan heat low core (1008 $\mathrm{hPa}$ contour of sea level pressure, thick red contour); the mean position of the inter-tropical discontinuity (solid blue line, as defined by the $10 \mathrm{~g} \mathrm{~kg}^{-1}$ contour of $925 \mathrm{hPa}$ specific humidity). The figure also highlights the location of the two Fennec supersites (SS1 yellow square, SS2 yellow circle), and approximate aircraft flight zone (green polygon). Also indicated are surface elevation (dashed cyan contours, 1000, 1500 and $2000 \mathrm{~m}$ ) and the approximate location of recent airborne field campaigns.

America working in collaboration with the meteorological services of Algeria and Mauritania in northern Africa.

This paper will focus on the airborne operations that were deployed as part of the Fennec programme and key scientific findings stemming from the airborne programme. Observations by means of an airborne platform provide an invaluable approach, including access to remote, inhospitable regions of the Sahara, tracking of non-static atmospheric features and providing vertical profile observations as well as dust observations above the surface layer, which is vital to understanding the capacity for long-range transport of uplifted dust. Airborne platforms can be positioned at appropriate altitudes for dedicated remote sensing surveys such as above/below radiatively active layers of mineral dust. Measurements on aircraft platforms provide the ability to link together spatial and temporal features which are simply not accessible through fixed ground sites or satellites or even a combination of both. Furthermore, specifically in the June 2011 intensive observation period (IOP), two aircraft were operated and their combined capabilities meant that specific events could be followed through staggered missions. Finally, the combination of ground, airborne and satellite observations provide the fullest picture possible of the area of interest.

During 2011 and 2012 an extensive data set was collected as part of the Fennec intensive observation programme. These included the deployment of two airborne platforms: the UK BAe146 FAAM and French SAFIRE (Service des Avions Français Instrumentés pour la Recherche en Environnement) F-20 aircraft, and also ground-based observations via two supersites located on the western and eastern flanks of the central Sahara: Zouerate, Mauritania (Todd et al., 2013) and Bordj Badji Mokhtar, Algeria (Allen et al., 2013; Marsham et al., 2013b). These were supplemented by a network of automated weather stations which were installed in the remote desert (Hobby et al., 2013). An overview of the aircraft deployments are provided in Table 2; more detailed flight information is presented later. As part of the outreach activities of the Fennec project a film, "Into the Cauldron: A Meteorological Adventure", was also produced (Sternberg, 2013).

In addition to the Fennec programme, a number of supplementary projects took advantage of the aircraft deployment to the region. The Lagrangian Dust Source Inversion Experiment (LADUNEX) (Sodemann et al., 2015) used the in situ and remote sensing observations of mineral dust in order to validate a Lagrangian particle dispersion model FLEXPART (FLEXible PARTicle dispersion model) and improve its ability to represent dust transport in the atmosphere. The 
Table 2. Overview of IOPs.

\begin{tabular}{llllll}
\hline IOP & Date & Operating base & Aircraft & Number of flights & Number of dropsondes \\
\hline Pilot study & April 2011 & Ouarzazate, Morocco & BAe146 & 6 & 42 \\
IOP1 & June 2011 & Fuerteventura, Canary Islands & BAe146 & 16 (BAe146) & 81 (BAe146) \\
& & & FF-20 & $18($ FF-20) & 136 (FF-20) \\
IOP2 & June 2012 & Fuerteventura, Canary Islands & BAe146 & 14 & 40 \\
\hline
\end{tabular}

RAIN4DUST project exploited the remote sensing data from the French Falcon aircraft to investigate dust sources in relation to sediment supply and surface characteristics in the foothills of the central Saharan mountain ranges (Schepanski et al., 2013). Finally, the Sunphotometer Airborne Validation EXperiment (SAVEX) was designed to take advantage of the use of the island of Fuerteventura as an operating base from which to conduct an intercomparison of a number of sunphotometers installed on Tenerife with aircraft observations.

The aims of this paper are to, firstly, document and describe the flights and meteorology during the three Fennec IOPs in order to provide a reference and context for published and future articles. Secondly, we provide new scientific results that have come about as a result of the Fennec airborne programme, both through airborne observations in isolation over the remote Sahara, and through the integration of data from different platforms - i.e. dual-aircraft observations and ground-based, airborne and satellite platforms. Therefore, this paper provides insights into Saharan processes which separate papers cannot. Finally, despite many challenges, the Fennec aircraft campaigns have collected what is the only comprehensive in situ data set of the Saharan region - a region of substantial global climatic importance. Along with ground- and satellite-based measurements, these data provide a much-needed resource with which to develop the science linking dust, dynamics and radiation in the central Sahara, and will be heavily exploited in the coming years. This paper provides a detailed overview of the data and its context, as well as a survey of first results.

The paper is structured as follows: in Sect. 2 we describe the aircraft instrumentation, with a focus on instrumentation specifically developed or installed for Fennec, and also provide information on data provision for the scientific community. Section 3 describes the meteorology during Fennec and provides an overview of the flights performed. Section 4 provides a description of new scientific results, Sect. 5 concludes the article.

\section{Aircraft instrumentation}

Here we describe the instrumentation on both aircraft, the BAe146 and the Falcon F-20, with particular emphasis regarding instrumentation particularly relevant to Fennec measurements. Throughout this article, we refer to particle size in diameter.

\subsection{FAAM BAe146 Aircraft}

The UK's BAe-146-301 Large Atmospheric Research Aircraft, operated by the Facility for Airborne Atmospheric Measurements (FAAM) (henceforth the BAe146 aircraft) is available to the science community in a number of different configurations. These allow the most efficient use of space and access to inlets (which tend to be in the forward section of the cabin) as well as minimising the aircraft payload, which in turn maximises sortie duration. Due to the remoteness of the areas of interest for Fennec the instrument fit was customised to provide the best balance of observational rigour and range. Table 4 details the instrument fit for the Fennec IOPs; some instruments were only available for some of the deployments, these are indicated in the table. There are a number of excellent descriptions of the standard instrumentation from previous campaigns which have utilised the BAe146 aircraft (e.g. Renfrew et al., 2008; Highwood et al., 2012; McConnell et al., 2008; Haywood et al., 2011a); other specific instrumental references are provided in Table 4. Instrumentation specifically developed, installed or configured for Fennec are described in more detail below.

\subsubsection{Lidar}

The BAe146 aircraft operates a commercial Leosphere ALS450 backscatter lidar suitable for aerosol and thin cloud observation (Marenco et al., 2011). A description of the lidar system is provided by Chazette et al. (2012) and technical information is available in Table 1 of Marenco et al. (2014). The nadir-viewing lidar provides elastic backscatter at $355 \mathrm{~nm}$ and features an uncalibrated depolarisation channel, used qualitatively to distinguish depolarising layers. Data are recorded at a vertical resolution of $1.5 \mathrm{~m}$ and an integration time of $2 \mathrm{~s}$, giving a horizontal resolution of approximately $200 \mathrm{~m}$ at aircraft speeds. The instrument is lightweight, has a relatively small receiver aperture of $15 \mathrm{~cm}$ diameter, has a $12 \mathrm{~mJ}$ pulse energy $(20 \mathrm{~Hz}$ PRF) output and requires a low level of maintenance which makes it ideal for frequent operation aboard the BAe146 aircraft. However, as a consequence of aperture size and pulse energy, the signalto-noise ratio is poorer compared to the Falcon LEANDRE Nouvelle Génération (LNG) lidar.

Initial quick-look data are provided as a range-squarecorrected signal (arbitrary units), which is proportional to the total backscatter coefficient from molecules and particles at a 
given range, $r$, times the two-way transmission of light from the laser source to the range $r$ (i.e. a function of the atmospheric optical depth), for example, as shown in Figs. 7 and 17 , for which no attempt has been made to correct for attenuation by the aerosol layers. In these cases, we use the Leosphere lidar data to locate dust layers and clouds, for which the range-corrected backscattered signal is sufficient, although dust layers lower in the atmosphere may not always be evident with such a representation, due to attenuation at higher altitudes.

In a further step, aerosol extinction coefficient can be computed from the lidar range-square-corrected backscatter signal using the method described by Marenco et al. (2013), although this is labour-intensive since the method is not automated and it requires a profile-by-profile review of assumptions. Additionally, the signal-to-noise ratio for the dust laden atmosphere in the Fennec region often causes difficulties in inverting the lidar backscatter signal to extinction coefficients. This can be overcome by integrating the lidar signals as in Sodemann et al. (2015): decreasing resolution to $300 \mathrm{~m}$ in the vertical and a $60 \mathrm{~s}$ integration time, translating to extinction coefficient profiles provided at a $\sim 9 \mathrm{~km}$ along-track footprint at a typical ground speed of $\sim 150 \mathrm{~m} \mathrm{~s}^{-1}$. In the lowest $0-2 \mathrm{~km}$ layer, the uncertainty in the extinction coefficient is of the order of $100 \%$, but this uncertainty quickly decreases above this height, the extent of which is dependent on the ambient aerosol conditions (e.g. Marenco et al., 2014).

\subsubsection{Low turbulence inlet (LTI)}

A very important consideration when observing aerosol particles is the efficiency of the transmission system which passes external aerosol into the aircraft cabin for collection or in situ analysis. This is highlighted in the difficulty in making accurate and reliable measurements from an aircraft platform, particularly that of coarse-mode aerosol (Wendisch et al., 2004). For objectives such as those of the Fennec programme, this is of particular importance since a significant fraction of mineral dust is in the coarse mode (Weinzierl et al., 2009). Inlet design can modify aerosol size distribution through either underestimation due to aerosol losses or overestimation due to enhancements.

The BAe146 has a specialised low turbulence inlet (LTI) which is designed to provide a characterised community inlet capable of delivering supermicron aerosol into the cabin. This is achieved by reducing turbulent flow within the tip of the inlet, reducing impaction of particles to the walls of the inlet (Wilson et al., 2004). The LTI further maintains isokinetic sampling flow using a feedback-controlled pumping system.

A Grimm Technik optical particle counter (OPC) was mounted inside the aircraft cabin behind the LTI (LTIGRIMM), and showed that size distributions behind the LTI compare well with those from the externally mounted aircraft probes. In order to further evaluate inlet efficiency on the BAe146, Grimm OPCs were mounted behind various Rosemount inlets. This allowed for the evaluation of the size distributions passed by the standard BAe146 Rosemount inlets for the first time, from which many of the internally installed aerosol instruments draw their sample from, such as the nephelometer, particle soot absorption photometer and aerosol mass spectrometer (Trembath, 2012; Trembath et al., 2012). Significant losses and enhancements of the size distribution have been found to occur at different size ranges.

\subsubsection{Double nephelometer setup}

During Fennec, two TSI 3563 integrating nephelometers measuring scattering at 450,550 and $700 \mathrm{~nm}$ were operated inside the aircraft cabin behind a Rosemount inlet. During Fennec 2011, the nephelometers were run in series with a BGI Very Sharp Cut Cyclone Impactor between them. The impactor has a $50 \%$ penetration efficiency at $2.5 \mu \mathrm{m}$ aerodynamic diameter, or around $1.5 \mu \mathrm{m}$ geometric diameter, at a flow rate of 16.67 litres per minute $\left(\mathrm{L} \mathrm{min}^{-1}\right)$. This therefore allows the "first" nephelometer to measure scattering due to all particles passing the Rosemount inlet and the pipe work (estimated to be particles smaller than 2.5 microns, Trembath, 2012), and the "second" nephelometer to measure scattering from the fraction of particles smaller than 1.5 microns. However, due to the nephelometers being located in a series, it was difficult to account for the loss of particles between the two instruments. Therefore, during Fennec 2012 the two nephelometers were operated in parallel to avoid this problem. This was possible because a more powerful pump was used, capable of $50 \mathrm{~L} \mathrm{~min}^{-1}$, even up to altitudes of up to $9000 \mathrm{~m}$. Secondly, a volume flow controller was installed to replace the mass flow meter and needle valve.

The synergy in the approach of operating a Grimm OPC behind a Rosemount inlet to measure the size distribution, and the use of the impactor to separate the sub-1.5 micron scattering from that measured as standard by the nephelometer is novel; it allows any bias in scattering and absorption due to Rosemount inlet and pipe work effects on the BAe146 to be assessed for the first time, which can lead to significant underestimation of dust absorption properties when not accounted for (Ryder et al., 2013b).

\subsubsection{Size distribution measurements}

The BAe146 is well equipped to measure aerosol size distributions (for example, see Haywood et al., 2008; Johnson et al., 2012). However, the Fennec campaign was unusual amongst aerosol campaigns in the large number of instruments operated to measure particles larger than $3 \mu \mathrm{m}$ diameter, and in the measurement of "giant-mode" particles of over 30-40 $\mu \mathrm{m}$. Interestingly, the recent eruption of Eyjafjallajökull in Iceland has reinvigorated the interest in 1-10 $\mu \mathrm{m}$ particles since volcanic ash is generally in the same size region as mineral dust and they both have similar challenges to 
understanding such as non-spherical morphology (Ansmann et al., 2012); therefore, there is considerable benefit to be gained from the concerted efforts surrounding the observation of volcanic ash.

Instruments measuring size distribution, and the size ranges measured, are shown in Table 4 and also in detail by Ryder et al. (2013b). During Fennec 2011, a total of six different instruments successfully measured size distributions between 0.15 and 300 microns diameter - namely the Passive Cavity Aerosol Spectrometer Probe (PCASP; accumulation mode), CDP (cloud droplet probe), LTI-GRIMM, SID2H and Cloud and Aerosol Spectrometer (CAS; coarse mode), and the University of Manchester CIP15 in giant mode (see Table 4 for explanation of acronyms). All of these are wing mounted except the LTI-GRIMM, and all are optical particle counters, making use of light-scattering techniques, except the CIP which uses imaging shadowing techniques (Knollenberg, 1970). Although the CIP15 is capable of measuring particles sizes of up to $930 \mu \mathrm{m}$, electrical noise only allowed measurements of up to $300 \mu \mathrm{m}$. During Fennec 2012, a slightly different suite of instruments was operated given certain logistical requirements and consisted of a PCASP, CDP, 2DC, SID2H, FAAM CIP15 and FAAM CIP100. Unfortunately the CIP15 suffered from electrical noise during the 2012 IOP and the data were not usable. However, the operation of other instruments such as the CDP and 2DC provide alternative measurements for this size range. Additionally, the operation of the CIP100 probe extends the measurement range up to $6200 \mu \mathrm{m}$.

When interpreting OPC size distribution data, it is important to note various limitations and uncertainties (e.g. Reid et al., 2003). In order to deal with several sources of uncertainty regarding OPC measurements, the instruments were calibrated and size distributions carefully processed as described in detail by Rosenberg et al. (2012). The PCASP was calibrated with PSL nanospheres with diameters from 0.4 to $3 \mu \mathrm{m}$ and oil particles size selected by a differential mobility analyser (DMA) with diameters from 0.145 to $0.360 \mu \mathrm{m}$. The CDP was calibrated with glass beads, ranging from 15.9 to $49.9 \mu \mathrm{m}$. Smaller beads were not used due to a tendency for them to clump together; therefore, the calibration was extrapolated below this size (including over the size range influenced by the inflection in the Mie response curve). Uncertainties due to this extrapolation were included in the total uncertainty budget. Our approach is to use a rigorous methodology to assign uncertainties to the data which take account of inherent problems associated with processing OPC data. Each OPC is considered to be an instrument which directly measures the particle scattering cross section and it is calibrated in terms of this variable. Using the uncertainty in this calibration and Mie theory with an appropriate refractive index for the measured aerosol, we derive a probability density function which gives the probability of a particle of a particular size being counted in a particular OPC bin. Integrating this probability density function allows us to de- rive the mean diameter and effective width of each bin. This method also permits full uncertainty propagation including ambiguities caused by the nonlinear and non-monotonic Mie theory relating scattering cross-section to particle diameter. For example, there is an inflection point in this relationship in the 5 to $10 \mu \mathrm{m}$ range, which results in larger bin size errors across this size range (e.g. see horizontal error bars in Fig. 4). Thus, we represent the degeneracy in the response curve using uncertainties in the bin widths and bin centre points without any need for arbitrary smoothing or human thresholds. Note that this method results in bin widths significantly different to those provided by the manufacturer, which if used, would have introduced artefacts in the size distributions. Finally, we highlight the regular calibration of the CDP probe during the campaign, which results in better characterised size distributions (see Rosenberg et al., 2012).

Reid et al. (2003) outline various other deficiencies in previously presented OPC results. For example, they suggest that their OPCs were not able to represent size distribution variability which they believed was occurring in reality. This was not the case during Fennec; for example, the effective diameter ranged from under $2 \mu \mathrm{m}$ to over $20 \mu \mathrm{m}$ (Ryder et al., 2013b), and Fig. 4 in this article clearly shows contrasting size distributions where the peaks were either narrow and centred at 10 microns diameter or broad - from 10 to $70 \mathrm{mi}-$ crons. During Fennec the OPCs were clearly responding to different ambient distributions. Reid et al. (2003) also suggest that unknown particle refractive index and shape factor has affected OPC results. Here we processed the OPC data using refractive indices spanning $1.53-0.001 i$ to $1.53-0.003 i$ and errors in diameter and number concentration due to this uncertainty were propagated (sensitivity tests using different real parts of the refractive index showed little impact on the final size distribution). The size distributions were produced assuming spherical particles rather than non-spherical particles, which has been shown to have a negligible impact on the resulting size distributions (Osborne et al., 2011; Veihelmann et al., 2006; Lacis and Mishchenko, 1995; Liu et al., 1992). Additionally, instruments which utilised lightscattering measurements at different scattering angle ranges (such as the CDP at 4 to $12^{\circ}$, compared to the GRIMM Technik OPCs at 30 to $150^{\circ}$ and 81 to $99^{\circ}$ ) produced similar size distributions (Ryder et al., 2013b) suggesting that sensitivity to viewing angle during Fennec was minimal.

Of particular note during Fennec was the operation of shadow imaging probes, such as the CIP15 during 2011 for the measurement of particles sizes of 15 microns and above. These data are particularly valuable because unlike optical particle counter data, they do not rely the non-monotonic Mie scattering relationships to derive particle size. Both Rosenberg et al. (2012) and Ryder et al. (2013b) show that the CIP15 and CDP/SID2H size distributions agree well in the overlap zone, suggesting accurate measurements of size distributions, despite the different measurement techniques ap- 
plied. This further emphasises that the reliability of the Fennec size distributions presented here.

Additionally, the PCASP and CDP agree well at their overlap zones (see Ryder et al., 2013b, and Rosenberg et al., 2012 , for full details). The combination of these rigorous calibration regimes, detailed processing procedures and agreement between instruments gives good confidence in the measured size distributions, particularly when significant numbers of coarse particles are present (e.g. see Sect. 4.1.1). When operated and processed with care and attention as described above, where the key uncertainties are quantified and in combination with other instrumentation, OPCs provide results which are reliable for representing volume distributions in the coarse mode.

\subsubsection{Spectrally resolved radiation measurements}

In addition to the core pyranometers on the upper and lower parts of the aircraft fuselage measuring downwelling and upwelling shortwave irradiance respectively, a number of specialist radiometers were operated during Fennec, which in the future will allow for considerably more detailed radiative measurements and radiative closure to be performed. In the shortwave spectrum, the Spectral Hemispheric Irradiance MeasurementS (SHIMS) measured spectrally resolved upand downwelling irradiance from 0.3 to $1.7 \mu \mathrm{m}$. The shortwave spectrometer (SWS) measures spectrally resolved radiances from 0.3 to $1.7 \mu \mathrm{m}$, using an externally mounted scanning telescope designed for viewing at particular angles. In the longwave spectrum, the Airborne Research Interferometer Evaluation System (ARIES) measured spectrally resolved radiances from 3.3 to $18 \mu \mathrm{m}$, at either nadir or zenith, as well as several different downward-pointing angles. Further details of SHIMS, SWS and ARIES can be found in Osborne et al. (2011). Operation of these instruments allows detailed radiative closure to be performed (e.g. Haywood et al., 2011b; Osborne et al., 2011). Further work will examine the radiative measurements made under extremely high dust loadings when very large particles were present.

\subsubsection{Turbulence probe}

Due to the scientific objectives of the Fennec programme, the ability of the aircraft to make robust observations of atmospheric turbulence was of paramount importance. Threedimensional wind vectors are generated using a five-port radome-mounted turbulence probe at the aircraft nose which provides angle of attack (AOA) measurements. These are combined with pitot tube measurements of air speed and position information from a GPS inertial navigation unit to generated ground referenced wind vectors at $32 \mathrm{~Hz}$ (Petersen and Renfrew, 2009). A known linear dependence between the vertical component and aircraft pitch results in additional post-processing. This is likely the result of uncertainties in the calibration of the turbulence or pitot probes. Some of the parameters (static pressure and airspeed required for the processing) are generated through the on-board aircraft computer; this is calibrated in situ annually as part of the maintenance schedule, using a pressure calibrator. Airspeed is calibrated similarly. The radome transducers are calibrated at a calibration laboratory annually, or as determined by inspection of the data for drifts or other artefacts. The inertial navigation unit (INU) alignment is assessed annually with a physical survey for pitch, roll, and heading. AOA and angle of sideslip (AOSS) calibrations derive from AOA/AOSS flight manoeuvres that were carried out when the facility was commissioned, as they are physically dependent on the radome mounting. These were subsequently validated to confirm this. The AOA/AOSS are further corrected using yawing orbits, where further corrections are introduced to these quantities. True airspeed is corrected using reverse-heading manoeuvres, where the correction minimises the difference in derived upward/downward wind measurements.

\subsubsection{Cloud condensation nuclei observations}

The concentration and properties of cloud condensation nuclei $(\mathrm{CCN})$ were measured using a commercial dual column continuous flow stream-wise thermal gradient instrument (Droplet Measurement Technologies, Boulder, Co). The principles of its design are outlined in Roberts and Nenes (2005), Lance et al. (2006) and Rose et al. (2008). Ambient air is drawn into a pair of temperature-controlled columns where it encounters a particle free sheath flow which is humidified to near-saturation. A thermal gradient exists along each of the columns, meaning that supersaturation occurs as the samples flows through the columns. Activated aerosol forms droplets which increase in size depending upon their hygroscopicity. The instrument is configured to provide a pair of supersaturations at any time and has a supersaturation range nominally between 0.07 and $2 \%$. The residence time within the humidified zone is sufficient for these activated droplets to grow to diameters larger than $1 \mu \mathrm{m}$; all particles with a diameter below this threshold are judged to be unactivated interstitial particles. An optical particle counter at the base of each column estimates the size distribution of the droplets $(0.75-10 \mu \mathrm{m}$ across 20 size bins).

In order to ensure stable volumetric flow to the $\mathrm{CCN}$ instrument, vital for robust measurements across altitude ranges encountered by airborne platforms, it draws air from a reduced pressure buffer volume which is connected to a modified Rosemount 102E inlet (Trembath, 2012). In addition to the CCN, a condensation particle counter, CPC (modified 3786 UCPC, Quant Technologies) also samples from this plenum to allow the total concentration of particles $(2.5 \mathrm{~nm}-$ $3 \mu \mathrm{m})$ to be determined. 


\subsection{SAFIRE Falcon F-20 Aircraft}

The SAFIRE Falcon 20 (F20) performed research flights during the June 2011 IOP. In contrast to the BAe146, it was equipped mostly with instrumentation designed to target the Saharan heat low region remotely from high altitudes (see Table 3 detailing the F20 instrumentation).

The F20 was equipped with the backscatter lidar LNG (de Villiers et al., 2010), allowing the measurement of atmospheric reflectivity at three wavelengths $(355,532$ and $1064 \mathrm{~nm}$ ) to analyse the structure and radiative characteristics of desert dust plumes with a vertical resolution of $15 \mathrm{~m}$ and a horizontal resolution of $2 \mathrm{~km}$ (corresponding to a temporal averaging of the data of $10 \mathrm{~s}-$ or 200 shots - in order to reach a signal-to-noise ratio above 100). The lidar also has depolarisation capability for the $355 \mathrm{~nm}$ channel. During Fennec, the profiles of aerosol extinction coefficient at $532 \mathrm{~nm}$ are retrieved with an uncertainty of the order of $15 \%$ using a standard lidar inversion technique which is described at length in Banks et al. (2013) and Schepanski et al. (2013). The aerosol lidar ratio used for the inversion is considered to be constant with altitude and set to $47 \mathrm{sr}$. This value is intermediate between the value derived at $532 \mathrm{~nm}$ from spaceborne, airborne, and ground-based lidar systems over northern Africa (i.e. 55 sr: Heintzenberg, 2009, and Schuster et al., 2012, 50-60 sr: Tesche et al., 2009, Gross et al., 2011) and those derived over Sahelian Africa (i.e. 41 sr: Omar et al., 2009, and Schuster et al., 2012).

In addition to the lidar, the Falcon 20 was also equipped with a Vaisala AVAPS dropsondes launching system (a total of $136 \mathrm{~s}$ were launched from the Falcon aircraft during the 2011 deployment), radiometers (broadband up- and down-looking Kipp and Zonen pyranometers and pyrgeometers), the radiometer CLIMAT (Legrand et al., 2000) in situ pressure, temperature, humidity and wind sensors. There was also a nadir-pointing visible camera (Basler SCA 140030FM with a $9 \mathrm{~mm}$ lens; Fujion, 2/3") mounted aboard the Falcon providing high-resolution aerial photographs of the surface (Schepanski et al., 2013).

\subsection{Access to data}

UK-Fennec FAAM aircraft data from the BAe146 is available at the British Atmospheric Data Centre (BADC, http: //badc.nerc.ac.uk/home/index.html) and is freely available subject to registration. Fennec-France aircraft data are available from the Sedoo (Service de données de l'OMP, http: //catalogue.amma-international.org/) and is attached to the AMMA database, subject to free registration, listed under "Fennec" in the project list.

\section{Flights and meteorology}

We now provide an overview of the meteorology and dust events during the campaigns, and a description of the flights performed in relation to these. A preliminary mission with the BAe146 was carried out in April 2011, using Ouarzazate, Morocco as the aircraft base, with measurements taken over Mauritania. However, flight restrictions from this base meant that it was logistically more straightforward to operate from Fuerteventura, one of the Canary Islands, Spain, from where subsequent campaigns in June 2011 (both aircraft) and June 2012 (BAe146 only) were based. From Fuerteventura, research flights operated over Mauritania, Mali, Senegal and the eastern Atlantic Ocean. In the following sections, flight numbers prefixed with "b" refer to BAe146 flights, whereas flight numbers starting with " $F$ " refer to Falcon flights.

\subsection{Meteorology}

Here, we consider the synoptic-scale structure of the atmosphere in the northern African sector during the three Fennec observational phases shown in Table 2. We relate this in general terms to the structure of the SABL and dust conditions observed in the Fennec flight domain of the western Saharan region. In specific relation to the two summertime phases of June 2011 and 2012, we consider the state of the dominant features of the summertime low-level circulation over northwestern Africa, namely the Azores high pressure system, the SHL and the inter-tropical discontinuity (ITD), as well as the upper-level circulation in the adjacent mid-latitudes. The SHL has a pronounced seasonal cycle (Lavaysse et al., 2009) involving a southeast to northwest migration from its position to the south of the Hoggar Mountains $\left(\sim 18^{\circ} \mathrm{N}, 5^{\circ} \mathrm{E}\right)$ in May to its most northerly position close to $24^{\circ} \mathrm{N}$ and $0^{\circ} \mathrm{W}$ during July and August. The climatological mean date of transition between these two states is 20 June.

\subsubsection{Fennec pilot campaign 2011}

The synoptic situation during the short Fennec pilot campaign during 5-8 April 2011 generated numerous dust emission events characteristic of springtime dust events over the Sahara. On 1 and 2 April, a high pressure ridge over Algeria-Libya sector drove a strong northeasterly harmattan surge over the central-eastern Sahara activating multiple dust sources in Algeria, Libya, Niger and Chad created a large dust plume of advected dust southwestward over northern Mali, southern Algeria by 3 April. Further westward transport of this plume into the Fennec aircraft operations zone was prevented by strong northeasterly circulation around an intense cut-off low on 3-4 April (feature A in Fig. 3a). This low tracked northwards from western Algeria to Morocco over this period and was accompanied by strong cyclonic near-surface winds with pronounced dust emission along primary and secondary cold fronts penetrating southeastward over southern Morocco and northern Mauritania on 4 April. Fennec flight b589 was able to observe this dust feature and the accompanying cold surge. Subsequent flights on 5-8 April (see Table 5) observed the interaction of the cold 
Table 3. Instruments onboard the SAFIRE Falcon 20 during the 2011 IOP. NBM is nose boom mounted; CAB is inside aircraft cabin; RDM is radome mounted, BLM is belly mounted; RFM is roof mounted.

\begin{tabular}{|c|c|c|c|c|}
\hline Name & Instrument & Measures & $\begin{array}{l}\text { Sampling } \\
\text { rate }\end{array}$ & $\begin{array}{l}\text { Reference for } \\
\text { more detail }\end{array}$ \\
\hline LNG lidar & $\begin{array}{l}\text { Downward-facing high } \\
\text { spectral resolution lidar } \\
(\mathrm{CAB})\end{array}$ & $\begin{array}{l}\text { Atmospheric backscatter coefficients at } \\
532 \text { and } 1064 \mathrm{~nm} \text {. Aerosol extinction } \\
\text { coefficients at } 532 \mathrm{~nm} .\end{array}$ & $20 \mathrm{~Hz}$ & $\begin{array}{l}\text { Banks et } \\
\text { al. (2013), } \\
\text { Schepanski et } \\
\text { al. (2013) }\end{array}$ \\
\hline AVAPS II & $\begin{array}{l}\text { Airborne Vertical } \\
\text { Atmospheric Profiler } \\
\text { System \& RD94 GPS } \\
\text { dropsondes (CAB) }\end{array}$ & $\begin{array}{l}\text { Profiles of position, pressure, } \\
\text { temperature, relative humidity, wind } \\
\text { speed and direction }\end{array}$ & $2 \mathrm{~Hz}$ & \\
\hline $\begin{array}{l}\text { Basler SCA1400- } \\
\text { 30FM }\end{array}$ & $\begin{array}{l}\text { Downward-facing } \\
\text { monochrome (black/white) } \\
\text { camera }(\mathrm{CAB})\end{array}$ & $\begin{array}{l}\text { Pictures of ground surface with a } \\
\text { resolution of } 1392 \times 1040 \text { pixels. Each } \\
\text { photograph covers a horizontal area of } \\
3.3 \mathrm{~km} \times 4.4 \mathrm{~km} \text { along the track for a } \\
\text { nominal aircraft altitude of } 11 \mathrm{~km} \text { a.s.l. }\end{array}$ & $1 \mathrm{~Hz}$ & $\begin{array}{l}\text { Schepanski et } \\
\text { al. (2013) }\end{array}$ \\
\hline $\begin{array}{l}\text { Kipp \& Zonen } \\
\text { CPM22 }\end{array}$ & $\begin{array}{l}\text { Precision Spectral } \\
\text { Pyranometer (RFM \& } \\
\text { BLM) }\end{array}$ & $\begin{array}{l}0.2-3.6 \mu \mathrm{m} \text { up- and downwelling } \\
\text { irradiance }\end{array}$ & $0.2 \mathrm{~Hz}$ & \\
\hline $\begin{array}{l}\text { Kipp \& Zonen } \\
\text { CGR4 }\end{array}$ & $\begin{array}{l}\text { Precision Infrared } \\
\text { Radiometer (RFM \& BLM) }\end{array}$ & $\begin{array}{l}4.5-42 \mu \mathrm{m} \text { up- and downwelling } \\
\text { irradiance }\end{array}$ & $0.05 \mathrm{~Hz}$ & \\
\hline CLIMAT CE 332 & $\begin{array}{l}\text { Downward-facing radiome- } \\
\text { ter (BLM) }\end{array}$ & $\begin{array}{l}\text { Spectrally resolved directional } \\
\text { radiance: brightness temperature at } 8.7 \text {, } \\
10.8 \text { and } 12 \mu \mathrm{m}\end{array}$ & $1 \mathrm{~Hz}$ & $\begin{array}{l}\text { Legrand et } \\
\text { al. }(2000)\end{array}$ \\
\hline $\begin{array}{l}\text { General Eastern } \\
\text { 1011B (RDM) }\end{array}$ & $\begin{array}{l}\text { Hygrometer using the } \\
\text { chilled-mirror technique } \\
\text { (RDM) }\end{array}$ & $\begin{array}{l}\text { Water vapour (dewpoint temperature) } \\
\text { over }-65 \text { to } 50^{\circ} \mathrm{C}\end{array}$ & $1 \mathrm{~Hz}$ & \\
\hline $\begin{array}{l}\text { Aerodata Humicap } \\
\text { (RDM) }\end{array}$ & $\begin{array}{l}\text { Humidity capacity sensor } \\
\text { (RDM) }\end{array}$ & Relative humidity (0-100\%) & $10 \mathrm{~Hz}$ & \\
\hline Rosemount 1201 & $\begin{array}{l}\text { Pressure sensor } \\
(\mathrm{NBM})\end{array}$ & Static pressure $(250-1035 \mathrm{hPa})$ & $10 \mathrm{~Hz}$ & \\
\hline Rosemount 1221 & Pressure sensors (NBM) & $\begin{array}{l}\text { Differential incidence and drift } \\
\text { pressures }( \pm 70 \mathrm{hPa})\end{array}$ & $10 \mathrm{~Hz}$ & \\
\hline $\begin{array}{l}\text { Rosemount } 102 \\
\text { E2AL }\end{array}$ & Temperature sensor (RDM) & $\begin{array}{l}\text { Temperatures (non de-iced), calibrated } \\
\text { over }-60 \text { to } 40^{\circ} \mathrm{C} \text {; uncertainty } \\
\pm 0.5^{\circ} \mathrm{C}\end{array}$ & $10 \mathrm{~Hz}$ & \\
\hline Rosemount 871 & Ice Probe (RDM) & Indication of supercooled water & $1 \mathrm{~Hz}$ & \\
\hline LITTON 90-100 & $\begin{array}{l}\text { Inertial navigation unit } \\
(\mathrm{CAB})\end{array}$ & $\begin{array}{l}\text { Aircraft position, aircraft velocity com- } \\
\text { ponents, aircraft attitude (pitch, roll, } \\
\text { yaw), ground speed, wind speed and di- } \\
\text { rection, and drift angle (position and ac- } \\
\text { celeration at } 1 \mathrm{~Hz} \text { ) }\end{array}$ & $66 \mathrm{~Hz}$ & \\
\hline TRT AHV 8 & Radar altimeter $(\mathrm{CAB})$ & Altitude $(0-5000 \mathrm{ft}$, accuracy $\pm 2 \%)$ & $10 \mathrm{~Hz}$ & \\
\hline $\begin{array}{l}\text { Bancom BC635 on } \\
\text { Trimble Transducer }\end{array}$ & $\begin{array}{l}\text { Global positioning system } \\
\text { (CAB) }\end{array}$ & $\begin{array}{l}\text { Aircraft position, velocity and time } \\
\text { standard }\end{array}$ & $1 \mathrm{~Hz}$ & \\
\hline Collins ADC 80 & Air data computer (CAB) & $\begin{array}{l}\text { Barometric altitude }(-2000 \text { to } 7000 \mathrm{ft}) \\
\text { and true air speed }\end{array}$ & $10 \mathrm{~Hz}$ & \\
\hline
\end{tabular}


Table 4. Instrumentation on the BAe146 aircraft relevant to Fennec. WM is wing mounted, CAB is inside aircraft cabin, PNC is particle number concentration, OPT is optical scattering measurements, SH is light shadowing measurements. Size ranges shown for optical instruments refer to nominal ranges provided by manufacturers, i.e. not corrected for aerosol type-specific refractive indices. FAAM refers to the FAAM website where full instrumentation details are provided at http://www.faam.ac.uk/index.php/science-instruments.

\begin{tabular}{|c|c|c|c|c|c|}
\hline Name & Instrument & Property Measured & $\begin{array}{l}\text { Sampling } \\
\text { rate }\end{array}$ & Reference & $\begin{array}{l}\text { IOP in } \\
\text { Use }\end{array}$ \\
\hline \multicolumn{6}{|c|}{ Aircraft Position and Meteorological Measurements } \\
\hline GPS & Patch & $\begin{array}{l}\text { Aircraft position, velocity, and time } \\
\text { standard }\end{array}$ & $1 \mathrm{~Hz}$ & FAAM & All \\
\hline INU & Inertial navigation unit & $\begin{array}{l}\text { Aircraft velocity components, altitude, alti- } \\
\text { tude } \\
\text { rates, ground speed, and drift angle }\end{array}$ & $32 \mathrm{~Hz}$ & FAAM & All \\
\hline RadAlt & Radar altimeter & $\begin{array}{l}\text { Altitude above surface, max. } 5000 \mathrm{ft} \text { a.g.l. } \\
\text { (accuracy } \pm 2 \% \text { ) }\end{array}$ & $2 \mathrm{~Hz}$ & FAAM & All \\
\hline RVSM & $\begin{array}{l}\text { Reduced vertical separation } \\
\text { minimum data system }\end{array}$ & $\begin{array}{l}\text { Static and pitot-static pressures, pressure } \\
\text { altitude, indicated air speed }\end{array}$ & $32 \mathrm{~Hz}$ & FAAM & All \\
\hline $\begin{array}{l}\text { Rosemount } \\
\text { Temperature } \\
\text { Sensors }\end{array}$ & & $\begin{array}{l}\text { Deiced and non-deiced temperature, cali- } \\
\text { brated over } \\
-60 \text { to } 30^{\circ} \mathrm{C} ;\left( \pm 0.3{ }^{\circ} \mathrm{C}\right)\end{array}$ & $32 \mathrm{~Hz}$ & FAAM & All \\
\hline $\begin{array}{l}\text { Turbulence } \\
\text { probe }\end{array}$ & Turbulence (see also RVSM) & $\begin{array}{l}\text { Air speed and incidence angle; } 3-\mathrm{D} \\
\text { wind components; measurement } \\
\text { uncertainty } \pm 0.2 \mathrm{~m} \mathrm{~s}^{-1}\end{array}$ & $32 \mathrm{~Hz}$ & $\begin{array}{l}\text { Peterson and } \\
\text { Renfrew } \\
(2009)\end{array}$ & All \\
\hline AIMMS & $\begin{array}{l}\text { Aircraft-Integrated } \\
\text { Meteorological Measurement } \\
\text { System (Aventech Research, } \\
\text { Inc) }\end{array}$ & $\begin{array}{l}\text { General meteorological parameters, gener- } \\
\text { ally used as backup for core turbulence } \\
\text { probe. WM }\end{array}$ & & FAAM & All \\
\hline AVAPS & $\begin{array}{l}\text { Airborne Vertical Atmospheric } \\
\text { Profiler System (Vaisala RD94 } \\
\text { GPS dropsondes) }\end{array}$ & $\begin{array}{l}\text { Profiles of position, pressure, temperature, } \\
\text { relative humidity, wind speed and direction }\end{array}$ & $2 \mathrm{~Hz}$ & FAAM & All \\
\hline \multicolumn{6}{|c|}{ Water Content Measurements } \\
\hline TWC & $\begin{array}{l}\text { Total water content using } \\
\text { a Lyman-alpha absorption } \\
\text { hygrometer }\end{array}$ & $\begin{array}{l}\text { Water }\left(\mathrm{H}_{2} \mathrm{O}\right) \text { over } 0-20 \mathrm{~g} \mathrm{~kg}^{-1} \text { and } \\
\text { accuracy } \pm 0.15 \mathrm{~g} \mathrm{~kg}^{-1}\end{array}$ & $64 \mathrm{~Hz}$ & FAAM & All \\
\hline $\begin{array}{l}\text { General } \\
\text { Eastern }\end{array}$ & $\begin{array}{l}\text { Hygrometer (using the chilled- } \\
\text { mirror technique) }\end{array}$ & $\begin{array}{l}\text { Water vapour (dewpoint temperature) over } \\
220-320 \mathrm{~K} \text {; instrument response time can } \\
\text { be up to } 30 \mathrm{~s} \text {; measurement uncertainty } \\
\pm 0.25 \mathrm{~K} \text { above } 273.15 \mathrm{~K}, \pm 1 \mathrm{~K} \text { at } 210 \mathrm{~K}\end{array}$ & $4 \mathrm{~Hz}$ & FAAM & All \\
\hline $\begin{array}{l}\text { Johnson } \\
\text { Williams }\end{array}$ & Liquid water content probe & $\begin{array}{l}\text { Liquid water concentration in clouds } \\
\text { using heated wire resistance bridge over } \\
0-3 \mathrm{~g} \mathrm{~m}^{-3} ; \text { uncertainty } \pm 10 \%\end{array}$ & $4 \mathrm{~Hz}$ & FAAM & All \\
\hline Nevzorov & $\begin{array}{l}\text { Liquid and total water content } \\
\text { probe }\end{array}$ & $\begin{array}{l}\text { Liquid and total (ice plus liquid) water } \\
\text { in clouds using a heated wire over } \\
0.003-3 \mathrm{~g} \mathrm{~m}^{-1} ; \text { accuracy } \pm 10 \%\end{array}$ & $8 \mathrm{~Hz}$ & FAAM & All \\
\hline \multicolumn{6}{|c|}{ Aircraft Inlets } \\
\hline $\begin{array}{l}\text { Rosemount } \\
\text { 102E Inlets }\end{array}$ & $\begin{array}{l}\text { Aerosol inlets for cabin } \\
\text { instrumentation }\end{array}$ & $\begin{array}{l}\text { Originally designed for platinum } \\
\text { resistance thermometer (PRT) } \\
\text { measurements, only accumulation mode } \\
\text { particles passed }\end{array}$ & $\mathrm{n} / \mathrm{a}$ & $\begin{array}{l}\text { Trembath } \\
(2012)\end{array}$ & All \\
\hline LTI & Low turbulence inlet & $\begin{array}{l}\text { Fully characterised inlet, passes coarse- } \\
\text { mode particles }\end{array}$ & $\mathrm{n} / \mathrm{a}$ & $\begin{array}{l}\text { Trembath } \\
(2012) \text {, } \\
\text { Wilson et al. } \\
(2004)\end{array}$ & All \\
\hline $\begin{array}{l}\text { Filter sample } \\
\text { inlet }\end{array}$ & Parallel coarse-mode samplers & Supplies filter samples for offline analysis & $\mathrm{n} / \mathrm{a}$ & $\begin{array}{l}\text { Formenti et } \\
\text { al. (2014) }\end{array}$ & All \\
\hline
\end{tabular}


Table 4. Continued.

\begin{tabular}{|c|c|c|c|c|c|}
\hline \multicolumn{6}{|c|}{ In situ Aerosol Measurements } \\
\hline PCASP & $\begin{array}{l}\text { Passive Cavity Aerosol } \\
\text { Spectrometer Probe (PMS can- } \\
\text { ister } \\
\text { instrument) }\end{array}$ & PNC, $0.1-3 \mu \mathrm{m}, \mathrm{OPT},(\mathrm{WM}$ & $1 \mathrm{~Hz}$ & $\begin{array}{l}\text { Rosenberg et } \\
\text { al. }(2012) \text {, } \\
\text { FAAM }\end{array}$ & All \\
\hline $\mathrm{CDP}$ & Cloud droplet probe & PNC, $3-50 \mu \mathrm{m}, \mathrm{OPT}(\mathrm{WM})$ & $\begin{array}{l}1 \mathrm{~Hz} \\
\text { standard, } \\
10 \mathrm{~Hz} \\
\text { during } \\
\text { Fennec }\end{array}$ & $\begin{array}{l}\text { Rosenberg et } \\
\text { al. }(2012) \text {, } \\
\text { FAAM }\end{array}$ & All \\
\hline CIP15 & Cloud imaging probe & $\begin{array}{l}\text { PNC, } 15-930 \mu \mathrm{m}, 15 \mu \mathrm{m} \text { resolution, } \mathrm{SH} \\
\text { (WM). Provided by U.Manchester in } 2011 \\
\text { and by FAAM in } 2012.2012 \text { data suffered } \\
\text { from electronic noise. }\end{array}$ & $10 \mathrm{~Hz}$ & $\begin{array}{l}\text { Rosenberg et } \\
\text { al. }(2012) \text {, } \\
\text { FAAM }\end{array}$ & All \\
\hline CIP100 & Cloud imaging probe & $\begin{array}{l}\mathrm{PNC}, 100-6200 \mu \mathrm{m}, 100 \mu \mathrm{m} \text { resolution, } \mathrm{SH} \\
(\mathrm{WM})\end{array}$ & $1 \mathrm{~Hz}$ & FAAM & 2012 \\
\hline GRIMM OPC & $\begin{array}{l}\text { Grimm Technik } 1.129 \text { Sky } \\
\text { optical particle counter }\end{array}$ & $\begin{array}{l}\text { PNC, } 0.25-32 \mu \mathrm{m} \text {, placed behind different } \\
\text { inlets, OPT }(\mathrm{CAB})\end{array}$ & $1 \mathrm{~Hz}$ & $\begin{array}{l}\text { Heim et al. } \\
(2008)\end{array}$ & All \\
\hline $2 \mathrm{D}-\mathrm{C}$ & $\begin{array}{l}\text { Two-dimensional cloud particle } \\
\text { imaging probe (PMS canister } \\
\text { instrument) }\end{array}$ & $\begin{array}{l}5 \mathrm{~s} \text {-averaged values of PNC, condensed wa- } \\
\text { ter content, mean volume radius, precipita- } \\
\text { tion rate, and size spectrum }(25-800 \mu \mathrm{m}) \text {, } \\
\text { SH (WM) }\end{array}$ & $1 \mathrm{~Hz}$ & FAAM & 2012 \\
\hline SID2H & Small Ice Detector & $\begin{array}{l}\text { PNC, } 2-60 \mu \mathrm{m}, \mathrm{OPT} \text {, also non-sphericity } \\
\text { (WM) }\end{array}$ & $1 \mathrm{~Hz}$ & $\begin{array}{l}\text { Cotton et al. } \\
(2010)\end{array}$ & All \\
\hline CAS & $\begin{array}{l}\text { Cloud and Aerosol } \\
\text { Spectrometer }\end{array}$ & $\begin{array}{l}\text { PNC, } 0.6-50 \mu \mathrm{m} \text { OPT, }(\mathrm{WM}) \text {, part of } \\
\text { U.Manchester CAPS probe. }\end{array}$ & $1 \mathrm{~Hz}$ & $\begin{array}{l}\text { Baumgardner } \\
\text { et al. }(2001)\end{array}$ & 2011 \\
\hline $\begin{array}{l}\text { University of } \\
\text { Manchester } \\
\text { CAPS Probe }\end{array}$ & $\begin{array}{l}\text { Cloud, Aerosol and } \\
\text { Precipitation Spectrometer } \\
\text { (DMT) }\end{array}$ & $\begin{array}{l}\text { Aerosol particle and cloud hydrometeor } \\
\text { size }(0.51-50 \mu \mathrm{m}) \text {. Liquid water content } \\
\text { from } 0.01 \text { to } 3 \mathrm{~g} \mathrm{~m}^{-3} \text {. Aerosol probes com- } \\
\text { prise CAS and CIP15 instruments (WM) }\end{array}$ & $1 \mathrm{~Hz}$ & FAAM & 2011 \\
\hline $\mathrm{CCN}$ & $\begin{array}{l}\text { Dual-column continuous flow } \\
\text { cloud condensation nuclei } \\
\text { counter (DMT) }\end{array}$ & $\begin{array}{l}\text { Concentration and properties of cloud con- } \\
\text { densation nuclei (CAB) }\end{array}$ & $1 \mathrm{~Hz}$ & $\begin{array}{l}\text { Trembath } \\
(2012)\end{array}$ & All \\
\hline $\mathrm{CPC}$ & $\begin{array}{l}\text { Modified TSI } 3786 \text { condensa- } \\
\text { tion particle counter }\end{array}$ & Aerosol particles $(2.5 \mathrm{~nm}-3 \mu \mathrm{m})(\mathrm{CAB})$ & $1 \mathrm{~Hz}$ & $\begin{array}{l}\text { Trembath } \\
(2012)\end{array}$ & All \\
\hline Nephelometer & $\begin{array}{l}\text { TSI } 3563 \text { Integrating } \\
\text { nephelometer }\end{array}$ & $\begin{array}{l}\text { Total scattering and hemispheric backscat- } \\
\text { tering coefficient at } 450,550 \text {, and } 700 \mathrm{~nm} \\
(\mathrm{CAB})\end{array}$ & $1 \mathrm{~Hz}$ & $\begin{array}{l}\text { Ryder et } \\
\text { al. }(2013 b) \text {, } \\
\text { FAAM }\end{array}$ & All \\
\hline PSAP & $\begin{array}{l}\text { Radiance Research particle } \\
\text { soot absorption photometer }\end{array}$ & Absorption coefficient at $567 \mathrm{~nm}(\mathrm{CAB})$ & $1 \mathrm{~Hz}$ & $\begin{array}{l}\text { Ryder et } \\
\text { al. }(2013 b) \text {, } \\
\text { FAAM }\end{array}$ & All \\
\hline \multicolumn{6}{|c|}{ Radiometric Measurements } \\
\hline BBR & $\begin{array}{l}\text { Broadband shortwave } \\
\text { Radiometers (pyranometers) }\end{array}$ & $\begin{array}{l}0.3-3 \mu \mathrm{m} \& 0.7-3 \mu \mathrm{m} \text { up- and downwelling } \\
\text { irradiance }\end{array}$ & $1 \mathrm{~Hz}$ & FAAM & All \\
\hline SHIMS & $\begin{array}{l}\text { Spectral Hemispheric } \\
\text { Irradiance MeasurementS }\end{array}$ & $\begin{array}{l}\text { Spectrally resolved irradiance, up- and } \\
\text { downwelling, } 0.3-1.7 \mu \mathrm{m}\end{array}$ & $0.1 \mathrm{~Hz}$ & $\begin{array}{l}\text { Osborne et al. } \\
\text { (2011) }\end{array}$ & All \\
\hline
\end{tabular}


Table 4. Continued.

\begin{tabular}{|c|c|c|c|c|c|}
\hline SWS & Shortwave spectrometer & $\begin{array}{l}\text { Spectrally resolved directional radiance, } \\
0.3-1.7 \mu \mathrm{m}\end{array}$ & $0.1 \mathrm{~Hz}$ & $\begin{array}{l}\text { Osborne et al. } \\
\text { (2011) }\end{array}$ & All \\
\hline ARIES & $\begin{array}{l}\text { Airborne Research Interferom- } \\
\text { eter Evaluation System }\end{array}$ & $\begin{array}{l}\text { Spectrally resolved directional radiance, } \\
3.3-18 \mu \mathrm{m}\end{array}$ & $1 \mathrm{~Hz}$ & $\begin{array}{l}\text { Wilson et al. } \\
\text { (1999), } \\
\text { Osborne et al. } \\
\text { (2011) }\end{array}$ & All \\
\hline Heimann & Downward-facing radiometer & $\begin{array}{l}\text { Downward-facing brightness temperature } \\
(8-14 \mu \mathrm{m})\end{array}$ & $4 \mathrm{~Hz}$ & FAAM & All \\
\hline Lidar & $\begin{array}{l}\text { Downward-facing aerosol } \\
\text { lidar (Leosphere ALS450) }\end{array}$ & $\begin{array}{l}\text { Aerosol and thin cloud retrievals, qualita- } \\
\text { tive depolarisation }\end{array}$ & $2 \mathrm{~s}$ & $\begin{array}{l}\text { Marenco et al. } \\
(2011,2013)\end{array}$ & All \\
\hline Video cameras & $\begin{array}{l}\text { Up/downward, forward, and } \\
\text { rear-view cameras }\end{array}$ & Digital video recordings & & FAAM & All \\
\hline \multicolumn{6}{|c|}{ Chemistry Measurements } \\
\hline Ozone & $\begin{array}{l}\text { TECO 49C UV photometric } \\
\text { instrument }\end{array}$ & Ozone $\left(\mathrm{O}_{3}\right)$; integration time $4 \mathrm{~s}$ & $1 \mathrm{~Hz}$ & FAAM & All \\
\hline $\begin{array}{l}\text { Carbon } \\
\text { Monoxide }\end{array}$ & CO Aerolaser AL5002 & $\begin{array}{l}\text { Carbon monoxide (CO) by UV } \\
\text { fluorescence at } 150 \mathrm{~nm}\end{array}$ & $1 \mathrm{~Hz}$ & FAAM & 2012 \\
\hline
\end{tabular}

Table 5. April 2011 pilot campaign flights of BAe146. MAU stands for Mauritania

\begin{tabular}{lllll}
\hline Date & Flight Number & Time, UTC & Locations & Purpose \\
\hline 04 April & b589 & $15: 51$ to 18:52 & MAU & Overflight of dust front \\
05 April & b590 & $08: 50$ to 13:28 & MAU & Sampling of maritime air underlying dusty continental air \\
& b591 & $15: 05$ to 18:38 & MAU & Sampling of maritime air underlying dusty continental air \\
07 April & b592 (2 flights) & $06: 52$ to 17:06 & MAU & Sampling of dust in recovering SABL \\
08 April & b593 & $08: 29$ to 13:41 & MAU & Surface albedo impact on recovering SABL \\
09 April & b594 & 09:13 to 13:59 & Ouarzazate to UK & Sampling of dust transported northwards towards UK \\
\hline
\end{tabular}

maritime intrusion with dusty Saharan air, after which the dust was transported towards Portugal (Preissler et al., 2011).

\subsubsection{Fennec IOP 2011}

During this IOP most of the F20 and BAe146 flights were conducted over northern Mauritania and northern Mali. In terms of the large-scale structure of the atmosphere during June 2011 in this region, a clear distinction can be made between a "maritime phase" from around 2 to 12 June and a "heat low phase" from around 13 to 30 June (see Todd et al., 2013, for full details). These phases essentially determine conditions across the entire central-western Sahara. These maritime and heat low phases are broadly congruent with the "east" and "west" and phases, respectively, of the intraseasonal SHL mode of variability described by Chauvin et al. (2010). During the maritime ("heat low east") phase the upper-level pattern exhibited a trough centred over the Iberian Peninsula extending southwards over the northern extremity of northern Africa (feature A in Fig. 3b). In addition, at low levels the SHL remained relatively stationary in an anomalously eastward location centred at $\sim 15^{\circ} \mathrm{E}$ (feature B in Fig. 3b), similar to the mean state for May, and the Azores High ridged towards the coast of northwest Africa. These conditions combined to drive anomalous westerlies throughout the troposphere over northwest Africa creating a strong northwesterly inflow of maritime air over much of the Fennec flight domain (feature $\mathrm{C}$ in Fig. 3b), with the ITD displaced southward (not shown). As such, the Sahara is effectively "ventilated" by cool advection from the Atlantic sector restricting the heat low to the central-eastern Sahara. Accordingly, Fennec observations at both supersites (not shown) indicate that the SABL during the maritime phase is anomalously cool and dry with shallow daytime convective boundary layer development (Marsham et al., 2013b; Todd et al., 2013) and generally cloud free conditions. Aerosol loading was low due to the relative absence over the Fennec flight domain of the two dominant dust-generating processes, namely cold pools from moist convective systems, favoured within the southerly monsoon flow (ITD "bulge") on the eastern flank of the SHL, and enhanced northeasterly harmattan winds around the western flank of the SHL trough. As a consequence, these two dust-generating activities were largely 
restricted to the central Sahara with the eastward-displaced SHL.

Subsequently, during the latter heat low (west) phase anomalous positive geopotential heights dominated over Iberia and the extremity of northwest Africa (feature A in Fig. 3c), associated with the passage of three upper-level ridges. At lower levels, the SHL exhibited an abrupt westward displacement to $\sim 5-10^{\circ} \mathrm{W}$ (feature B in Fig. 3c) in two distinct intraseasonal pulses. These conditions combined to drive anomalous mid- and upper-level easterly flow, with easterlies at lower levels around the SHL, evident over the western Saharan sector (feature $\mathrm{C}$ in Fig. 3c) and Fennec flight domain. Fennec ground-based observations indicate the SABL during the heat low phase of June 2011 to be substantially hotter with deeper afternoon convective boundary layer (CBL) development and cases of almost "pure" wellmixed near-dry adiabatic profiles from the surface to the top of the Saharan residual layer (SRL) at $\sim 5 \mathrm{~km}$ height. Dust aerosol loadings are substantially higher over the western Sahara region and Fennec flight domain during the heat low phase associated with enhanced mesoscale convective activity and strong easterlies around the heat low and African easterly wave troughs. Shallow convective clouds often developed in the late afternoon in the relatively moist upper SRL.

Flight planning to meet Fennec science objectives was largely determined by synoptic meteorology, as well as logistical constraints. As such, the science objectives of specific flights (Tables 5, 6 and 7) are geared to the prevailing meteorology described above. Overall, flights during the maritime phase (Falcon only) were able to sample substantial dust emission events over northern Mauritania (F13, F18). During the heat low phase, certain flights were able to measure dust/meteorological processes associated with both northeasterly low-level jet-related emissions (e.g. b600/601/602, b610, b614) and mesoscale convective system (MCS) cold pool events originating over central Mali (b604) and also the Atlas Mountains to the north (b605 and F22/F23). Flights to survey the SABL were able to measure the pronounced evolution in the structure of the PBL over this transition from the maritime (e.g. F14-F17) to heat low phases (e.g. b607/b608, F24/F25), representing the intraseasonal variability and seasonal evolution of the Saharan atmosphere.

\subsubsection{Fennec IOP 2012}

Unlike the equivalent period of June 2011 Fennec IOP 2012 period 1-17 June there was no clear projection of the circulation onto the east-west heat low mode of Chauvin et al. (2010). As such, the period was characterised by a relatively stationary SHL centred close to the triple point of Algeria, Niger and Mali, further west than during the first half of June 2011. However, relatively subtle synoptic-scale variations strongly influenced the circulation over the western Saharan sector and the Fennec flight domain. First, dur- ing the early part of June 2012 (1 to 9), a weak upper-level trough extended south towards the coast of Morocco (feature A, Fig. 3d) and a heat low extension was established over far western Algeria (feature B, Fig. 3d) driving a strong northwesterly maritime flow over the Fennec domain (feature C, Fig. 3d). As with the maritime phase of IOP 2011, this led to the characteristic maritime conditions of a cool, dry SABL with shallow CBL daytime development and relatively cloud- and aerosol-free conditions over almost all the domain. This maritime flow weakened after the 10 June and a heat low extension west into northwest Mali from 14 to 17 June (not shown) established more characteristic heat low SABL conditions over the eastern Fennec flight domain. Specifically, a strong northeasterly low-level flow around the western flank of the SHL trough favourable to dust emissions and a northern extension of monsoon flow to the east over Mali developed. MCS activity increased as the maritime flow weakened after 8 June and substantial cold pool events were observed in the monsoon flow over southern Mauritania on this day (see ITD "bulge" feature D in Fig. 3d) and over southern Mali on 12 and 14 June (not shown).

Fennec 2012 flights targeted specific features of the evolving Saharan atmosphere, including surveys of the maritime flow in the early period (b699/700), aged dust from MCS cold pools to the south of the flight domain sampled over the ocean (b702-3) and southern Mauritania (b704), boundary layer heat fluxes close to edge of the SHL (b705), the SHL tongue and low-level jet (LLJ) dust emission (b706-8) and dust uplift and radiative processes (b708-9).

\subsection{Description of flights}

Tables 5, 6 and 7 each flight conducted during the various Fennec phases. A brief description is provided here to link the meteorology described in Sect. 3.1 to each flight's scientific aims, and to provide information for future reference. Some flights and key scientific results are described further in Sect. 4.

\subsubsection{Flights during the pilot campaign 2011}

During the Fennec Pilot campaign in April 2011, seven flights were performed (Table 5, Fig. 2a). b589 was an initial shakedown flight to test operational logistics, and was conducted at high altitude only, but overflew a dust front which was observed with the lidar and dropsondes. b590 (morning) and b591 (afternoon) were the first flights performing in situ measurements, and sampled maritime inflow over Mauritania, which was overlaid by dust layers at higher altitudes. b592 took place 2 days later on 7 April (note b592 was actually two separate flights, one in the morning and one in the afternoon) and sampled the diurnal evolution of the recovering SABL (Saharan boundary layer) following the retreat of marine air. b593 continued the sampling of the recovering SABL, but over a different surface albedo. b594 was a sci- 
Table 6. June 2011 IoP Flights. Flight numbers with preceding "b" indicate BAe146 flight, with preceding "F" indicate Falcon flight. Abbreviations: EAO is the eastern Atlantic Ocean, MAU is Mauritania, MAL is Mali, SEN is Senegal, FUE is Fuerteventura, LLJ is lowlevel jet, MCS is mesoscale convective system, PBL is planetary boundary layer, ZOU is the Zouerate supersite.

\begin{tabular}{|c|c|c|c|c|}
\hline Date & Flight Number & Time, UTC & Locations & Purpose \\
\hline 2 June & F09 & $15: 27-18: 58$ & EAO & Dust outflow over EAO \\
\hline 6 June & F10 & $12: 00-15: 33$ & EAO & Dust outflow over EAO \\
\hline 10 June & F11 & $10: 28-14: 01$ & EAO, MAU, SEN & Dust outflow over EAO \& PBL over MAU \\
\hline 10 June & $\mathrm{F} 12$ & $16: 15-19: 40$ & EAO, MAU, SEN & Dust outflow over EAO \& PBL over MAU \\
\hline 11 June & F13 & 09:06-12:29 & N MAU & Dust uplift, RAIN4DUST \\
\hline 11 June & $\mathrm{F} 14$ & $14: 40-18: 09$ & N MAU & PBL \\
\hline 13 June & F15 & $11: 00-14: 22$ & N MAU and N MAL & $\begin{array}{l}\text { Survey of N MAU \& dust associated with Mediter- } \\
\text { ranean surge }\end{array}$ \\
\hline 14 June & F16 & 14:37-18:09 & N MAU & PBL \\
\hline 15 June & F17 & $14: 33-18: 02$ & N MAU & PBL \\
\hline 16 June & F18 & $09: 13-12: 24$ & N MAU & Dust uplift, RAIN4DUST \\
\hline 16 June & F19 & $14: 42-18: 12$ & N MAU & PBL; approaching African easterly wave (AEW) \\
\hline \multirow[t]{3}{*}{17 June } & b600 & $07: 48-12: 41$ & MAL, N MAU & Characterisation of LLJ winds and dust \\
\hline & F20 & $15: 28-18: 58$ & N MAL, N MAU & $\begin{array}{l}\text { Survey of N MAU and N MAL \& dust associated with } \\
\text { Mediterranean surge and AEW }\end{array}$ \\
\hline & b601 & $14: 43-19: 37$ & N MAL, N MAU & Characterisation of LLJ winds and dust \\
\hline \multirow[t]{2}{*}{18 June } & b602 & $08: 10-12: 40$ & N MAL, N MAU & Characterisation of LLJ winds and dust \\
\hline & b603 & $14: 15-15: 55$ & Canary Islands & High-altitude radiation instrument calibration \\
\hline \multirow[t]{2}{*}{20 June } & b604 & $12: 47-17: 51$ & MAU & Sampling of dust uplifted by MCS, LADUNEX \\
\hline & $\mathrm{F} 21$ & $13: 22-17: 00$ & $\mathrm{~N}$ and central MAU & Survey of dust associated with ITD and SHL \\
\hline \multirow[t]{4}{*}{21 June } & b605 & $08: 10-11: 58$ & MAU & Sampling of dust uplifted by Atlas Mts density current \\
\hline & b606 & $14: 04-19: 20$ & MAU & SABL development and heat fluxes \\
\hline & $\mathrm{F} 22$ & $07: 18-10: 35$ & N MAU and N MAL & $\begin{array}{l}\text { Survey of dust associated with Mediterranean surge and } \\
\text { density currents from Atlas Mts }\end{array}$ \\
\hline & $\mathrm{F} 23$ & $13: 13-16: 30$ & N MAU and N MAL & $\begin{array}{l}\text { Survey of dust associated with Mediterranean surge and } \\
\text { density currents from Atlas Mts }\end{array}$ \\
\hline \multirow[t]{4}{*}{22 June } & b607 & 08:04-12:37 & MAU, MAL & Sampling of SHL with lidar and dropsondes \\
\hline & b608 & $15: 10-20: 16$ & MAU, MAL & Sampling of SHL with lidar and dropsondes \\
\hline & $\mathrm{F} 24$ & $09: 17-12: 45$ & N MAU & $\begin{array}{l}\text { Survey SHL; dust associated with Mediterranean surge } \\
\text { (N) \& ITD (S \& E) }\end{array}$ \\
\hline & $\mathrm{F} 25$ & $15: 21-18: 49$ & N MAU & $\begin{array}{l}\text { Survey of SHL; dust associated with Mediterranean } \\
\text { surge (N) \& ITD (S \& E) }\end{array}$ \\
\hline 23 June & F26 & 08:33-12:00 & N MAU & Dust uplift, RAIN4DUST \\
\hline 24 June & b609 & $11: 29-16: 45$ & MAU & Dust-cloud interactions \\
\hline \multirow[t]{2}{*}{25 June } & b610 & $07: 31-12: 17$ & MAU & Dust uplift by LLJ \\
\hline & b611 & $14: 14-19: 16$ & MAU & Overflight of Zouerate ground site \\
\hline \multirow[t]{2}{*}{26 June } & b612 & $07: 29-12: 22$ & MAU & Dust and radiative fluxes \\
\hline & b613 & $13: 55-18: 59$ & MAU & SABL development and heat fluxes \\
\hline 27 June & b614 & $06: 34-11: 39$ & MAU & Dust uplift by LLJ \\
\hline 28 June & b615 & $08: 14-11: 29$ & Canary Islands & Radiation instrument calibration \\
\hline
\end{tabular}

ence transit return of the BAe146 to the UK, sampling dust transported northwards by a low pressure system over Morocco.

\subsubsection{Flights during Fennec IOP 2011}

June 2011 was the main flying period of Fennec, when both the Falcon and the BAe146 conducted missions over the Sahara. Eleven flights were performed with the F20 during the period 2-16 June (Fig. 2b, Table 6). The first four flights (F09-F12) were designed to sample the dust outflow from the continent, over the coastal Atlantic, though almost no dust was sampled during F10. The subsequent seven flights were conducted over the continent, with two flights (F13 and F18) dedicated to the study of the morning dust uplift over alluvial sources of northern Mauritania in connection with the decay of the low-level jet. The flights were part of the RAIN4DUST project funded by the EUropean Facility for Airborne Research, EUFAR (Schepanski et al., 2013), designed to examine alluvial deposits as a dust source. Four flights were conducted along the exact same track (F14, F16, 
Table 7. June 2012 Fennec IOP flights.

\begin{tabular}{lllll}
\hline Date & Flight Number & Time, UTC & Locations & Purpose \\
\hline 1 June & b698 & $09: 42-17: 08$ & UK to FUE & Science transit to FUE with radiation calibrations \\
6 June & b699 & $12: 01-16: 54$ & N MAL, N MAU & Atlantic inflow 1 \\
8 June & b700 & $07: 56-12: 57$ & N MAL, N MAU & Atlantic inflow 2 \\
9 June & b701 & $07: 55-13: 08$ & Central MAU & Dust at ITD 1 \\
10 June & b702 & $08: 04-12: 41$ & Central MAU & Dust at ITD 2 (to Dakar) \\
10 June & b703 & $14: 12-17: 20$ & EAO & Dust outflow over EAO \\
11 June & b704 & $12: 14-17: 19$ & S MAU & Very heavy dust at ITD 3 \\
12 June & b705 & $11: 27-17: 07$ & N MAL & Midday heat fluxes \\
14 June & b706 & $13: 07-18: 13$ & N MAL & Dust uplift 1 \\
15 June & b707 & $09: 13-14: 33$ & N MAL & Dust uplift 2 \\
16 June & b708 & $07: 56-13: 08$ & N MAL, W MAU & Dust uplift by LLJ and Radiative Closure \\
17 June & b709 & $12: 14-17: 24$ & N MAL & Dust in SABL and Radiative Closure \\
18 June & b710 & $07: 51-13: 11$ & ZOU & SAVEX flight over Zouerate \\
19 June & b711 & $07: 55-10: 39$ & FUE and EAO & Science transit to Porto \\
\hline
\end{tabular}

F17 and F19) to document evolution of the thermodynamics, the dynamics and the composition of the SABL over north central Mauritania in response to an approaching Saharan heat low (SHL), which was migrating westward during that period (see Sect. 3.1). Flight F15 was conducted to document the SABL over northern Mauritania together with a dust plume transported from Algeria and associated with a Mediterranean wind surge.

The first three flights performed by the BAe146 on 17 and 18 June were a set of missions designed to investigate very strong low-level winds over northern Mali (b600, b601 and b602). During these flights, some of the largest particles encountered during Fennec were measured (see Sect. 4.1.1), and elevated dust concentrations were seen at altitudes beneath $1 \mathrm{~km}$, although vertical mixing played a role in the afternoon. The Falcon also flew on 17 June (F20) with a mission dedicated to the documentation of the SABL over northern Mauritania and northern Mali, west of an approaching African easterly wave, and of the structure of the dust plume associated with a Mediterranean wind surge.

Flight b603 was a calibration flight performed over the $\mathrm{Ca}$ nary Islands at high altitudes under clear skies for the radiation instruments. Flight b604 was a LADUNEX EUFAR flight sampling dust which had been uplifted more than $24 \mathrm{~h}$ previously by an MCS and associated haboob over Mali, and then transported over Mauritania by prevailing winds (Sodemann et al., 2015), retaining giant-mode dust particles despite large transport distances (Ryder et al., 2013a). The BAe146 crossed the dust front at high and low altitudes for in situ and remote sensing measurements. F21 consisted of a long rectilinear flight across northern Mauritania and northern Mali to survey the SABL as well as document the dust uplift in the region of the intertropical discontinuity (ITD, i.e. the near-surface convergence zone between the monsoon and the harmattan flow) to the south of the SHL, over Mali.
On 21 June both the Falcon and BAe146 performed two flights each (b605, b606, F22 and F23). On the preceding day, convection over the Atlas Mountains initiated a dust front which propagated southwards over Mauritania by 21 June, with aged dust overlying it. During the day the layers mixed together. Both aircraft missions aimed to sample this dust and diurnal mixing (see Sect. 4.3.3). On 22 June, again, both aircraft missions were in the morning and afternoon (b607, b608, F24 and F25). The missions were aimed at sampling the SHL and therefore flight tracks extended well into Mali (Fig. 2). Lidar, dropsondes and radiation instrumentation were used to sample the spatial and diurnal evolution of the SHL (see Engelstaedter et al., 2015). On 23 June, F26 performed a mission dedicated to the study of the morning dust uplift over alluvial sources of northern Mauritania in connection with the decay of the low-level jet (RAIN4DUST project).

From 24 June onwards, dust conditions were generally more well-mixed vertically with less fresh dust being sampled. Flight b609 on 24 June sampled dust and cumulus developing on the top of the dust layers (see Sect. 4.1.4). Flight b610 sampled the low-level jet and dust uplift mechanisms over eastern Mauritania. b611 flew over the Zouerate ground supersite - see Sect. 4.2.2 for a comparison of in situ measurements to sunphotometer retrievals. The purpose of the b612 and b613 missions on 26 June were to achieve radiative closure and measure heat fluxes over the desert. Both were performed under clear sky conditions with a series of stacked runs, under low dust loadings. Flight b614 sampled dust uplift and the low-level jet early in the morning. Flight b615 on 28 June was the return transit to the UK, and included radiation calibration manoeuvres. 

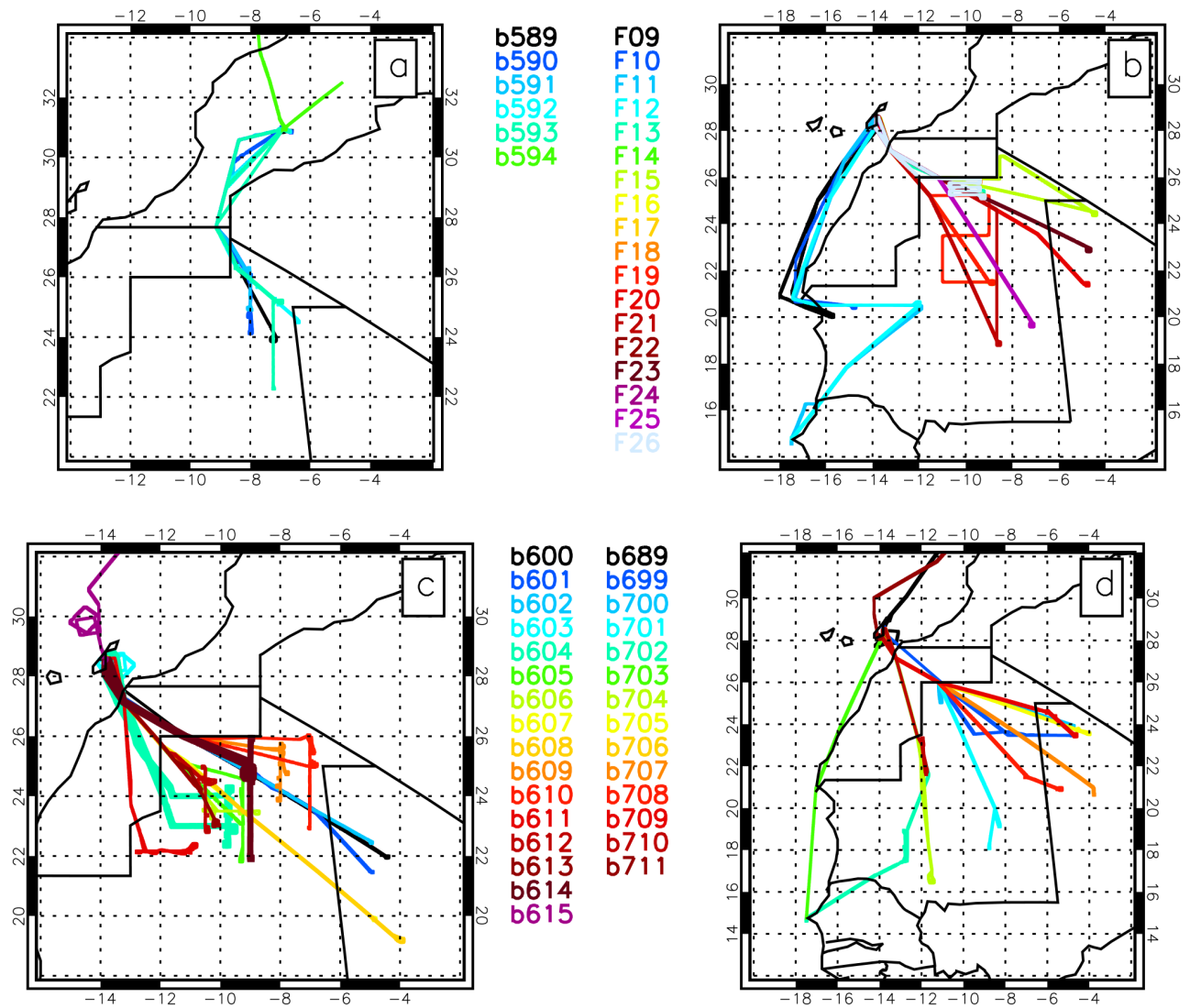

Figure 2. Flight tracks of the BAe146 and Falcon during Fennec: (a) Fennec Pilot, April 2011, BAe146; (b) June 2011, Falcon, (c) June 2011, BAe146, (d) June 2011, BAe146. Each colour shows a different flight. Note that in (b) and (d), the tracks of the following flights are the same and therefore not visible: F11, F12 and F26; F13 and F18; F14, F16, F17 and F19; F22 and F23; F24 and F25; b706 and b707.

\subsubsection{Flights during Fennec IOP 2012}

Since the initial flying period during Fennec 2012 was initially dominated by Atlantic inflow, with dust being observed at the confluence of this and Saharan air (see Sect. 3.1.3), most of the earlier flights aimed to sample this boundary (Table 7). b698 was a science transit from the UK to Fuerteventura, during which calibration manoeuvres for radiation instruments were performed. b699 and b700 were a pair of flights on 6 and 8 June which sampled the gradient of Atlantic inflow and its eastern boundary at high and low levels over northern Mali and northern Mauritania. b701 and b702 were similar flights, but here the edge of the Atlantic inflow was contingent with the ITD, and larger dust loadings were sampled over central and southern Mauritania. Following b702, the BAe146 landed at Dakar, and then returned to Fuerteventura over the Atlantic (b703) sampling continental dust outflow. Flight b704 sampled Atlantic inflow and the ITD again, this time measuring the highest submicron aerosol optical depths (AODs) of Fennec, 3.4 at $550 \mathrm{~nm}$, over southern Mauritania. b705 on 12 June was performed around midday to measure Saharan heat fluxes over a stable pressure gradient.
The b706 and b707 pair of flights examined dust uplift over the Mauritania-Mali border, with exactly the same track, and uplift began to happen under stronger winds during b707. b708 was designed to measure dust uplift by the LLJ over Mali under clear sky conditions so that the radiative impact of the dust could also be measured. This flight saw the highest scattering measurements on the nephelometer during the campaign (see Sect. 4.3.4), from dust at very low altitudes. By contrast, b709 on 17 June sampled dust which had been transported into the SHL and was well-mixed vertically up to $6 \mathrm{~km}$. This flight aimed to sample the pressure structure of the SHL and also perform radiative closure. b710 flew over the Zouerate ground supersite as part of SAVEX in order to compare AERONET (AERosol Robotic NETwork) retrievals and aircraft measurements of dust. Finally, b711 was a science transit return to the UK.

\section{Key scientific results from the Fennec airborne programme}

Here we present key scientific results from the Fennec airborne programme. They are grouped by dust characterisation 
(a) Fennec Pilot: 06:00 UTC, 4 April 2011

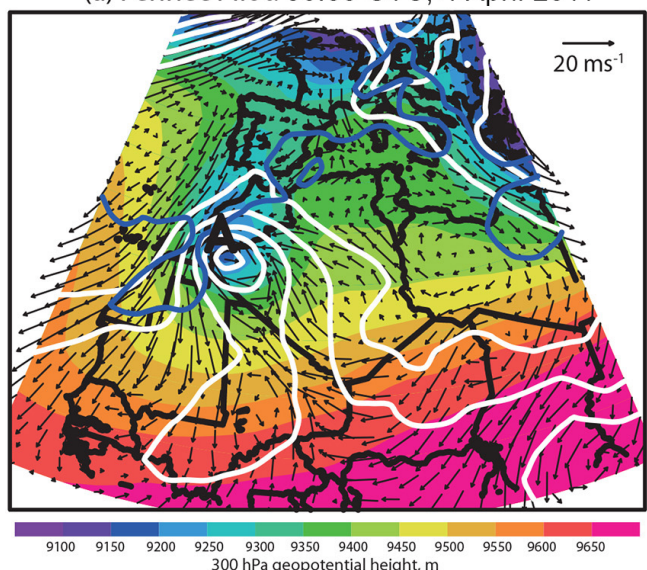

(c) Fennec 2011 IOP Heat-low Phase 13-30 June

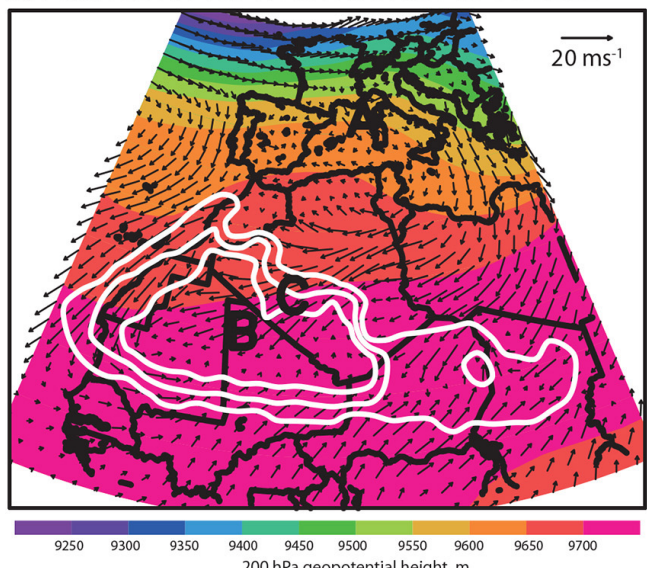

(b) Fennec 2011 IOP Maritime Phase 1-12 June

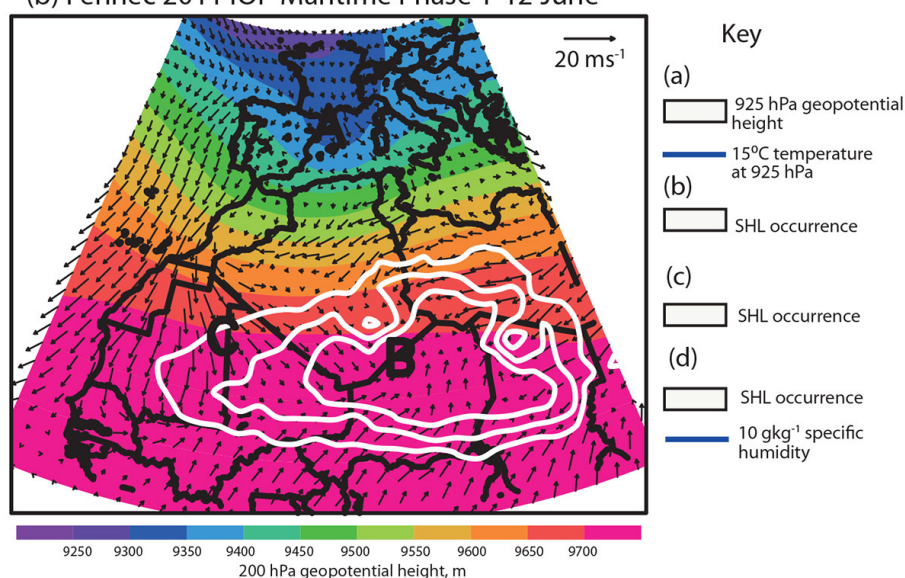

(d) Fennec 2012 IOP 1-18 June

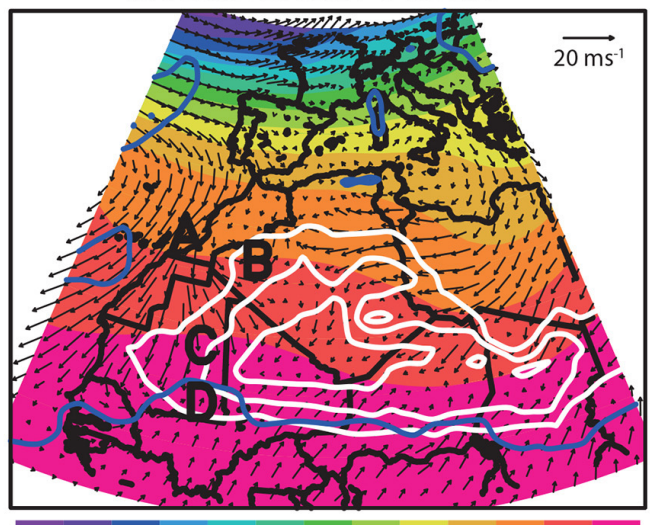

$\begin{array}{llllllllllll}9150 & 9200 & 9250 & 9300 & 9350 & 9400 & 9450 & 9500 & 9550 & 9600 & 9650 & 9700\end{array}$

$200 \mathrm{hPa}$ Geopotential Height, $\mathrm{m}$

Figure 3. Synoptic conditions during the Fennec flight campaigns. (a) $300 \mathrm{hPa}$ (m, shaded), $925 \mathrm{hPa}$ geopotential height (white contours with intervals at $700,725,750$ and $800 \mathrm{~m}), 925 \mathrm{hPa}$ winds $\left(\mathrm{m} \mathrm{s}^{-1}\right.$ ) and $15^{\circ} \mathrm{C}$ contour of $925 \mathrm{hPa}$ temperature (blue line) to show cold air advection, at 06:00 UTC 4 April 2011. Feature A marks the position of the cut-off low. (b) Daily mean $200 \mathrm{hPa}$ geopotential height (m, shaded), $925 \mathrm{hPa}$ winds $\left(\mathrm{m} \mathrm{s}^{-1}\right.$ ) and mean frequency of the SHL occurrence (white contours with intervals at $0.25,0.5$ and 0.75 , as defined using the method of Lavaysse et al., 2009) averaged over the period 1-12 June 2011 (the maritime phase). Features A, B and C indicate the approximate locations of an upper-level trough, SHL centre and maritime low-level flow, respectively. (c) as (b) except for the period 13-30 June 2011 (heat low phase) and where features A, B and C indicate the approximate locations of an upper-level ridge, SHL centre and enhanced northeasterly harmattan level flow, respectively. (d) as (b) except for the period 1-18 June 2012, and a $10.0 \mathrm{~g} \mathrm{~kg}^{-1} 925 \mathrm{hPa}$ specific humidity contour (blue line) and where features A, B, C and D indicate the approximate locations of an upper-level trough, SHL extension trough, maritime low-level flow and ITD bulge, respectively.

(Sect. 4.1), cross-platform assessment of dust measurements (Sect. 4.2), dust uplift and transport (Sect. 4.3) and SABL processes, dynamics and interactions with dust (Sect. 4.4).

\subsection{Dust characterisation}

\subsubsection{Size distributions}

During Fennec 2011 six different instruments were used to measure size distribution, as described in Sect. 2, covering the size range of 0.1 to $300 \mu \mathrm{m}$ diameter. Of these, the PCASP, CDP and CIP operated consistently during the whole campaign (see Rosenberg et al., 2012, for details of calibration and errors). Very large particles were measured during
Fennec 2011, with the effective diameter of the full size distribution ranging from 2.3 to $19.4 \mu \mathrm{m}$ (Ryder et al., 2013b). Examples of different types of size distribution are shown in Fig. 4. The solid lines show measurements from flight b600 at around $700 \mathrm{~m}$ above ground level, under aerosol optical depths greater than 3.0 at $550 \mathrm{~nm}$ when the dust was being actively uplifted by strong winds and was encountered beneath $1 \mathrm{~km}$ above ground level. These were some of the largest particles encountered during Fennec 2011, and the size distribution shows a strong coarse and giant mode present with a broad peak in volume concentration from around 10 to $60 \mu \mathrm{m}$. Contrastingly, b612 (dashed lines) shows more aged dust (24-48 h based on satellite imagery) which was well- 


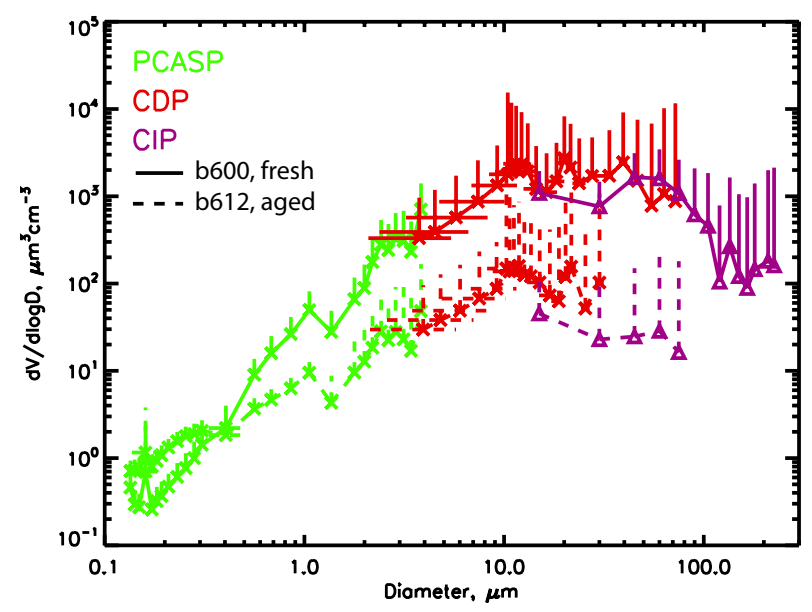

Figure 4. Example size distributions measured in different dust layers during Fennec 2011. Size distributions were measured using the PCASP (green), CDP (red) and CIP15 (purple). Solid lines show measurements from b600 during active uplift close to the desert surface; dashed lines show measurements from b612 which was dust aged by several days and well-mixed within a deep SABL. Vertical error bars show one standard deviation of the data combined with instrumental uncertainty, and only upwards errors are shown for clarity. Horizontal errors show uncertainty in bin centre diameter.

mixed within the SABL up to $5 \mathrm{~km}$, with optical depths at $550 \mathrm{~nm}$ of around 0.6. Here there are fewer particles across all sizes upwards of $0.5 \mu \mathrm{m}$ compared to b600, and the peak volume concentration is now at $10 \mu \mathrm{m}$ diameter, reflecting a shift to lower number concentrations and fewer coarse particles as dust is mixed vertically through the entire SABL, and larger particles are deposited during transport as well as dispersion decreasing the total number concentration. Ryder et al. (2013a) examined the effects of vertical mixing and transport on dust properties further. Interestingly, at sizes smaller than $0.5 \mu \mathrm{m}$ there are more particles in the case of b612, which gives the size distribution a flatter shape than $b 600$. This may be due to different dust sources, soil types or uplift wind speeds acting.

For the first time on the FAAM BAe-146, all size-resolved particle measurements were made with high temporal resolution $(\geq 10 \mathrm{~Hz})$ allowing their correlation with the vertical wind speed, and therefore permitting measurements of the eddy covariance particle flux. This technique has been previously employed to derive heat, momentum and moisture fluxes from FAAM BAe-146 data (Petersen and Renfrew, 2009). During Fennec we were able to resolve particle flux both in terms of eddy length scales and particle diameter. During flights b600, b601 and b602, upward particle fluxes were observed associated with synoptic-scale winds in Algeria and northern Mali. Upward particle fluxes were also observed during flight b604 again associated with synopticscale winds in this area. In general it has been found that particles above $10 \mu \mathrm{m}$ diameter dominate the mass flux and in some cases particles above $100 \mu \mathrm{m}$ diameter make a significant contribution. Full details are provided in Rosenberg et al. (2014).

\subsubsection{Chemical composition}

To date, information on the mineralogical composition of coarse mineral dust can only be obtained by post-field analysis of filter samples. Mineralogical composition is a fundamental property for determining the impacts of mineral dust on climate. Mineralogical composition controls the complex refractive index, determining the radiation interactions in the shortwave and longwave spectrum (relevant to the direct radiative effect); the water uptake capability, determining the cloud and ice nuclei activation efficiency (relevant to the indirect radiative effect); the solubility in water, controlling the capability of deposited mineral dust to be assimilated by the marine phytoplankton; and the surface reactivity relevant to interactions with the gas phase (Formenti et al., 2011a; Scheuvens et al., 2013).

The mineralogical composition of mineral dust is obtained by X-ray diffraction (XRD) (Caquineau et al., 2002). Nonetheless, this technique is not always applicable to aircraft samples because of limited sampling times yielding light loadings which are incompatible with the detection limits of this analytical technique. Typically, about $800 \mu \mathrm{g}$ of total dust mass are needed for analysis (Caquineau et al., 1997). For this order of magnitude, at least $1 \mathrm{~h}$ sampling at high volume is required $\left(\sim 50 \mathrm{~L} \mathrm{~min}^{-1}\right)$ for low to moderate atmospheric concentrations $\left(<200 \mu \mathrm{g} \mathrm{m}^{-3}\right)$ and at least half an hour for concentrations of the order of $200 \mu \mathrm{g} \mathrm{m}^{-3}$ and above.

Alternatively, useful indications on the mineralogical composition of mineral dust can be obtained by examining the concentrations of typical trace elements such as $\mathrm{Al}, \mathrm{Si}, \mathrm{Fe}$, $\mathrm{Ti}, \mathrm{Ca}, \mathrm{K}, \mathrm{Mg}$ and $\mathrm{Na}$, which can be obtained by X-ray fluorescence techniques which have typical detection limits of $10 \mu \mathrm{g}$ or less across a filter sample (Formenti et al., 2011b). In particular, the inter-elemental ratios provide indications of the origin of mineral dust. Typically, $\mathrm{Al}$ is used as a unique tracer as aluminosilicates dominate the dust mass. However, the $\mathrm{Fe} / \mathrm{Ca}$ ratio has also proven useful for tracing the origin of the dust plumes (Kandler et al., 2007; Formenti et al., 2011a, 2014; Scheuvens et al., 2013).

Ninety-three samples are available in total from the Fennec 2011 and 2012 campaigns from the BAe146 (55 and 38 for each field phase, respectively). Samples were collected in the Saharan boundary layer at altitudes ranging between 350 and $2700 \mathrm{~m}$ a.s.1. The total dust concentrations, estimated as the sum of oxides of $\mathrm{Na}, \mathrm{Mg}, \mathrm{Al}, \mathrm{Si}, \mathrm{K}, \mathrm{Ca}, \mathrm{P}, \mathrm{Fe}$, and $\mathrm{Ti}$, varied between 22 and $4012 \mu \mathrm{g} \mathrm{m}^{-3}$.

The analysis of dust uplift potential (DUP, Sect. 4.3.1) restricted to the filter sampling legs suggests that the Fennec 2011 was characterized exclusively by emissions from 

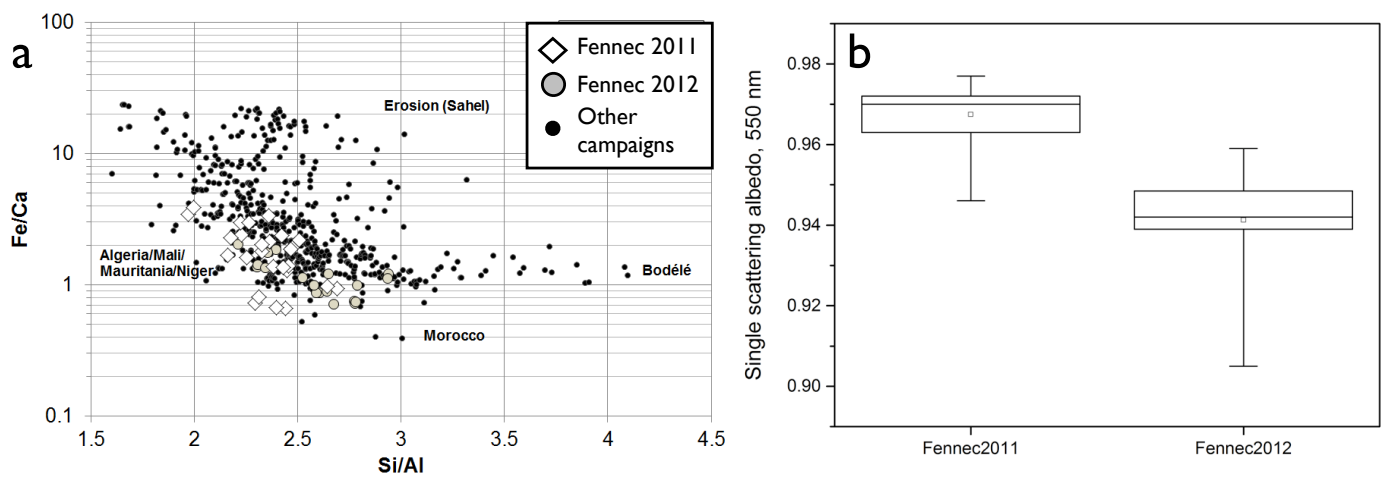

Figure 5. (a) Scatter plot of the elemental Fe / Ca vs. the Si / Al ratios for the Fennec 2011 and 2012 samples compared to samples collected during the AMMA, DODO and GERBILS campaigns (Formenti et al., 2014). Indications of the source regions according to the values of those tracers are also given. (b) Box plot of SSAs at $550 \mathrm{~nm}$ measured during Fennec 2011 and 2012 for horizontal runs corresponding to filter samples taken. SSAs are calculated from scattering measured by the nephelometer and absorption measured by the PSAP on the BAe146 mounted behind Rosemount inlets, and therefore represent accumulation mode only. Box lines represent the median and interquartile range, whiskers represent the minimum and maximum values and the squares represent the mean.

Saharan sources in Algeria, Western Sahara and Mauritania, with the exception of samples from b604 where dust had been uplifted by MCS outflow over Mali and transported by a large-scale haboob (Sodemann et al., 2015). However, during the Fennec 2012 period, additional emissions of Sahelian dust from convective activity in Mali constituted a much larger proportion of the samples. This contrast is a result of the dominant heat low west phase during the latter half of Fennec 2011 driving anomalous northeasterlies over western Algeria (Fig. 3c, Sect. 3.1.2) compared to a northern extension of the monsoon flow over Mali during Fennec 2012 with increased MCS activity (Sect. 3.1.3).

The elemental composition is consistent with the DUPs indications for those source regions. This is shown in Fig. 5a, where the $\mathrm{Fe} / \mathrm{Ca}$ and the $\mathrm{Si} / \mathrm{Al}$ ratios obtained for the Fennec 2011 and Fennec 2012 samples are compared to those measured during the AMMA, DABEX, DODO and GERBILS campaigns summarised in Formenti et al. (2014). As a consequence, and with the exception of samples collected during flights b699 and b700 when dust originated from the sources in the Algeria, Western Sahara and Mauritania areas, samples collected during Fennec 2012 had a lower Ca and Mg percent content with respect to Fennec 2011, reflecting the absence of calcium carbonates (calcite and dolomite) in Sahelian soils (Journet et al., 2014).

Likewise, there is a clear difference between the measured single scattering albedo (SSA) at $550 \mathrm{~nm}$ during Fennec 2011 and Fennec 2012 (Fig. 5b). Even when excluding the outlier corresponding to a pollution plume encountered during flight b710 at Zouerate during Fennec 2012, when the single scattering albedo value averaged over the filter collection run was $0.91( \pm 0.02)$, the mean single scattering albedo value for the Fennec 2012 period is lower than that for Fennec 2011 $(0.94 \pm 0.01$ and $0.97 \pm 0.01$, respectively).
Future work will investigate the possible link between the changes in composition and optical properties during the 2011 and 2012 periods. This will also involve taking into account the particle size distribution as a function of origin and of the age of the sampled air masses.

\subsubsection{Column aerosol loading from in situ measurements}

It is possible to use in situ measurements of scattering and absorption by the nephelometer and PSAP on the BAe146, respectively, to calculate extinction profiles and hence AOD. Measurements are restricted firstly by the altitudes flown by the aircraft, which are usually between above the aerosol layer and as close to the surface as is safe and permissible. Depending on visibility, this varied between around $50 \mathrm{~m}$ and $1 \mathrm{~km}$ during Fennec. Secondly, the measurements are restricted by the aircraft inlets, which do not sample particles larger than around $2 \mu \mathrm{m}$ (Ryder et al., 2013b). The former has been accounted for by assuming that the aerosol profile is constant beneath the minimum aircraft altitude to the ground, while the latter is not accounted for and therefore the AODs presented here represent only extinction from the submicron size distribution, and are therefore an underestimate. Scattering and absorption measurements are corrected as described in Ryder et al. (2013b).

AODs from Fennec 2011 and 2012 are shown in Fig. 6, with circles representing 2011 and diamonds 2012. AODs ranged from 0.2 to 3.6 at $550 \mathrm{~nm}$. Of particular interest were a few heavy dust events which the aircraft sampled, including b600, b601 and b602 on 17 and 18 June 2011 in northern Mali (orange, red and green circles), during which very large dust particles were measured and dust fluxes have been calculated (as described in Sect. 4.1.1). Secondly, flights b707 (blue and green diamonds on Mali-Mauritania border) and 


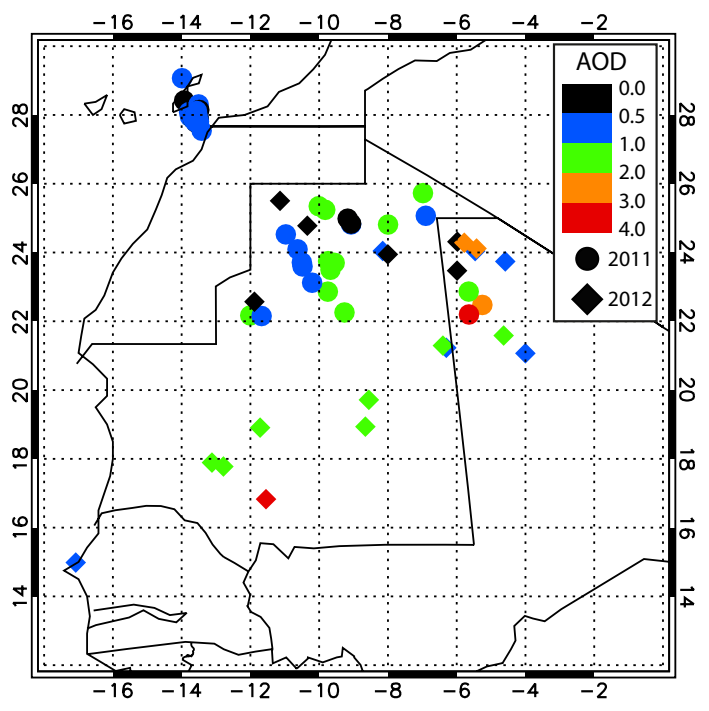

Figure 6. Aerosol optical depths at $550 \mathrm{~nm}$ measured by the nephelometer and PSAP on the BAe146 during profiles, representing accumulation-mode $550 \mathrm{~nm}$ AOD. AODs are an underestimate since they do not include contributions from coarse particles. Circles represent 2011 data, diamonds 2012 data.

b708 (orange diamonds in northern Mali) in 2012 sampled very high dust loadings, the first with very low-altitude fresh dust (see Sect. 4.3.4), and the second with well-mixed dust to above $5 \mathrm{~km}$, both under clear skies (i.e. no cloud). These flights will make excellent radiation closure case studies. Thirdly, we draw the reader's attention to the large number of profiles over the ocean between the land and Fuerteventura. The vertically resolved changes in particle size and optical properties between fresh, aged and oceanic profiles are examined by Ryder et al. (2013a), who find a significant reduction in particle size, number and associated changes in optical properties for dust measured over the ocean.

\subsubsection{Dust-cloud interactions}

Saharan clouds have the potential to be significantly different than other continental mid-latitude clouds due to the abundance of dust, which can act as ice nuclei (IN) and giant cloud condensation nuclei (GCCN), and the fact that the hot dry boundary layer prevents precipitation from reaching the surface. Flight b609 on 24 June 2011 investigated a convective system in northern Mauritania. According to analyses from the Met Office operational Africa Limited Area Model, an overnight monsoon surge associated with an easterly wave brought moist southerlies as far as $24^{\circ} \mathrm{N}$ at $8^{\circ} \mathrm{W}$. Over the course of the day, a linear convective feature formed, extending from $18.5^{\circ} \mathrm{N}$ to link with a system over the Atlas Mountains at $30^{\circ} \mathrm{N}$. Dusty cold pool outflows, which affected supersite 2 (BBM), were visible in SEVIRI (Spinning Enhanced Visible Infra-Red Imager) satellite imagery from at least 18:00 to 23:00 UTC. Flight b609 consisted of an over- flight of the system and a series of north-south aligned legs at $8.0^{\circ} \mathrm{W}$ between 23.8 and $25.8^{\circ} \mathrm{N}$ on the eastern flank of the convective system from 12:42 to 15:36 UTC. The run locations were restricted by operational constraints.

Figure 7 shows the flight pattern and measurements. The flight path (thick black lines) consisted of an initial highlevel leg, followed by a descent to minimum altitude and then three legs beneath the clouds, each increasing in altitude to $4500 \mathrm{~m}$, just below the cloud base (5400 to $5800 \mathrm{~m}$ ). Once above the cloud base, a series of short legs were performed targeting three cloud cells, with the aircraft finally ascending through the cloud tops at $8000 \mathrm{~m}$. Cloud droplet concentration is shown in Fig. 7 on top of the aircraft track, appearing red when the aircraft was in clouds. Range-corrected Leosphere lidar backscatter signal is shown measured during the highest-altitude aircraft leg and also beneath the aircraft descent where available, since the signal is strongly attenuated by the clouds along the high-level leg. Here we solely use the lidar measurements to describe the presence and structure of clouds present, not the vertical distribution of dust, due to the strong attenuation of the lidar signal by the clouds.

The initial lidar observations indicated that cloud tops ranged from $6.1 \mathrm{~km}$ to above the aircraft altitude of $8.75 \mathrm{~km}$, equivalent to approximately -11 to $-28^{\circ} \mathrm{C}$ (based on the profile measured during the descent). It was observed visually from the aircraft cockpit that the cloud tops had no observable anvil cirrus outflow. During the descent to low levels, the aircraft passed through one isolated cloud at $24.18^{\circ} \mathrm{N}$. Lidar observations of this cell $13 \mathrm{~min}$ prior to the intersection provided a cloud top height of $6.65 \mathrm{~km}$, which is estimated to be at $-15.0 \pm 0.2^{\circ} \mathrm{C}$. The lidar data showed no links to, or particle flow between, any other clouds. Particle images recorded by the CIP showed that this cloud consisted of pristine hexagonal plates. Freezing at this warm temperature is uncommon even for clouds in the vicinity of a source of IN (Kanitz et al., 2011; Ansmann et al., 2008; Sassen et al., 2003; Raymond and Blyth, 1989). An explanation could be the very high dust concentrations acting as IN in the heart of the Sahara.

The descent to $500 \mathrm{~m}$ provided a measurement of the aerosol input into the cloud. At the surface particle concentrations above $0.13 \mu \mathrm{m}$ diameter measured by the PCASP and CDP ranged between 60 and $80 \mathrm{~cm}^{-3}$ south of $25.33^{\circ} \mathrm{N}$. North of this point the concentrations were $200 \mathrm{~cm}^{-3}$. Note that most of this concentration is measured by the PCASP and therefore does not show up on the number concentration scale in Fig. 7. As the aircraft climbed to the cloud base, the aerosol concentration fell to $40 \mathrm{~cm}^{-3}$, although the number of particles above $4 \mu \mathrm{m}$ diameter rose from 0.05 to $0.15 \mathrm{~cm}^{-3}$.

During ascent back towards the cloud base, sporadic ice precipitation was observed by the CIP probe from altitudes of $4.4 \mathrm{~km}\left(4^{\circ} \mathrm{C}\right)$ and graupel was observed impacting the aircraft. Clouds were encountered at $5.75 \mathrm{~km}\left(-8^{\circ} \mathrm{C}\right)$ although the cloud base could have been slightly lower (minimum of 


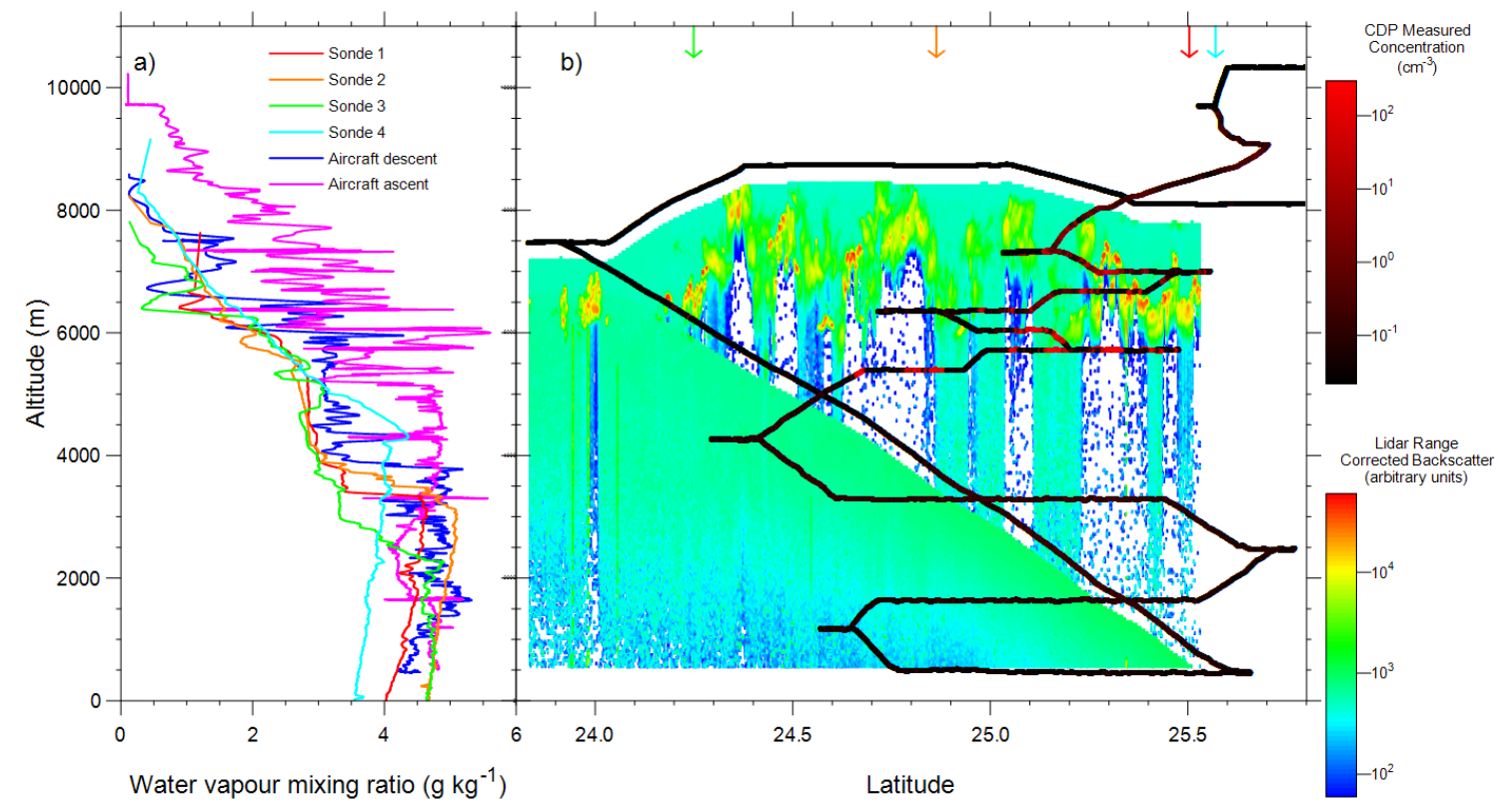

Figure 7. b609 dropsonde/aircraft moisture profiles and range-corrected lidar cross section of 1934 the scientific area of interest (red-blue colour scale, arbitrary logarithmic units) including an aircraft track coloured by the droplet concentration as measured by the CDP plus PCASP (black to red colour scale). The lidar data collected during descent (thick sloping black line) are plotted instead of the high-level data when available. Above this, lidar data from the high-level flight leg are shown. Arrows indicate locations of dropsondes. Sondes 1-3 were dropped on entry to the area and sonde 4 on exit.

$5.4 \mathrm{~km}$ or $-5^{\circ} \mathrm{C}$ ). It is of note that cloud base may have been too cold for the Hallett-Mossop ice multiplication process which occurs around $-6^{\circ} \mathrm{C}$. No columnar ice crystals typically produced by this process were observed. Near the cloud base, the cloud was found to be in mixed phase with the droplet number peaking at $250 \mathrm{~cm}^{-3}$ coincident with the peak updraught speed of $10 \mathrm{~m} \mathrm{~s}^{-1}$. This measured droplet concentration was found to be significantly higher than the aerosol concentration reported by the PCASP and CDP below the cloud base: the shortfall in CCN must have been made up of particles smaller than the PCASP detection limit. Twohy et al. (2009) showed that dust with zero hygroscopicity, $\kappa$, is entirely activated in cloud by a $10 \mathrm{~m} \mathrm{~s}^{-1}$ updraught and, because of its large size, it can form the majority of the $\mathrm{CCN}$ population over other hygroscopic particles when they have a small but non-zero $\kappa$ (Koehler et al., 2009). It is therefore likely that dust particles were acting as $\mathrm{CCN}$ or GCCN in this case. Higher in the cloud, there is evidence of liquid water in updraught regions, and near the cloud top a population of homogeneously nucleated bullet rosettes were observed. No cirrus or precipitating particles were observed above the cloud top.

These measurements have shown that dust is likely acting as a $\mathrm{CCN}$ and as an IN at temperatures of $-15^{\circ} \mathrm{C}$. Sampling of clouds earlier in their evolution would provide further limits on the effectiveness of dust as an IN. The lack of the Hallett-Mossop process in these clouds makes them a useful case for assessing IN concentrations and the extreme size of the dust particles may provide tests on the impact of GCCN.

For a non-precipitating cloud we expect that equivalent potential temperature, $\theta_{\mathrm{e}}$, and total water concentration (condensed plus vapour) are conserved and hence any point in cloud should lie on a mixing line or in a mixing region of these parameters (Paluch, 1979; Blyth et al., 1988). Here the cloud is precipitating meaning that total water concentration is no longer conserved but these variables are still useful in diagnosing the transport and mixing processes (Fig. 8).

Much of the sampled in-cloud air had higher water content, greater than $5 \mathrm{~g} \mathrm{~kg}^{-1}$, but similarly high ranges of $\theta_{\mathrm{e}}$ compared to boundary layer air (Fig. 8). These are inconsistent with the clouds being a simple mixture of boundarylayer and entrained air. Out of cloud and above-cloud-base air had some regions consistent with simple mixing, some in a similar moist warm region to the in-cloud air, but also some regions with low moisture content less than $1 \mathrm{~g} \mathrm{~kg}^{-1}$ and high $\theta_{\mathrm{e}}$, similar to boundary layer air. Profiles of water vapour mixing ratio (WVMR) (Fig. 7) show that in the boundary layer (below $2500-5000 \mathrm{~m}$, varying from profile to profile) WVMR increases with altitude. Similar behaviour was also seen in the mean WVMR profile at Fennec supersite 1 (BBM) between 15:00 and 18:00 UTC, the time of maximum cloudiness (Marsham et al., 2013b). This is again inconsistent with simple mixing of a growing boundary layer. We hypothesise that in this low shear environment, precipitation is evaporating in the boundary layer air but is not able 


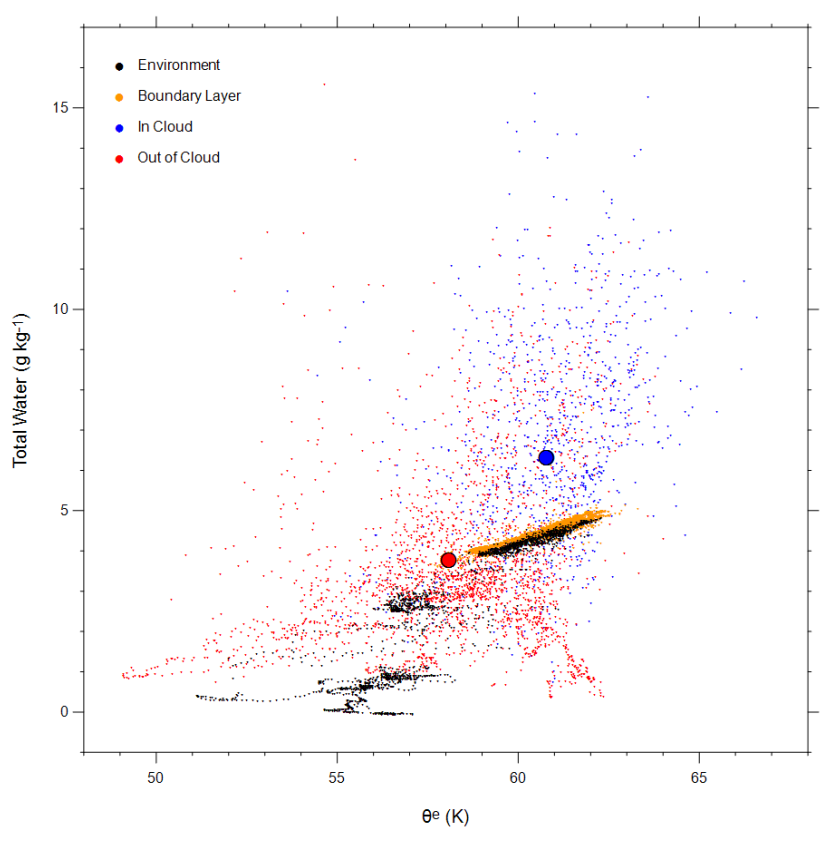

Figure 8. Equivalent potential temperature and total water content during the flight. "Environment" points represent data from the descent out of cloud, "Boundary Layer" points represent data collected during aircraft ascent to an altitude of $5000 \mathrm{~m}$, "In cloud" points represent data collected during aircraft ascent above $5000 \mathrm{~m}$ where cloud droplet number was measured greater than $0.5 \mathrm{~cm}^{-1}$ and "Out of cloud" points represent data collected during aircraft ascent above $5000 \mathrm{~m}$ where cloud droplet number was less than $0.5 \mathrm{~cm}^{-1}$. Mean in- and out-of-cloud values are shown with large circles outlined in black.

to arrest the updraught, allowing water to be recycled and concentrated in the cloud. High $\theta_{\mathrm{e}}$ air rises in the boundary layer and receives extra water from evaporating precipitation, such that when it enters the cloud base it has more moisture than its environment. In cloud air parcels either precipitate adding to the recycled moisture reservoir before being detrained as dry, high $\theta_{\mathrm{e}}$ air, or they do not precipitate and are instead detrained as moist, high $\theta_{\mathrm{e}}$ air. We also expect dust and aerosol to be affected by this recycling process. Precipitation accumulates $\mathrm{CCN}$ and upon total evaporation releases them as a single aggregate particle. The increase in large dust particle concentration below the cloud base is qualitatively consistent with this expectation. This concentrating of moisture and dust in the boundary layer top and the modification of the dust size distribution has implications for long-range transport of these atmospheric constituents. To our knowledge, these are the first observations of such a mechanism increasing the moisture content within the SABL mid-levels.

\subsubsection{Dust-ozone interactions}

Heterogeneous uptake of photochemical species leads to changes in the gas-phase composition of the atmosphere, af- fecting the global ozone budget (Bauer et al., 2004). Previous campaigns have observed ozone depletion during high dust loadings (de Reus et al., 2000, 2005). These have also been investigated through modelling (Bian and Zender, 2003) and laboratory studies (Chang et al., 2005; Hanisch and Crowley, 2003). There is still some debate as to whether the removal of ozone is due to heterogeneous chemistry on the surface of the dust or to a feature associated with a change in air mass between high and low dust loadings. The alkalinity of mineral dust has been shown to enhance the uptake of gases on the surface (Grassian, 2002). Bauer et al. (2004) propose that the coarse-mode of mineral dust could be important for heterogeneous uptake, whilst Chang et al. (2005) found that there was no mass accommodation limitation to the rate of ozone uptake coefficients, concluding that freshly emitted Saharan dust is potentially a significant route of ozone loss. Hanisch and Crowley (2003) discussed that mineral dust surface sites could be deactivated by the extended presence of ozone. Ultimately, the change in the surface of mineral dust may have repercussions for subsequent aerosol-cloud interactions and modify the cloud nucleating properties of the mineral dust. A number of cases observed during the Fennec campaigns were investigated Brooke (2014).

Fennec flight profiles provided the opportunity to sample very recently lofted mineral dust which would not have undergone significant atmospheric "processing" and thus provided a good opportunity to investigate heterogeneous dust/ozone interactions. These observations of decreased ozone concentrations correspond with increased mineral dust surface area associated with elevated dust concentrations. Figure 9 presents box and whisker diagrams of mineral dust mean surface area correlated with ozone mass mixing ratios observed during b707, where dust uplift was encountered at the far eastern section of the flight track in northern Mali (orange line in Fig. 2d). The red central line of the box and whisker denotes the median, the edges of the box are the 25th and 75th percentiles and the whiskers extend to the most extreme data points. Mean surface areas of 0.15 to $0.35 \mu \mathrm{m}^{2} \mathrm{~cm}^{-3}$ (roughly count median diameters of 0.22 to $0.33 \mu \mathrm{m}$ ) correspond to ozone mass mixing ratio of $49-52 \mathrm{ppb}$. As the mean dust surface area increases to 0.45 to $0.75 \mu \mathrm{m}^{2} \mathrm{~cm}^{-3}$ (count median diameters of 0.38 to 0.49 ), the ozone mass mixing ratio decreases to $41-44 \mathrm{ppb}$. The spread in ozone concentrations at mean surface areas of $0.45 \mu \mathrm{m}^{2} \mathrm{~cm}^{-3}$ is associated with crossing into a harmattan airflow.

These in situ observations suggest that increased mineral dust surface area associated with fresh dust uplift and a large coarse-mode contribution to the size distribution act as a route for the reduced ozone concentrations. However, from the analysis presented here, it is not possible to unequivocally conclude if the air mass initially contained lower ozone concentrations and that the mineral dust was subsequently uplifted, or if mineral dust uplift could have contributed to the reduced ozone concentrations observed. There is scope 


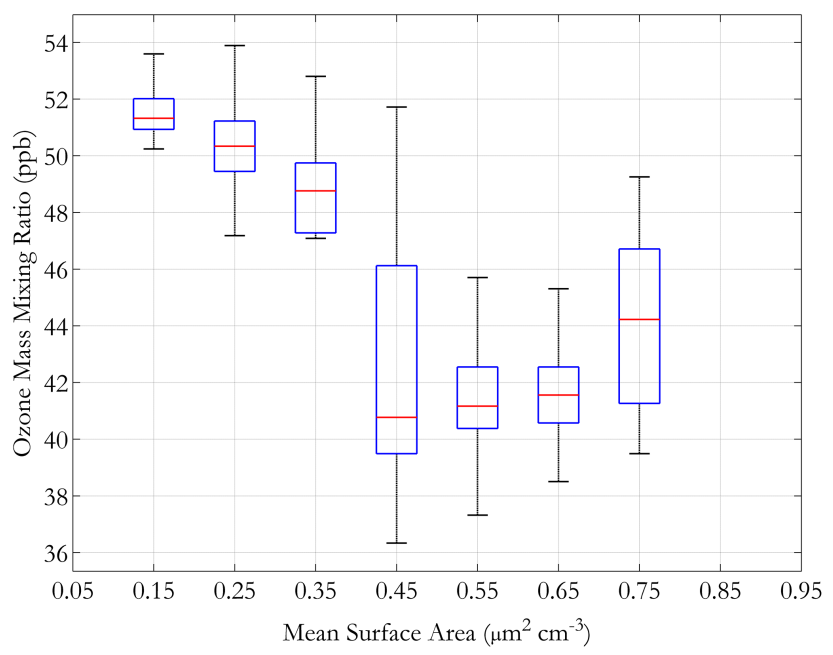

Figure 9. Box and whisker diagram of mineral dust mean surface area and ozone mass mixing ratio along the b707 (15 June 2012) flight transect. Surface area is calculated from PCASP count median diameter.

within the Fennec data set to further investigate air mass source regions, potentially with Lagrangian study methods.

\subsection{Cross-platform assessment of dust measurements}

\subsubsection{Falcon lidar and satellite validation}

Aircraft data can play an important role in validating satellite-based retrievals of AOD, covering a more extensive spatial area than that which is viewed from fixed groundbased measurements. Particularly useful in this regard are active remote sensing observations from lidar, since they can sample the full depth of the atmosphere below the aircraft instantaneously (i.e. a physical vertical profile by the aircraft is not required) and can provide vertically resolved information.

In Fig. 10, middle panel, we show an example of the level of agreement seen between three different co-located measures of AOD, one provided at $532 \mathrm{~nm}$ by the LNG lidar on the F20, one from MODIS Aqua, derived using the Deep Blue algorithm collection 5.1 (Hsu et al., 2004) and one from the SEVIRI instrument on Meteosat-9 (Brindley and Russell, 2009; Banks and Brindley, 2013), all at a wavelength of $550 \mathrm{~nm}$. Here we focus on an afternoon flight (F23, see Fig. 2c) made by the Falcon on a track leading across to northern Mali from northern Mauritania on the 21 June 2011.

The satellite observations are co-located spatially with the lidar by averaging the satellite pixels within $25 \mathrm{~km}$ of each lidar pixel. Temporally, the Aqua satellite overpass time is always within 90 min of the aircraft observations, with a minimum time difference of $37 \mathrm{~min}$. For SEVIRI, we take advantage of the improved temporal sampling available from geostationary orbit such that each lidar observation is within
$30 \mathrm{~min}$ of the corresponding satellite retrieval. The lower panel in the figure shows the vertical extinction coefficient derived from the lidar observations, while the top coloured band illustrates the colouring of the standard "desert-dust" red-green-blue (RGB) composite (Lensky and Rosenfeld, 2008) extracted from SEVIRI along the flight track.

Looking at the middle panel, the longitudinal behaviour of the AOD derived from all three instruments is generally in good agreement although SEVIRI tends to show consistently higher AODs than those derived from the lidar and from MODIS. The MODIS retrievals contain more data gaps as a result of various data quality tests: both the lidar and SEVIRI retrievals and the RGB composites suggest that these tests may be slightly too severe as there is no clear evidence of a break in the aerosol layer or the presence of cloud. The intense pink colour of the composite at the western edge of the track would suggest the largest dust loadings are located here, associated with a thick dust plume at an altitude of $\sim 3 \mathrm{~km}$ and another distinct layer observable at $\sim 5.5 \mathrm{~km}$ seen in the lidar profile (which may have originated from Mali on 19 June). By the eastern end of the track, the AODs measured by MODIS, SEVIRI and the lidar are slightly smaller than the values seen at the western end, the dust is much more uniformly spread throughout the lowest ca. $5 \mathrm{~km}$ of the atmosphere, and the intensity of the RGB signal is somewhat reduced.

Further work has explored co-located aircraft and satellite data in more detail, utilising a more extensive suite of satellite instruments (such as the Multi-angle Imaging SpectroRadiometer (MISR) instrument on Terra and the IASI instrument on the METOP satellites (Banks et al., 2013), and between the BAe146 in situ measurements and spaceborne lidar CALIOP (Pappas et al., 2015). In the former study, the differences between retrievals were investigated, including an evaluation of the sensitivity of the retrievals to variations in dust loading, to atmospheric conditions (such as column water vapour), to surface features (such as albedo) and to aerosol height. As diagnosed by Banks et al. (2013), when the dust loadings are high, the SEVIRI retrievals appear most capable of retrieving the appropriate AODs, whereas the other retrievals are biased low. On the other hand, the SEVIRI retrievals are most sensitive to meteorological conditions, especially column moisture, under high levels of which the SEVIRI-retrieved AODs are biased high; conversely, the MODIS Deep Blue and MISR aerosol retrievals appear to be relatively insensitive to such factors. The aircraft data will be of substantial benefit to interpreting the "desert-dust" RGB imagery.

\subsubsection{Comparison of AERONET and aircraft size distributions}

Considering the wide application of size distributions from AERONET retrievals such as for aerosol models and climate forcing assessments (e.g. García et al., 2012; Kinne et al., 


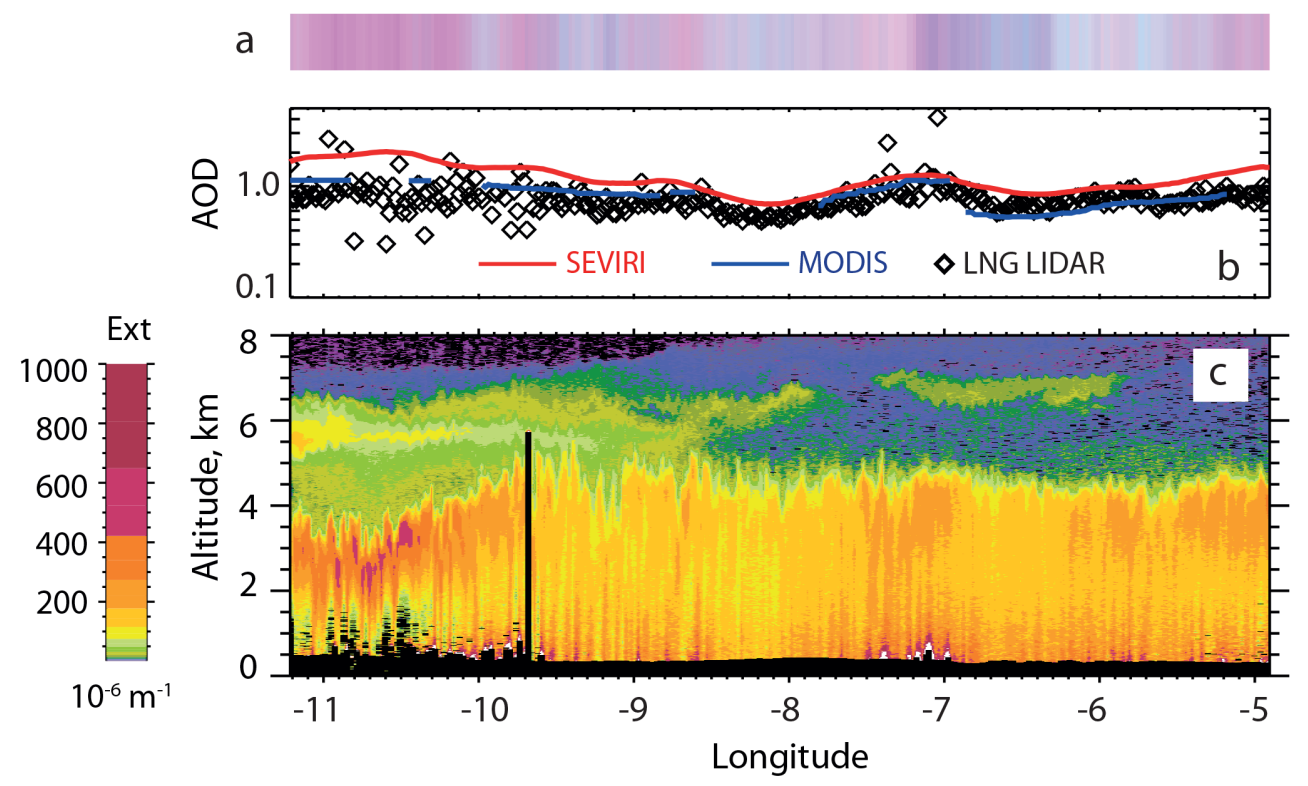

Figure 10. Aircraft and satellite observations along the track of the outbound Falcon flight F23 on the 21 June (13:52-14:45 UT), across northern Mauritania and ending in northern Mali. Lower panel: lidar vertical extinction coefficient cross1953 section (at $532 \mathrm{~nm}$ ); middle panel: co-located SEVIRI, MODIS, and lidar (LNG) AOD retrievals along the Falcon flight track; upper panel: the along-track SEVIRI RGB "desert-dust" imagery.

2003), it is important to validate AERONET retrievals where possible with field observations. Moreover, some discrepancies have been found between retrieved size distributions using the AERONET algorithm (Dubovik and King, 2000; Dubovik et al., 2006) and the same size distributions derived with the Sky Radiation (SKYRAD) algorithm (Nakajima et al., 1996), as described in Campanelli et al. (2012) and Estellés et al. (2012b). The SAVEX project aims to explore these discrepancies, and its creation was motivated by studies such as Estellés et al. (2012a, b), where differences between different sunphotometer retrieval algorithms are examined.

AERONET CIMEL sunphotometers were installed and operated at the two supersites of Zouerate (western Mauritania) and Bordj Badji Mokhtar (BBM, Algeria) as part of the Fennec programme. As part of the SAVEX project, sunphotometers were also installed and operated at several different sites on Tenerife during June 2012 with the intention of overflying the instruments during dust events. However, overflights were not performed at Tenerife due a lack of dust outflow in this location during the campaign. The aircraft range from Fuerteventura did not permit overflights at BBM. Therefore, overflights as close as possible to the Zouerate station under dusty conditions were performed during 2011 (b611, 25 June) and 2012 (b710, 18 June, SAVEX flight).

During these flights, profiles and stacked legs were performed to measure in situ aerosol properties and radiative measurements to allow for radiative closure of the column above the ground site. Radiative flux measurements were also made at the ground site. Here we present some measure- ments from b611 in 2011. Dust sampled during this flight was around 19 to $43 \mathrm{~h}$ old, originating from Algeria (Ryder et al., 2013b), with AERONET AODs at $440 \mathrm{~nm}$ from 0.8 to 0.94 , and was relatively well mixed in the SABL up to around $5.5 \mathrm{~km}$, although extinction coefficient measurements from the aircraft approximately doubled beneath $2.5 \mathrm{~km}$. Similar measurements are available from flight b710, although for that flight, layers of anthropogenic pollution were detected between dust layers, thus making comparisons between platforms more complicated, and are not shown here.

Figure 11 shows a comparison of the size distributions measured by the BAe146 compared to AERONET retrievals on 25 June 2011. The in situ aircraft measurements were taken over a vertical profile close to Zouerate on 25 June 2011 between $8 \mathrm{~km}$ and $80 \mathrm{~m}$ a.g.l. from 15:58 to 16:27 UTC. In situ size distribution measurements shown in Fig. 11 are therefore shown as the median, and the 10th and 90th percentiles between $80 \mathrm{~m}$ and $5.5 \mathrm{~km}$.

Sunphotometer retrievals of size distribution from almucantar scans are not present during much of the day due to cloud cover over Zouerate. Nevertheless, several retrievals are available during the morning (dark blue), one during the flight (black) and two from 18:06 and 18:30 after the aircraft had left the region (light blue). Size distribution retrievals shown are those directly available from AERONET (L1.5, V2) and converted to $d V / d \log (D)$ to match the aircraft measurements, and adjusted to measurements in $\mathrm{cm}^{-3}$ assuming the dust layer is distributed evenly above $5.5 \mathrm{~km}$. Further work will examine measurements from aircraft legs at differ- 


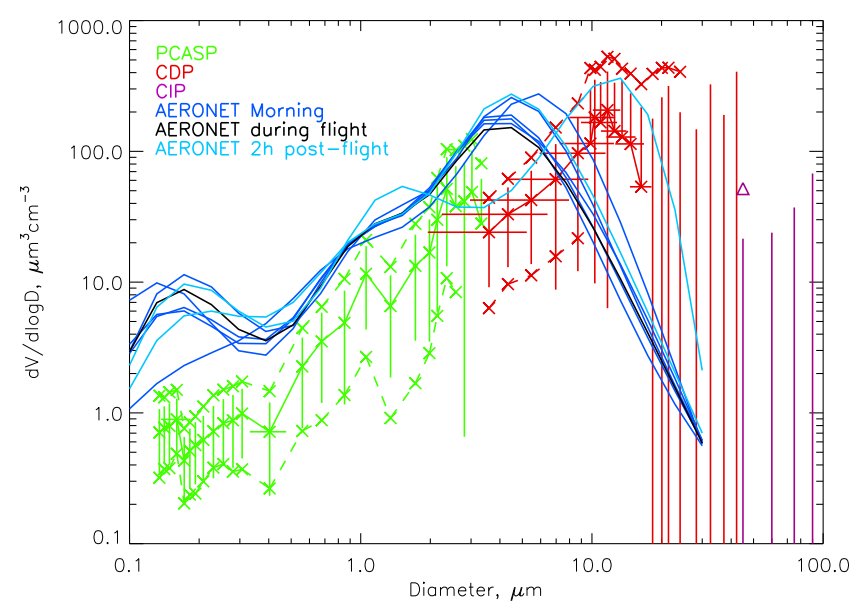

Figure 11. Volume size distributions from BAe146 flight b611 Profile 1 (15:58 to 16:27 UTC) compared to AERONET retrievals. Aircraft size distribution measurements are shown by green (PCASP), red (CDP) and purple (CIP15). Solid lines show the median volume concentrations over the column up to $5.5 \mathrm{~km}$. Vertical error bars show standard deviation over the column (where lower error bars reach below the plot minimum, they have been omitted for clarity). Horizontal error bars show uncertainties in bin size. Points with dashed lines represent the 10th and 90th percentiles across the column. AERONET retrievals from the Zouerate site over the day are shown in dark blue (morning), black (retrieved during the flight) and light blue (retrieved shortly after the flight).

ent altitudes, and different ways of representing a columnaverage measurement from the aircraft measurements, such as extinction-weighted averaging.

The median aircraft measurements show a peak volume concentration at $12 \mu \mathrm{m}$, while the AERONET retrievals show peaks between 3 and $6 \mu \mathrm{m}$. This is consistent with previous aircraft-AERONET comparisons finding larger particles measured by aircraft (Reid et al., 2003; Müller et al., 2012, 2010b; McConnell et al., 2008). However, only one retrieval shows a peak volume concentration at $13 \mu \mathrm{m}$ which appears to agree much more closely with the shape of the size distribution from the aircraft measurements. Satellite images show a small convective cloud developing close to, but not over, Zouerate around this time. It is possible that small-scale downdraughts produced some freshly uplifted dust which may have resulted in different size distribution retrievals. However, we cannot reject the possibility that optically thin cirrus cloud contamination affected the quality of this inversion (although it is not visible in satellite imagery), which would bias the size distribution towards larger sizes, and we note that the retrieval error is around double for this particular time compared to the others shown. At sizes smaller than $3 \mu \mathrm{m}$, differences in volume concentration are substantial between AERONET and the aircraft, with AERONET reporting more particles. Further work will explore possible factors causing this difference.
Rather few coarse particles were seen during b611 (towards the end of the campaign) relative to the rest of Fennec, perhaps due to the aged nature of the dust which meant that the largest particles had already been deposited. This is reflected by the absence of particles larger than $16 \mu \mathrm{m}$ in the median, and the absence of particles larger than $45 \mu \mathrm{m}$ in the 90th percentile (see the one CIP data point for the 90th percentile), though particles of these sizes were measured, but the standard deviation was very large, as shown by the large error bars on the median above sizes of $16 \mu \mathrm{m}$.

Existing publications show contrasting examples of agreement and disagreement between airborne, ground-based and AERONET size distributions, and there has been much debate over the causes. Reid et al. (2003) provide an overview of many commonly used sizing techniques and their limitations. These authors find that aerodynamic measurement methods and sunphotometer inversions tend to produce mass median diameters (MMDs) of around $3 \mu \mathrm{m}$ diameter, while published OPC measurements at that time produced volume median diameters (VMDs) of the order of $8-13 \mu \mathrm{m}$. Limitations of OPCs, as described in Sect. 2.1.4, are principally uncertainties due to assumptions of refractive index, particle shape and the Mie response curve, the latter leading to a sizing ambiguity in the range of $5-10 \mu \mathrm{m}$. As outlined in Sect. 2.1.4, we consider uncertainty due to particle shape to be small (as evidenced by similar size distributions resulting from OPCs measuring over different scattering angles), and we provide error bars to account for the remaining uncertainties. Aerodynamic measurement systems, such as aerodynamic particle sizers (APS) and cascade impactors rely on the particle dynamic shape factor, which varies with dust particle shape, causing uncertainties in the size distribution and may undersize particles by $25 \%$ for dynamic shape factors of 1.2. These instruments are also impacted by cut-offs of larger particle sizes imposed by inlets. Open path OPC instruments such as the CDP and CIP do not suffer from inlet effects, but do have uncertainties in their measurement volume. Cascade impactors can also be affected by particles bouncing off substrates. Thus, each measurement technique has its own advantages and disadvantages. Reid et al. (2003) found for dust aerosol at Puerto Rico that the AERONET and APS size distributions agreed well with MMD at around $3.5 \mu \mathrm{m}$, while OPC size distributions produced a VMD of $9 \mu \mathrm{m}$. Reid et al. (2003) conclude that OPC data are most likely to have the largest biases based principally on the response function and uncertainty/variability in particle refractive index and shape. However, no attempt was made by Reid et al. (2003) to determine uncertainties in the size distributions due to the response function or the uncertain refractive index. This error analysis has been rigorously performed here, and is represented in the error bars in Figs. 4 and 11. Additionally, data from the CIP, which uses light-shadowing techniques rather than light-scattering techniques as with the OPCs, further increase confidence in the shape of the Fennec size distribution presented by the CDP data. 
Reid et al. (2006) compared aircraft OPC measurements to surface-based APS observations in an environment dominated by sea-salt aerosol, and drew similar conclusions to Reid et al. (2003). AERONET size distribution inversions were also found to compare favourably to APS surface measurements. However, in this sea-salt environment, aerosols are not likely to reach such large sizes as was observed during Fennec - the precise size range which poses challenges for sunphotometer retrievals, and additionally the inlet to the APS had a cut point of around $12 \mu \mathrm{m}$ in this case. Finally, Reid et al. (2008) report observations of dust from the United Arab Emirates in 2004. The authors found that AERONET and APS size distributions agreed well, although here the inlet cut point to the APS was around $10 \mu \mathrm{m}$, thus excluding measurements in the exact size range challenging to AERONET retrievals.

Contrastingly, other previous work (Müller et al., 2012, 2010b; McConnell et al., 2008) has found relative disagreement between aircraft and AERONET size distribution retrievals for dust, finding that AERONET retrievals significantly undersize dust. In some of these cases detailed radiative closure has been achieved, validating OPC observations when a reasonable coarse mode was sampled, both for dust (Osborne et al., 2011; Müller et al., 2010b, a) and for volcanic ash (Turnbull et al., 2012; Newman et al., 2012). Thus, despite the contrasting conclusions concerning AERONET size distributions, it is important to repeat these closure flights in dusty environments.

Additionally, AERONET size distribution retrievals are subject to their own set of limitations and associated errors. Firstly, the maximum diameter extends only to $30 \mu \mathrm{m}$ and the tails of the size distributions are constrained to very small values (Hashimoto et al., 2012), and encounter large errors (Dubovik and King, 2000) which are dependent on the particle size. As noted in Estellés et al. (2012b), for the diameter interval 0.2 to $14 \mu \mathrm{m}$, the retrieval errors do not exceed $10 \%$ in the maxima but could increase up to $35 \%$ in the minima. Outside this intermediate range the errors increase, rising up to $80-100 \%$ or higher for diameters less than $0.2 \mu \mathrm{m}$ and greater than $14 \mu \mathrm{m}$ (Dubovik et al., 2002).

Unfortunately the flights during Fennec when large particles were strongly evident did not take place close to AERONET sites, due to the remoteness of the flight locations. Ryder et al. (2013b) find that particle sizes are larger close to dust sources in remote locations, and Ryder et al. (2013a) show that giant particles $(d>37.5 \mu \mathrm{m})$ are a feature of freshly uplifted dust events, and some longrange transported cases. This should be a caution for using AERONET retrievals as a basis for dust size distributions over the central Sahara, particularly since they only extend to $30 \mu \mathrm{m}$ diameter and the tails of the size distributions are constrained to very small values (Hashimoto et al., 2012). Further studies will examine aircraft and sun-photometer data from both 25 June 2011 and 18 June 2012, in terms of in situ aircraft measurements, airborne and ground-based radiation measurements, and using both the AERONET and SKYRAD retrievals for the inversion of sun-photometer radiances.

\subsection{Dust uplift and transport}

\subsubsection{Dust source areas from dust uplift potential}

It is relevant for several areas of dust measurement analysis to identify the sources of dust sampled during research flights (e.g. Sect. 4.1.2). Lagrangian backward trajectory calculations with the FLEXPART model (Stohl et al., 2005) have been initiated in "tropospheric curtains" run along the track of each research flight to investigate the sources of the dust sampled. For this a large number of virtual air parcels (1000) were released at $30 \mathrm{~s}$ intervals in a vertical column between the surface and a pressure of $200 \mathrm{hPa}$ along the flight tracks. Each parcel was tracked for 3 days backward in time using ECMWF analysis winds at a $1 \times 1^{\circ}$ horizontal grid spacing. We utilise the metric of dust uplift potential (DUP), defined as $\mathrm{f} U^{3}\left(1+U_{\mathrm{t}} / U\right)\left(1-U_{\mathrm{t}}^{2} / U^{2}\right)$, with $\mathrm{f}$ being the desert and bare soil fraction, the wind velocity $U$, and the threshold velocity $U_{\mathrm{t}}=6.5 \mathrm{~m} \mathrm{~s}^{-1}$ (Marsham et al., 2011). Despite being a simplified representation of likely dust uplift (e.g. variations in soil moisture are neglected, and dust uplift may not be linear with threshold velocity (Kok et al., 2014), DUP is a useful indicator of where likely uplift occurred and is relatively easily computed. DUP was calculated along the 3-day back-trajectories for locations where the tracked air parcels were within the boundary layer. DUP values were gridded on a $0.25 \times 0.25^{\circ}$ grid and integrated over time. The DUP thus calculated for the tropospheric column at the aircraft location characterises the air mass as measured by the onboard lidars when the BAe146 and Falcon were flying at high altitudes. During lower flight legs this analysis allows for the interpretation of in situ dust measurements with respect to their mobilisation conditions and source regions.

Figure 12 shows the composite of the DUP from (a) all the Fennec 2011 Falcon flights, (b) Fennec 2011 BAe146 flights and (c) Fennec 2012 BAe146 flights. The areas contributing to the sampled air masses, which experienced strong winds that would be associated with dust uplift for dust source regions (i.e. high DUP areas), were mostly located in a NESW oriented swath extending from central Algeria to northern Mali and Mauritania during 2011. This dominant pattern is related to the inflow into the Saharan heat low, as shown by the $925 \mathrm{hPa}$ winds in Fig. 3c over southwest Algeria. DUP locations from 2012 suggest more southerly dust sources, from southern Mauritania, stretching to the MaliAlgeria-Niger triple point and along the Mali-Algeria border towards southern Libya. This is consistent with additional convective activity in Mali driving emissions which were more Sahelian-dominated during 2012 (Sect. 3.1.3).

Individual flights exhibit additional sources and substantial variability (see Supplement for DUP maps for individual flights). For example, dust from more southerly sources 

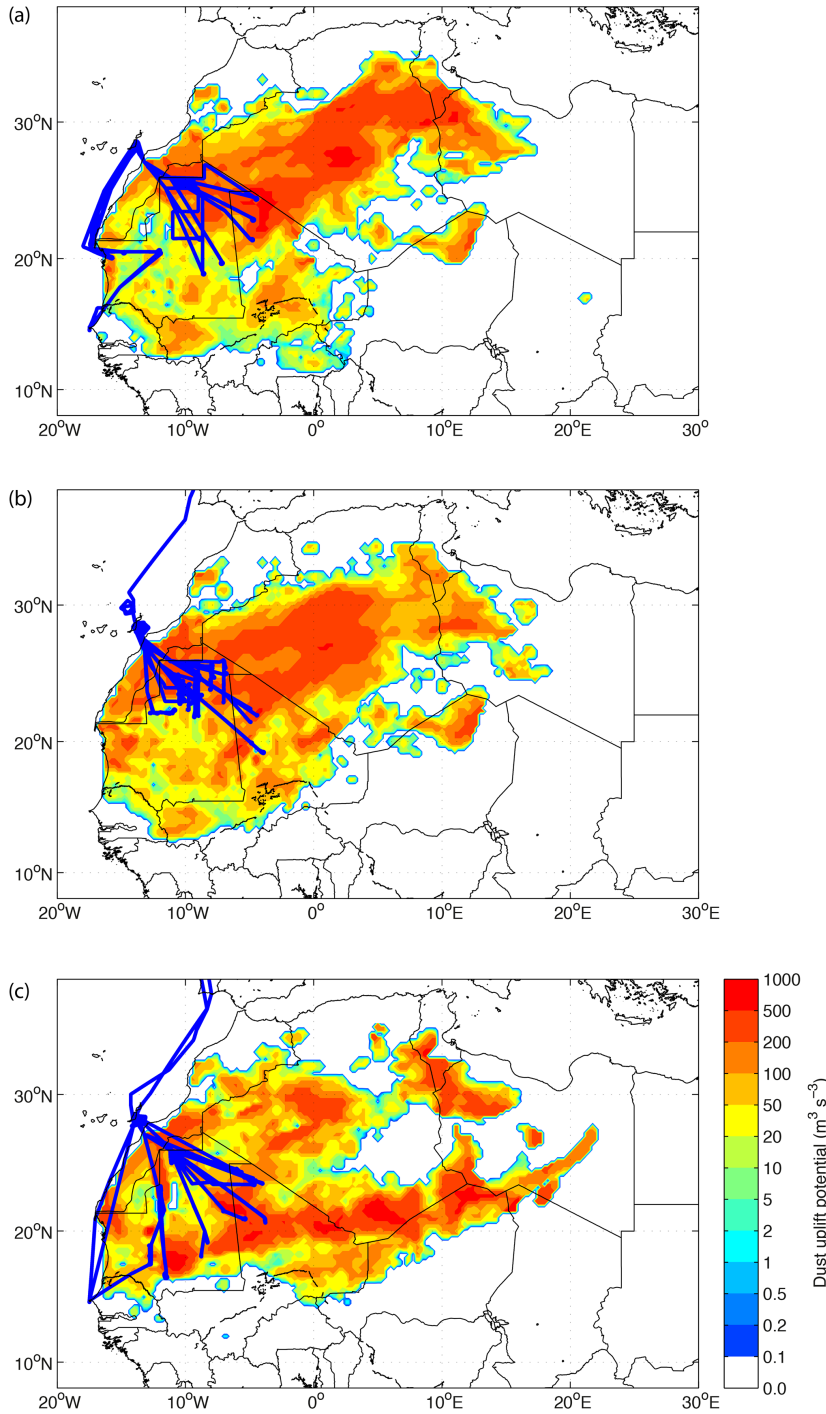

Figure 12. Composite of the dust uplift potential (DUP, shading, $\mathrm{m}^{3} \mathrm{~s}^{-3}$ ) for the air masses observed by the aircraft lidars during all flights from each campaign (blue lines). Calculations have been performed for tropospheric curtains along the flight tracks, integrating the dust uplift potential for the 3 days preceding each research flight. DUPs are shown for (a) Fennec 2011 Falcon flights; (b) Fennec 2011 BAe146 flights; (c) Fennec 2012 BAe146 flights.

in Mali and Mauritania was intercepted during flights b600602, b604-b606, b608, b611 and b614. Dust from northern Niger was sampled during flight b607. Note that the connection of dust filter samples to Fig. 12 is not immediate, because only the DUP for the selected legs corresponding to the filter sampling duration and position are considered in that case (see Sect. 4.1.2). We note that DUP from events associated with convective downdraughts such as haboobs may not be accurately represented due to the ECMWF analyses not fully capturing these events (Marsham et al., 2011). For example, this is the case for b604, where a large MCS gen- erated a haboob over Mali, which subsequently travelled towards Mauritania (Sodemann et al., 2015). Therefore, in situations where it is possible for dust to be uplifted by events associated with convection, back trajectories and more generally operational meteorological analysis and forecast data should not be used in isolation to determine dust source regions. For example, a combined analysis of SEVIRI RGB satellite imagery and Lagrangian methods can be used to ensure consistency with observations (e.g. Ryder et al., 2013b).

\subsubsection{Heavy dust loadings from a low-level jet breakdown over northern Mali}

One particularly notable flight was b600 during the morning of 17 June 2011, under which the highest dust loadings observed during Fennec 2011 and very large particles were measured. This was followed by flight b601 in the afternoon, and b602 the following morning in the same region. At this time, the SHL was centred on the Mali-Algeria-Niger triple point, producing strong low-level northeasterlies through Algeria to northern Mali, which were particularly pronounced on the morning of the 17 (b600, Fig. 13c, d, e). A region of lighter winds in Mauritania was associated with moisture remaining from the monsoon flow. Flights b600 to b602 were aimed at sampling these air masses, travelling out at high levels to descend into the strong winds in northern Mali and returning northwestwards at low levels into the moister air mass (Fig. 13a, b). In situ aircraft profile measurements are shown in Fig. 14.

Forecasts showed a pronounced decrease in the strong $925 \mathrm{hPa}$ winds in northern Mali from 06:00 to 09:00 UTC, with a corresponding increase in $10 \mathrm{~m}$ winds, consistent with the downward mixing of momentum from the nocturnal LLJ around the SHL, likely deflected around the Hoggar Mountains (Birch et al., 2012). The existence of a LLJ is confirmed by the observation from the b600 descent into Mali (Fig. 14, black) of a wind maximum of $16.7 \mathrm{~m} \mathrm{~s}^{-1}$ at a pressure height of $1700 \mathrm{~m}$ ( $1400 \mathrm{~m}$ a.g.1.), located above the growing turbulent moist and dusty CBL found below $1400 \mathrm{~m}$ a.g.1.. The dust number and mass concentrations below $1400 \mathrm{~m}$ were the highest observed during the Fennec 2011 campaign with particularly large particles observed during b600 and b601; the size distribution during the initial part of the horizontal run in the dusty CBL following the profile descent of b600 can be seen in Fig. 4, with particles present up to nearly $300 \mu \mathrm{m}$. The high dust concentrations are consistent with the very high extinction measurements from the nephelometer and PSAP of over $1250 \mathrm{Mm}^{-1}$ in both profile descents (Fig. 14). By the time of the profile descent of b601 at approximately 17:00 UTC, the dust had been mixed up into a CBL that reached $3.7 \mathrm{~km}$ (Fig. 14, red), with no remaining LLJ. The upwards vertical mixing of the dust resulted in the "pinkness" in the SEVIRI images (Fig. 13a, b) becoming more pronounced by the time of the second flight (the RGB product is sensitive to dust altitude; Brindley et al., 2012). Flight 

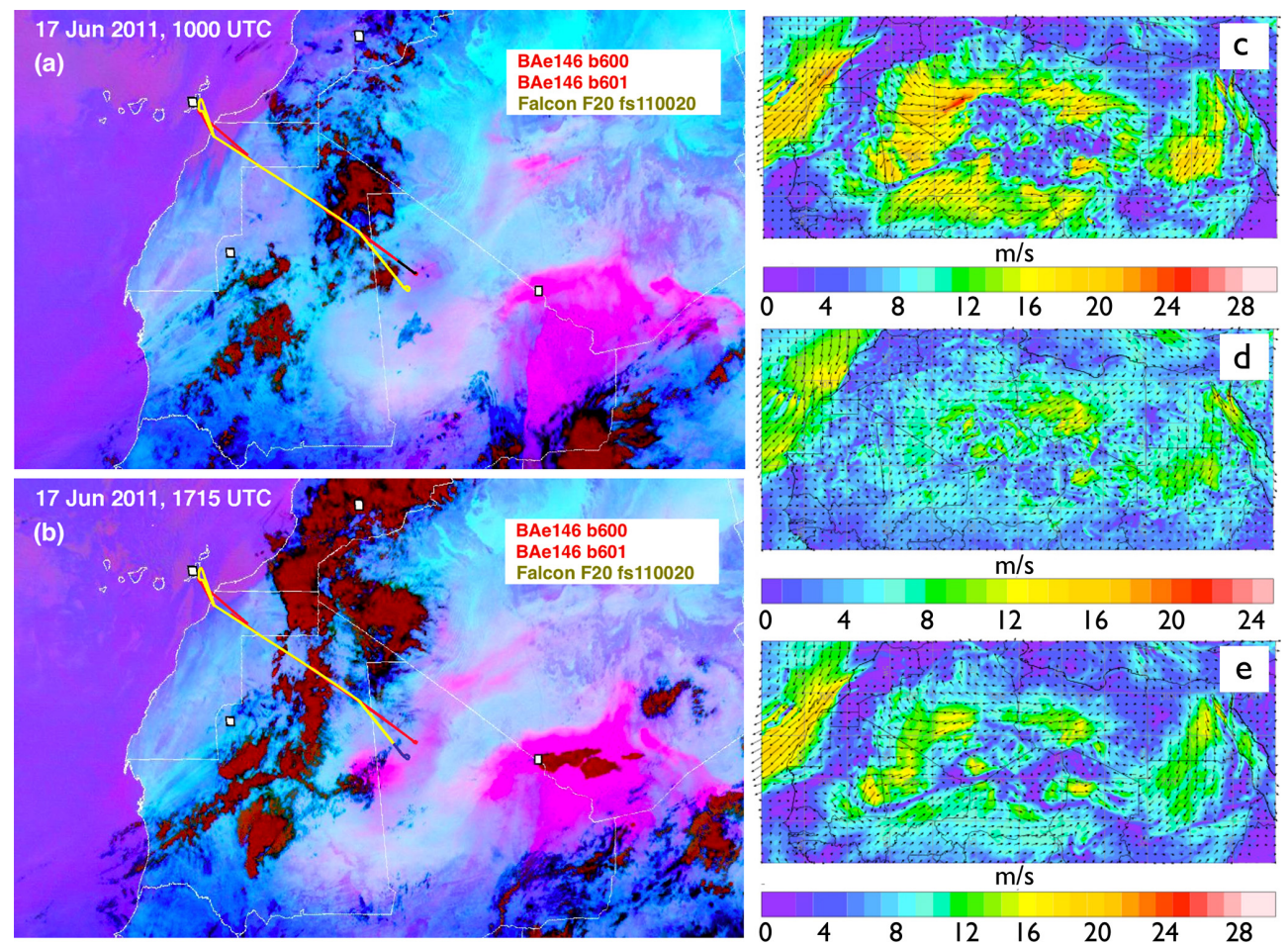

Figure 13. (a) and (b) SEVIRI RGB dust imagery for 10:00 and 17:00 UTC, and showing the flight tracks of flight b600 and b601 respectively (BAe146 track in red, F20 track in yellow, black track sections show location of aircraft at satellite image time. (c), (d) and (e) UK Met Office wind forecasts for 06:00 UTC at $925 \mathrm{hPa}$ (c), 06:00 UTC at $10 \mathrm{~m} \mathrm{(d)} \mathrm{and} \mathrm{09:00} \mathrm{UTC} \mathrm{for} 925 \mathrm{hPa}$ (e), all for 17 June 2011 on the morning of the flight.

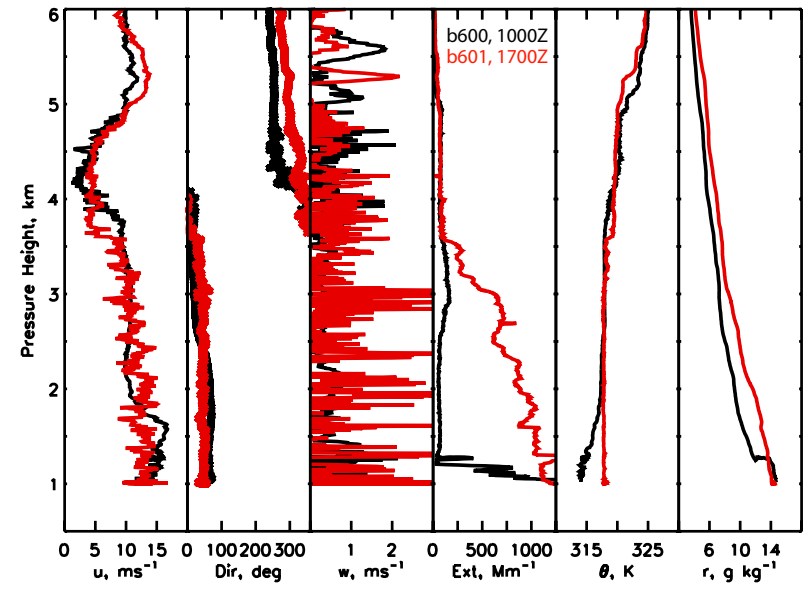

Figure 14. Aircraft measurements from the profile descent of b600 (around 10:00 UTC, black) and b601 (around 17:00 UTC, red) corresponding to the tracks, imagery and forecasts shown in Fig. 13. Figure shows wind speed $(u)$, wind direction, vertical wind speed $(w)$, corrected extinction coefficient (Ext) calculated from the nephelometer scattering and PSAP absorption, potential temperature, and water vapour mixing ratio $(r)$. Note that altitude is shown in pressure height, corresponding to minimum altitudes of 825 and $784 \mathrm{~m}$ a.g.l. respectively for b600 and b601. b601 then travelled back under the moist convection developing over Mauritania, with some precipitation observed falling onto the aircraft, but no extensive cold pool outflows at the aircraft altitude at this time.

To the authors' knowledge, this is the first airborne observation of dust size distributions (including the presence of coarse and giant particles) measured under uplift conditions caused by the breakdown of the Saharan nocturnal LLJ. Flights b706, b707 and b708 (Sect. 4.3.4) from 2012 also collected in situ measurements of dust under LLJ breakdown conditions, thus providing scope for further analysis.

\subsubsection{In situ sampling of an aged haboob}

Recent studies have shown that haboobs (dust fronts occurring at the leading edge of cold pools emanating from convective storms) are a significant source of dust over the Sahara and Sahel (Flamant et al., 2007; Knippertz et al., 2007; Schepanski et al., 2009; Tulet et al., 2010). For example, Marsham et al. (2008b, 2013b) and Allen et al. (2013) show that haboobs cause around $50 \%$ of dust uplift in the summertime Sahara, contributing to the seasonal cycle in dustiness. Radiosonde observations show that the transport of cold moist air in haboobs was a major cause of global model forecast bias at the Fennec BBM supersite in June 2011 (GarciaCarreras et al., 2013), consistent with the role of haboobs di- 

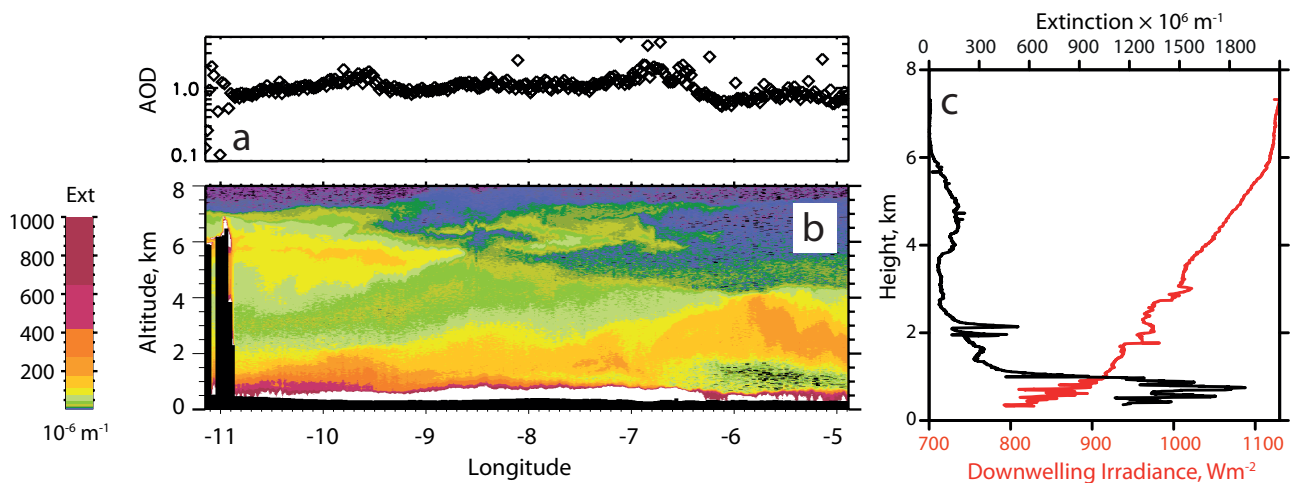

Figure 15. (a) AOD computed from the Falcon 20 LNG lidar extinction coefficient profile at around 10:00 UTC on 21 June 2011 , flight F22. (b) Cross section of the LNG lidar extinction coefficient $\left(10^{-6} \mathrm{~m}^{-1}\right)$. (c) Shortwave downwelling irradiance $\left(\mathrm{W} \mathrm{m} \mathrm{m}^{-1}\right.$, red) and extinction coefficient $\left(10^{-6} \mathrm{~m}^{-1}\right.$, black) as a function of the pressure during the ascent of the BAe146 from within the haboob to upper levels, flight b605. Note that the minimum pressure height of $360 \mathrm{~m}$ is equivalent to $105 \mathrm{~m}$ above ground level.

agnosed from convection-permitting simulations (Marsham et al., 2013a).

On 21 June 2011, aircraft measurements were taken over and through an aged haboob emanating from convection over the Atlas Mountains in Morocco (Kocha et al., 2013). The cold pool passed over dust sources and uplifted large quantities of dust. The haboob was observed over the central Sahara over northern Mauritania and northern Mali in the morning with the LNG lidar on the Falcon 20 during flight F22 (see Fig. 2b).

The haboob appears as the layer characterized by large extinction coefficient values at pressure heights beneath $1.5 \mathrm{~km}$ (Fig. 15a). The aerosol optical thickness (AOT) derived from the lidar extinction coefficient profiles reached an average of 1 around 09:00 UTC. At the same time, the BAe146 flew through the haboob to directly sample its characteristics during flight b605. In situ measurements from the BAe146 show that the dust concentration and observed extinction in the cold pool air increased by a factor of around three compared to its environment. The number of large particles of size around $10 \mu \mathrm{m}$ increased to $0.1 \mathrm{~cm}^{-3} \mu \mathrm{m}^{-1}$ (not shown). The properties of the dust sampled during this event also had a significant impact on the radiative fluxes within the haboob. For instance, the downward shortwave flux measured by the BAe146 decreased by $100 \mathrm{Wm}^{-2}$ when entering the dusty cold pool (Fig. 15b).

In the afternoon, both aircraft sampled the growth of the SABL again (flights F23 and b606) as the haboob was mixed into the Saharan residual layer above. An unambiguous influence of the haboob composition and thermodynamics was observed on the development of the SABL (Kocha et al., 2013). Simulations with and without dust are being used to investigate role of the haboob on the dynamics/thermodynamics on the development of the SABL over the central Sahara.

\subsubsection{Radiation observations during dust uplift}

Several flights were performed during Fennec to use in situ aircraft aerosol measurements and radiative measurements to potentially achieve radiative closure and examine the radiative properties of dust. Flight b708 on 16 June 2012 aimed to observe freshly uplifted dust at the time of downwards mixing of strong LLJ winds to the surface which was forecast to uplift dust over the Mali-Mauritania border. Additionally, since clouds were absent, the flight aimed to attain radiative closure measurements since the dust loadings were high but with very low-altitude dust, with AODs at 550nm of 0.54 and 1.92 measured during the two aircraft profiles by the nephelometer and the PSAP.

Figure 16b shows information from the aircraft profiles: extinction calculated from corrected scattering and absorption measurements is shown for the descent (black) and ascent (red) in Mali. During this flight, the aircraft flew a highlevel leg at $7.5 \mathrm{~km}$ for radiative measurements, followed by a profile down to minimum safe altitude, which was around $100 \mathrm{~m}$ above ground level (a.g.l.) initially (see black line in Fig. 16a). During the descent the aircraft entered the dust layer at around $900 \mathrm{~m}$. At this time the dust was not visible in the SEVIRI RGB desert dust imagery, despite an AOD of 0.54 , likely because the RGB imagery is sensitive to dust altitude (Brindley et al., 2012). Absence of a "pink" signal in the SEVIRI RGB imagery during active dust uplift such as occurred during this flight would have major implications for dust source maps that have previously been created based on this imagery (e.g. Schepanski et al., 2007). Following the descent, the aircraft flew a low-level leg. Figure 16a shows the extinction as a function of longitude. As the aircraft flew eastwards, the amount of dust increased until visibility was so poor that the aircraft had to ascend to $400 \mathrm{~m}$ a.g.l. Despite this, extinction continued to increase to the east, with a maximum of $5500 \mathrm{Mm}^{-1}$, the highest value ever observed from the FAAM nephelometer and PSAP. 

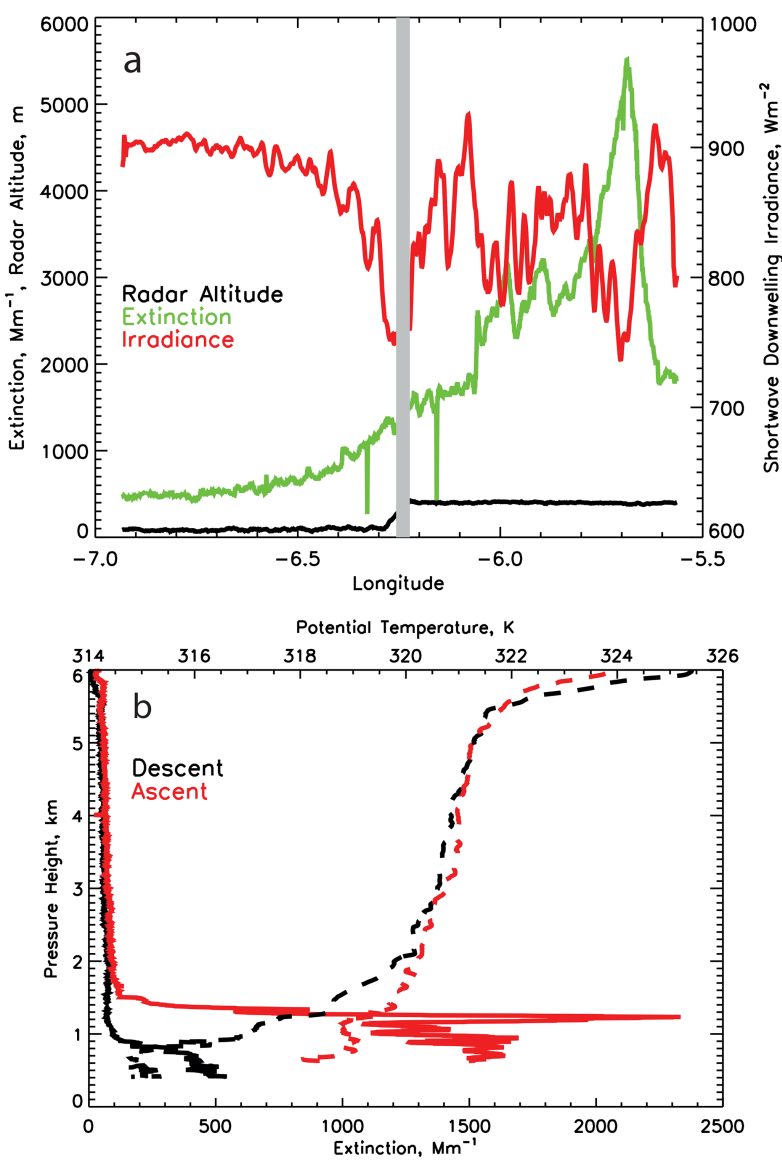

Figure 16. (a) Measurements made during low-level runs in flight b708 on 16 June 2012 sampling uplifted dust by a low-level jet. The black line shows radar altitude (height above ground, left axis), accumulation-mode extinction measured by the nephelometer and PSAP (green line, left axis), and downwelling shortwave irradiance (red line, right axis) measured by a pyranometer, averaged with a moving window of $20 \mathrm{~s}$. Grey shading indicates the times when the aircraft ascended due to poor visibility. (b) Profiles of extinction (solid lines) and potential temperature (dashed lines) measured during flight b708, for the descent (black) and ascent (red). Potential temperature is averaged over $5 \mathrm{~s}$ windows.

At the end of the low-level leg, the aircraft ascended (red line in Fig. 16b). The dashed lines in Fig. 16b mark potential temperature and show inversions at the height of the rapid increases in dust extinction. This is one example of many during Fennec where the dust was encountered in a low layer, which was gradually mixed upwards during the day as the SABL grew. The red line in Fig. 16a shows the measured downwelling shortwave irradiance (SWD) during the lowlevel run. Note that during the legs (around $30 \mathrm{~min}$ ), the solar zenith angle decreased in a way that SWD would be expected to increase with increasing longitude. Instead, during the western portion of the leg, SWD decreased with increasing extinction (dust above the aircraft). During the eastern portion of the leg there is a notable drop in SWD of around
$150 \mathrm{Wm}^{-2}$ at around $-5.7 \mathrm{~W}$ at the same time as the peak in extinction. This flight, as well as b709 in the SHL where dust was well mixed vertically up to $5 \mathrm{~km}$, will be further used to examine the radiative effect of dust over the Sahara under different dust conditions, using the spectral radiation instruments SHIMS, ARIES and SWS on the BAe146 in conjunction with radiative transfer models and satellite observations.

\subsection{Boundary layer processes, dynamics and interactions with dust}

\subsubsection{Lidar and dropsonde observations}

Combining lidar observations and dropsonde-derived atmospheric profiles allows for a detailed analysis of the spatial and vertical structure of the atmosphere as well as the boundary layer processes that control the emission, vertical mixing and transport of mineral dust. Flights b607 and b608 were part of an extensive survey of the troposphere in the SHL region with the aim (a) to characterise the spatial variability the SHL, CBL, monsoon inflow and dust distribution in the central Sahara, (b) to analyse how these features change throughout the day and (c) to assess the processes that control these features and dust dynamics. Both flights followed a straight track crossing from northern Mauritania into Mali in the morning of 22 June 2011 (see Fig. 2c for b607 flight track; the afternoon flight b608 overlies b607). The aircraft flew the track twice, once in the morning (b607) and once in the afternoon (b608), allowing the evolution of the atmosphere over time to be studied. Dropsonde measurements were obtained during the outward and return flight at fixed locations. Dropsonde data were interpolated to reference times at each location thereby creating a snapshot of the state of the atmosphere in the study region at the reference times. Engelstaedter et al. (2015) analysed the observed SHL characteristics and evaluated the performance of the UK Met Office limited area model for Africa (Africa-LAM). They identified two moisture transport pathways, one curving around the SHL core in the north (especially pronounced in a morning near-surface layer), and the other going towards the northeast within the roughly $2 \mathrm{~km}$ deep monsoon surge. The deep afternoon CBL simulated by the Africa-LAM in the monsoon surge region (more than twice as deep as observations) suggests a significant model error due to moisture being vertically mixed into northeasterly flow above about $2 \mathrm{~km}$.

As an example of the combination of observations from different instruments, Fig. 17 shows Leosphere lidar and dropsonde-derived data from BAe146 flight b607.

The range-corrected lidar signal (see Sect. 2.1 for more detail on the lidar measurements) is shown here as coloured blocks and has a vertical resolution of $45 \mathrm{~m}$ and an integration time of $1 \mathrm{~min}$. It is used here as an indicator for the presence of dust and clouds in the atmosphere but limitations apply. For instance, attenuation of the laser beam when it passes through an elevated dust layer can limit the lidar's ability to 

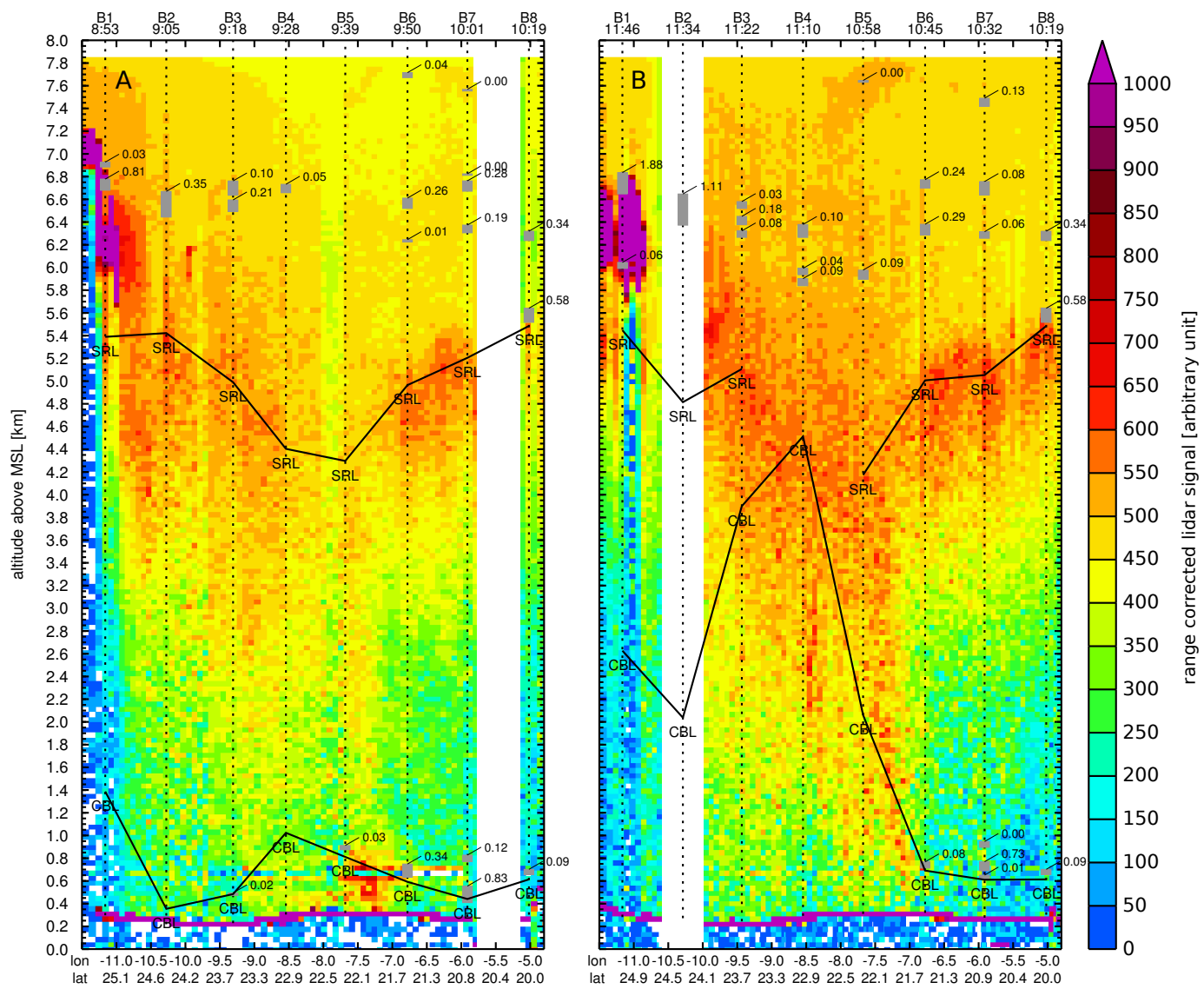

Figure 17. Lidar and dropsonde observations from 22 June 2011 morning flight b607 (yellow line in Fig. 2c) plotted along longitude for the (a) outgoing and (b) return legs. BAe146 lidar measurements (coloured boxes) are shown as the range-corrected lidar backscatter signal $355 \mathrm{~nm}$. White regions identify periods of lidar data dropouts. Dotted vertical lines indicate dropsonde locations. Black solid lines mark the top of the CBL (convective boundary layer) and SRL (Saharan residual layer). Grey boxes along dropsonde tracks show depth of temperature inversions (change in ${ }^{\circ} \mathrm{C} \mathrm{km}^{-1}$ shown next to the box). Purple line indicates ground level. Dropsonde location ID and release time are indicated above each dropsonde track.

detect dust at lower levels. Dropsonde observations allow for the identification of atmospheric structures such as the top of the CBL and SRL as well as temperature inversions. The CBL depth was determined by locating the altitude in the sonde profile (from the surface upwards) where the potential air temperature $(\theta)$ first reaches $0.3^{\circ} \mathrm{C}$ above the value at $150 \mathrm{~m}$ above the surface. In cases where $\theta$ increased monotonically from the surface up to $150 \mathrm{~m}$, the surface $\theta$ value was used as a reference. The top of the SRL was determined manually where possible by identifying a sharp decrease in water vapour mixing ratio coinciding with a sharp increase in $\theta$. The resulting CBL and SRL tops were linked by solid lines in Fig. 17 in order to illustrate spatiotemporal changes of these features. The depth of air temperature inversions, defined as an increase in air temperature with altitude, are indicated as grey boxes along the vertical sonde tracks together with the inversion strength in ${ }^{\circ} \mathrm{C} \mathrm{km}^{-1}$ (Fig. 17).

Dropsonde-derived near-surface winds ranging between 11 and $17 \mathrm{~m} \mathrm{~s}^{-1}$ observed during the b607 outgoing flight (not shown) led to local dust emissions observed by the lidar at about $7.3^{\circ} \mathrm{W}$ (also seen in lidar depolarisation data, not shown) that were prevented from upward mixing by a low-level temperature inversion (Fig. 17a). At that time in the morning, the CBL was still relatively shallow (mostly $<1 \mathrm{~km}$ deep), the top of the SRL varied between about 4.3 and $5.5 \mathrm{~km}$ a.m.s.l. and an aged dust layer of varying intensity could be identified close to the SRL top. Cloud development was identified west of $11^{\circ} \mathrm{W}$ in the lidar data. In the time that passed between the outgoing and return flight, surface emissions ceased and the CBL expanded to about $4.5 \mathrm{~km}$ a.m.s.l. (B4, Fig. 17b) as a result of increasing near-surface temperatures. East of about $7.5^{\circ} \mathrm{W}$, the $\mathrm{CBL}$ was prevented from growing deep by temperature inversions and the influence of monsoon flow (not shown). Clouds continued to develop west of about $10.5^{\circ} \mathrm{W}$. CBL growth rates can be calculated for each dropsonde location based on the two dropsonde profiles. The SRL top showed little change compared to the outward leg apart from at B4 where the SRL was consumed 
completely by the fast-growing CBL (Fig. 17). It should be noted that SEVIRI imagery did not show any dust presence along the flight tracks on this day, suggesting that the lidar dust signal represents background dust levels - some dust is almost always present over northern Africa at this time of year (Israelevich et al., 2003).

As part of this SHL survey, the Falcon 20 took measurements at the same time as the BAe146 but on a more southern track (flight F24 in Fig. 2b). The analysis of the combined aircraft data showed that the SHL had an elongated shape with a NE-SW orientation. Moisture from the monsoon inflow was transported around the SHL at low levels in the morning. These unique measurements allow for the first time to challenge climate models in the SHL region and to understand the processes that control the observed temporal and spatial variability.

\subsubsection{First observations of the vertical profile of SABL fluxes and mesoscale circulations in the SABL}

The Saharan atmospheric boundary layer (SABL) is probably the deepest on Earth, often reaching 5-6 km, and is crucial in controlling the vertical redistribution and transport of dust, moisture, heat and momentum fluxes in the Sahara (Cuesta et al., 2009). Before Fennec, aircraft observations and radiosondes (Cuesta et al., 2009; Messager et al., 2010; Marsham et al., 2013b) showed the persistence of a deep near-neutral Saharan residual layer (SRL) over large areas of the Sahara throughout the day, with only a very small temperature inversion separating the SRL from the CBL below. Flamant et al. (2007) and Messager et al. (2010) showed that the SRL may have a maximum humidity mixing ratio at its upper levels, and that small errors in model representation of this humidity can have substantial consequences in terms of relative humidity, cloud cover and, therefore, radiation. This unusual structure of the SABL means that relatively small perturbations to CBL temperature (e.g. from a surface albedo anomaly) are expected to have significant impacts on vertical mixing and perhaps induce circulations that may affect the $\mathrm{CBL}$ in neighbouring regions. There was evidence of such effects in observations from the CBL (Marsham et al., 2008a) and in modelling studies (Birch et al., 2012; Huang et al., 2010), but observations of impacts on the SRL were lacking. Observations from Fennec BBM supersite 1 showed that the CBL tends only to reach 5 or $6 \mathrm{~km}$ between 15:00 and 18:00 UTC (Marsham et al., 2013b). Fennec flights have provided new insights into the vertical structure of and mixing within the SABL (see Garcia-Carreras et al., 2015, including schematic (their Fig. 14) and SABL mesoscale circulations, below).

During Fennec, aircraft lidar and in situ observations were used to better understand the vertical stratification and transport mechanisms within the SABL, as well as its temporal and spatial variability (Garcia-Carreras et al., 2015). In order to sample the turbulent vertical structure of the SABL dur- ing Fennec, stacked legs were performed at different heights, determined from inspecting dropsonde profiles launched at both ends of the leg before descending. Each run was at least 10 times the SABL depth $(\geq 60 \mathrm{~km})$ and took place between 13:00 and 15:00 LT, when sensible heating was maximum. Heat fluxes were computed from the stacked legs, as well as the ascents and descents, taking advantage of the shallow angle of the aircraft profiles. These indicate that entrainment fluxes are very weak, as a result of detrainment at the CBL top. This is a result of the weak temperature inversion, and high vertical velocity of overshooting parcels, which are characteristic of the SABL, and can explain the slow development of the CBL despite the strong surface heating. Lidar measurements from high-level runs also showed that the boundary layer depth can vary by up to $100 \%$ over distances of a few kilometres due to turbulent processes alone, so that any given dropsonde profile may not be representative of the whole run.

Figure 18 shows an example from a flight where small variations in heating from an albedo anomaly appear to be generating mesoscale circulations within the SABL. Figure 18 shows the vertical extinction coefficient at $532 \mathrm{~nm}$ retrieved with the LNG lidar on 20 June 2011 (14:0514:46 UTC, flight F21, see Fig. 2b) from the Falcon flying southeastward in Mauritania, with water vapour mixing ratio (WVMR) and wind profiles from four dropsondes overplotted. The lidar transect highlights a number of important boundary layer (BL) processes encountered during the Fennec campaign, showing variability from the turbulent to the synoptic scales, as described below.

At the synoptic scale, there is a temperature and humidity gradient across the transect, with warmer and drier conditions in the northwest (by $\sim 5 \mathrm{~K}$ and $7 \mathrm{~g} \mathrm{~kg}^{-1}$ ), leading to a deeper CBL compared to the southeast $\left(4 \mathrm{~km}\right.$ at $24^{\circ} \mathrm{N}$ compared with $2 \mathrm{~km}$ at $21^{\circ} \mathrm{N}$ ). The monsoon flow at night reached approximately $20^{\circ} \mathrm{N}$ along the flight track, bringing in cool moist air into the southern end of the transect (from UK Met Office analysis, not shown), which was then redistributed vertically as the CBL grew during the day. The more spatially homogeneous residual layer, on the other hand, reflects the conditions from the day before; the monsoon front on the night of 19 June was considerably further south, leading to a deep CBL throughout the transect. There is substantial variability in the SABL depth and structure superimposed on the synoptic gradient. Variability at the turbulent eddy scale can be observed in the northern end of the transect $\left(24.5-25.2^{\circ} \mathrm{N}\right)$, with changes in the depth of the well-mixed aerosol layer (and so the CBL) of $\sim 1 \mathrm{~km}$ over short horizontal distances $\left(5-10 \mathrm{~km}, \sim 0.05\right.$ to $\left.0.1^{\circ}\right)$, consistent with idealised simulations and lidar measurements described in Garcia-Carreras et al. (2015).

At the mesoscale, there is a region with cloud and deeper BLs at the boundary between the warm, dry conditions in the northwest and the moister conditions in the southeast (21.4 $22.5^{\circ} \mathrm{N}$ ), with an orange plume reaching $6 \mathrm{~km}$ at $22.2^{\circ} \mathrm{N}$. 
(a)

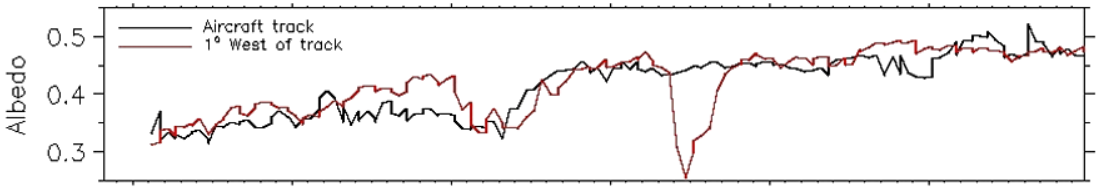

(b)

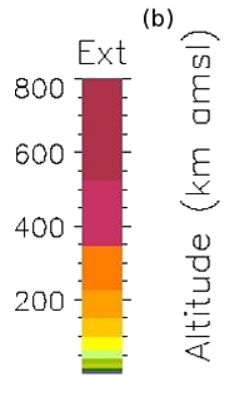

$\begin{array}{llllllllllll}2 & 4 & 6 & 8 & 1012 & 0 & 2 & 4 & 6 & 810 & 12\end{array}$

$02468 \quad 81012 \quad 0246681012$

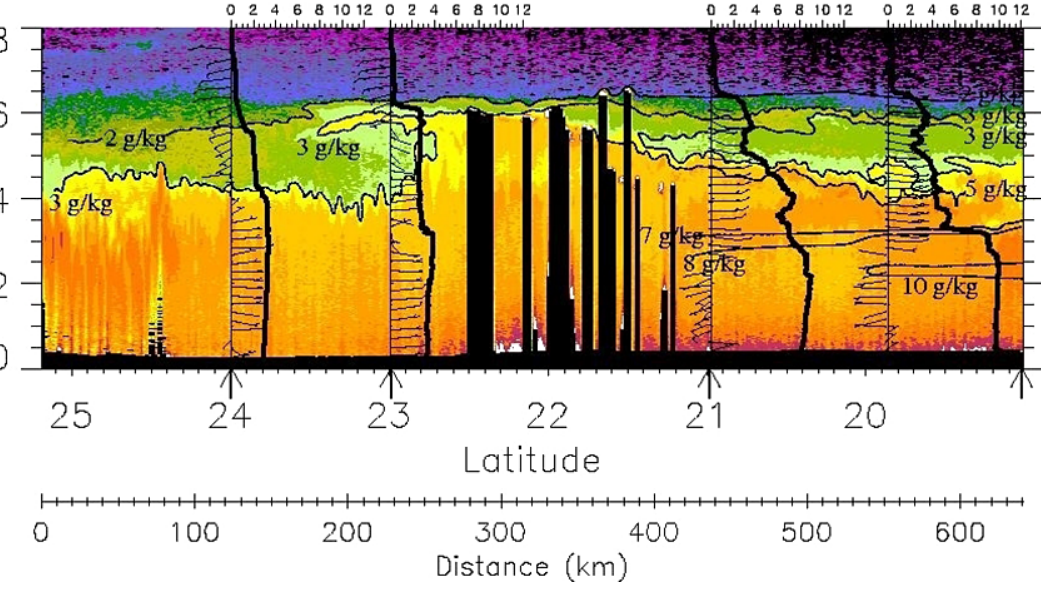

Figure 18. LNG lidar-derived extinction coefficient at $532 \mathrm{~nm}$ on 20 June 2011 during flight $\mathrm{F} 21$ from $25.0^{\circ} \mathrm{N}, 11.5^{\circ} \mathrm{W}$ to $19.0^{\circ} \mathrm{N}, 8.7^{\circ} \mathrm{W}$. Water vapour mixing ratio (WVMR, $\mathrm{g} \mathrm{kg}^{-1}$ ) and wind profiles from four dropsondes are superimposed (black lines, dropsonde locations indicated by arrows), with WVMR contours drawn by hand using the lidar backscatter; away from the dropsondes these are by necessity subjective and the 7 and $8 \mathrm{~g} \mathrm{~kg}^{-1}$ contours have not been continued west of $21.2^{\circ} \mathrm{N}$ due to a lack of data. Along-track albedo derived from MODIS satellite data and albedo $1^{\circ} \mathrm{W}$ of the flight track are shown in the upper panel.

Satellite imagery shows that the clouds observed by the lidar are part of a band of clouds coincident with a negative albedo anomaly of around 0.2 that is just west of the flight track at $21.6^{\circ} \mathrm{N}$ (red line, Fig. 18). The surface hotspot leads to a local increase in the CBL depth, cloud formation and an upward transport of dust. The impact of another smaller hotspot can be observed at $22.8^{\circ} \mathrm{N}$. Easterly winds in the SRL in the southeast lead to the air mass overriding the deeper CBL in the northwest, potentially contributing to the cloud formation. The $3 \mathrm{~g} \mathrm{~kg}^{-1}$ contour in Fig. 18 has been drawn using the dropsonde data and the lidar-inferred aerosol distribution and suggests that the deeper CBL around $22^{\circ} \mathrm{N}$ acts to transport water vapour and dust directly to the top of the SRL, where it spreads laterally, capping the adjacent CBL and leading to weak maxima in water vapour mixing ratios at the top of the SRL in the three eastern dropsondes. This supports the hypotheses of Marsham et al. (2008a) and Messager et al. (2010) of mesoscale variability in the SABL and its role in the transport of CBL air into the SRL, with implications for the long-range transport of dust.

\subsubsection{North American wildfire emissions measured over Africa}

Approximately 15 pollutant plumes were observed on the BAe146 in the upper troposphere (6 to $8.5 \mathrm{~km}$ altitude) above the Sahara desert during the Fennec campaign in June 2011. Using Hybrid Single Particle Lagrangian Integrated Trajectory (HYSPLIT) model trajectory analysis and MODIS satel- lite fire products, four source regions were identified for these pollutant plumes: flaring from oil fields in Algeria and biomass burning in the southern USA, Venezuela and western Africa. The pollutant plumes displayed high concentrations of ozone and sub-micron particles, with differing characteristics from each source region. Values for the single scattering albedo ranged from 0.57 to 0.99 and for the Angstrom exponent from -0.85 to 2.44 for individual plumes. If the HYSPLIT trajectory calculations are robust (uncertain due the substantial errors identified in the vertical wind fields), it is believed this is the first aircraft measurement of flaring from oil fields and merits the attention of further research, planned for the forthcoming DACCIWA field campaign in southern west Africa.

\section{Conclusions}

We have presented a description of the Fennec airborne fieldwork of 2011 and 2012 over the western Sahara region in order to provide a reference and context for published and future articles. Secondly, we have presented new scientific results which have developed from the airborne measurements to show how the exploitation of aircraft measurements can deepen our understanding of weather, climate and dust processes over remote regions of the Sahara not otherwise accessible. Finally, the Fennec airborne data provide the only comprehensive source of in situ Saharan observations with which to develop the science linking dust, dynamics and ra- 
diation in the central Sahara. Along with the ground- and satellite-based measurements, these will be heavily exploited in the coming years, and therefore we have provided a detailed overview of the data and their context.

The research areas and key findings of published articles relating to the Fennec aircraft observations are summarised in Table 8. We emphasise that giant-mode dust particles were measured with the CIPs (up to $300 \mu \mathrm{m}$ during Fennec 2011 and $6200 \mu \mathrm{m}$ during Fennec 2012), and also note the advancement of technologies that have made size distribution measurements across the full size range at $10 \mathrm{~Hz}$ possible (Rosenberg et al., 2012). The former have been used to demonstrate a significant presence of particles larger than $10 \mu \mathrm{m}$ over remote parts of the Sahara, including providing uncertainties in the size distribution due to refractive index assumption and the degenerate Mie response curve. Volume distributions peaked between 10 and $60 \mu \mathrm{m}$ in many fresh, heavy dust cases while the peak volume distribution shifted to 10 to $20 \mu \mathrm{m}$ in more aged dust events with a reduction in total concentrations (Ryder et al., 2013a, b). The measurement of size distributions at $10 \mathrm{~Hz}$ has allowed dust fluxes in the SABL to be measured from an aircraft for the first time (Rosenberg et al., 2014).

The new scientific findings presented in this article are as follows:

- During the second half of June 2011 sources over central Algeria dominated, driven primarily by stronger easterlies associated with the westward movement of the SHL, in contrast to the second half of June 2012 when more Sahelian dust sources dominated due to a northern extension of the monsoon flow and increased MCS and cold pool activity over Mali. This is associated with differences in the chemical composition and optical property results between campaigns, which show higher dust absorption and lower calcium content in 2012 compared to 2011, characteristic of dust emitted from Sahelian soils. This change in composition and associated dust absorption can have significant radiative impacts which can be driven by dust uplift locations and the dominant meteorology. These first results of dust chemical composition in the SHL region indicate the importance of large-scale meteorology in affecting dust composition and therefore radiative properties.

- Comprehensive aerosol and cloud instrumentation on the BAe146 has been used to explore the interaction between dust layers and clouds, indicating that dust particles likely act as $\mathrm{CCN}$, and also as IN at temperatures of $-15^{\circ} \mathrm{C}$.

- Ozone concentrations have been compared to size distribution measurements of surface area in an attempt to determine the role of dust on ozone depletion. Results suggest that coarser, fresher dust particles can provide a route to decrease ozone concentrations, though in this case a change of air mass during sampling prevented unequivocal attribution.

- Dust uplift under the breakdown of the nocturnal LLJ has been observed, including its impact on shortwave irradiance and the presence of coarse and giant particles in these very fresh dust events, which are observed at low altitudes and often before they become visible in SEVIRI imagery.

- F20 lidar measurements have been combined with BAe146 in situ extinction and vertically resolved shortwave flux measurements to describe the influence of haboob thermodynamics on the development of the SABL, and the subsequent mixing of the haboob through the SABL.

- Combined lidar and dropsonde observations show the spatial and diurnal structure of the SHL. The CBL develops throughout the day while the influence of the southerly monsoon flow restricts this growth. Variability in the SABL plays an important role in the transport of CBL air into the SRL, which has implications for the long-range transport of dust, with evidence of surface albedo features driving such variability.

- Vertical profiles of turbulent fluxes have revealed unusual characteristics of entrainment and detrainment of thermals in the deep, dry SABL, which are a challenge for BL schemes in global models.

- Unique in situ observations suggest that precipitation is recycled as it is evaporated into BL air that feeds clouds (a common feature of the SABL), increasing the total water content of subsequent clouds and increasing the moisture content at mid-levels in the SABL. Observations suggest cloud-processing of dust and subsequent evaporation alters the size distribution of dust.

- In one case, a comparison of aircraft lidar data with satellite-based measurements from SEVIRI and MODIS shows good agreement as to the spatial distribution of dust but they disagree as to the loading, which may be indicative of different sensitivities to varying meteorological conditions. Further detailed comparisons were undertaken (see Table 8), demonstrating the value of aircraft-satellite validation studies.

- A comparison of column mean size distributions between AERONET and the BAe146 in situ measurements shows AERONET-retrieved peak volume size distributions at 3-6 microns, while aircraft measurements measured more coarse-mode distributions, with a peak at 12 microns. This was in a dust event with low concentrations of coarse and giant particles present the aircraft frequently encountered cases with a greater coarse mode present. We propagated uncertainties due 
Table 8. Key publications deriving from Fennec aircraft observations and summarising other Fennec ground-based observations.

\begin{tabular}{|c|c|c|}
\hline Research area & Key findings & Reference \\
\hline \multicolumn{3}{|c|}{ Publications deriving from Fennec aircraft observations } \\
\hline Size distribution measurements & A new method for correcting OPC data for particle optical properties & Rosenberg et al. (2012) \\
\hline BAe146 Inlets & $\begin{array}{l}\text { BAe146 Rosemount inlet significantly excludes particles larger than } \\
3 \mu \mathrm{m} \text { diameter }\end{array}$ & Trembath (2012) \\
\hline $\begin{array}{l}\text { Size distributions and optical } \\
\text { properties of dust }\end{array}$ & $\begin{array}{l}\text { Consistent presence of coarse and giant particles over Sahara; SSA at } \\
550 \mathrm{~nm} \text { of } 0.7 \text { to } 0.97 \text { strongly related to particle size; inverse relation- } \\
\text { ship between size and dust age. }\end{array}$ & Ryder et al. (2013b) \\
\hline $\begin{array}{l}\text { Impacts of transport on dust } \\
\text { size distribution }\end{array}$ & $\begin{array}{l}d_{\mathrm{eff}} \text { decrease of } 4.5 \mu \mathrm{m} \text {, and SSA increase from } 0.92 \text { to } 0.95 \text { between } \\
\text { fresh and Atlantic Saharan air layer dust. }\end{array}$ & Ryder et al. (2013a) \\
\hline Dust-ozone interactions & $\begin{array}{l}\text { Increased dust surface area associated with fresh dust uplift and a large } \\
\text { coarse mode act as a route for the reduced ozone concentrations. }\end{array}$ & Brooke (2014) \\
\hline Dust fluxes & $\begin{array}{l}\text { Size-resolved dust fluxes follow the power law predicted by the Kok } \\
\text { brittle fragmentation theory. Large size cut-off is significantly larger } \\
\text { than seen in other observations. Large fluxes were correlated with re- } \\
\text { gions of varying topography. }\end{array}$ & Rosenberg et al. (2014) \\
\hline Satellite retrievals of dust & $\begin{array}{l}\text { Imperial SEVIRI dust AOD products are most effective at high dust } \\
\text { loadings, but are sensitive to meteorological conditions; MODIS Deep } \\
\text { Blue and MISR AOD products more consistent at lower dust loadings. }\end{array}$ & Banks et al. (2013) \\
\hline $\begin{array}{l}\text { Lagrangian modelling of dust } \\
\text { uplift and transport }\end{array}$ & $\begin{array}{l}\text { Validation of Lagrangian dust transport model with dust mass concen- } \\
\text { tration underlines difficulties to quantify dust emission due to moist } \\
\text { convection. Manual inversion approach constrains dust source and flux. }\end{array}$ & Sodemann et al. (2015) \\
\hline Dust uplift from fluvial sources & $\begin{array}{l}\text { Dust emission from alluvial source observed by airborne remote sens- } \\
\text { ing; Nocturnal LLJ drives morning dust uplift; explicit representation } \\
\text { of endorheic systems as dust sources required in terms of their role as } \\
\text { dust sources. }\end{array}$ & Schepanski et al. (2013) \\
\hline $\begin{array}{l}\text { Structure and diurnal growth of } \\
\text { the SABL }\end{array}$ & $\begin{array}{l}\text { Turbulent structure, vertical fluxes and diurnal growth of SABL de- } \\
\text { scribed with radiosondes, aircraft measurements and a large eddy } \\
\text { model. Novel processes found, such as detrainment from the CBL top } \\
\text { which acts to slow down CBL growth. }\end{array}$ & $\begin{array}{l}\text { Garcia-Carreras et } \\
\text { al. (2015) }\end{array}$ \\
\hline $\begin{array}{l}\text { Moisture transport pathways in } \\
\text { the SHL region }\end{array}$ & $\begin{array}{l}\text { Observation-based SHL characterisation; monsoon surge splits into two } \\
\text { moisture transport pathways: (a) around the SHL and (b) towards the } \\
\text { northeast; afternoon CBL depth overestimation by model leads to mois- } \\
\text { ture advection error. }\end{array}$ & $\begin{array}{l}\text { Engelstaedter et } \\
\text { al. (2015) }\end{array}$ \\
\hline \multicolumn{3}{|c|}{ Further information from Fennec } \\
\hline Introduction to Fennec & & Washington et al. (2012) \\
\hline \multirow[t]{3}{*}{ Ground-based observations } & Supersite 1, Bordj Badji Mokhtar & Marsham et al. (2013b) \\
\hline & Supersite 2, Zouerate & Todd et al. (2013) \\
\hline & The Fennec Automatic Weather Station Network & Hobby et al. (2013) \\
\hline
\end{tabular}

to calibration, Mie response curve and refractive index in the aircraft optical particle counter size distribution measurements to clearly display uncertainties to the reader. Measurements from the shadow-based CIP further increased confidence in the aircraft size distributions. Contrasting evidence exists in the literature regarding the validity of AERONET dust size distri- bution retrievals. This work adds to the evidence that AERONET-derived size distributions should be used with caution when coarse dust particles are present, and it merits further detailed comparison under heavy dust loadings.

This paper demonstrates that the Fennec airborne campaign has delivered a novel, rich data set through the operation of 
two aircraft over remote regions of the Sahara. The power of these aircraft measurements will be enhanced via combination with the ground-based measurements available from the Fennec climate programme, providing a unique resource for further in-depth study of the vital SHL region of the Sahara. These will be further exploited through the Fennec Earth observation and modelling programmes.

\section{The Supplement related to this article is available online at doi:10.5194/acp-15-8479-2015-supplement.}

Acknowledgements. Core project funding for Fennec was from the UK Natural Environmental Research Council (NERC) under grant NE/G017166/1. In addition, Fennec received support from the NERC National Centre for Atmospheric Science (NCAS), the Agence Nationale de la Recherche (ANR no. 2010 BLAN 606 01), the Institut National des Sciences de l'Univers (INSU/CNRS) through the LEFE programme, the Centre National d'Etudes Spatiales (CNES) through the TOSCA programme and MétéoFrance. Airborne data from the BAe146 were obtained using the BAe-146-301 Atmospheric Research Aircraft operated by Directflight Ltd and managed by FAAM, which is a joint entity of the NERC and the UK Met Office. Airborne data from the F20 were obtained using the Falcon 20 Environment Research Aircraft operated and managed by SAFIRE, which is a joint entity of CNRS, Météo-France \& CNES. EUFAR (EUropean Facility for Airborne Research) is acknowledged for its support to the RAIN4DUST Falcon-20 flights and LADUNEX BAe146 flights. The UK Met Office is acknowledged for funding of flight b710 through SAVEX. SAVEX ground deployment at Tenerife was possible thanks to RIMA/AERONET and AEMET infrastructure; and support from Juan de la Cierva (JCI-2009-04455), Universidad de La Laguna (2012/0001624), MICIIN (CGL2012_33294) and Generalitat Valenciana (PROMETEO/2010/064) projects. Many other scientists and engineers were involved in the gathering of this outstanding data set. Additional partners include Directflight, AvalonAero, FAAM (Facility for Airborne Atmospheric Measurements), SAFIRE (Service des Avions Français Instrumentés pour la Recherche en Environnement), UK Met Office, and DMN Maroc. MODIS data used in this paper were produced with the LAADS online data system, developed and maintained by NASA Goddard, and we also acknowledge the MODIS scientists and associated NASA personnel for the production of the data used in this research effort. Flight forecasting would not have been possible without the model products made available especially for the Fennec project particularly the UK Met Office, the Météo-France AROME model team and the DREAM model team.

Edited by: R. Sullivan

\section{References}

Allen, C. J. T., Washington, R., and Engelstaedter, S.: Dust emission and transport mechanisms in the central Sahara: Fennec ground-based observations from Bordj Badji
Mokhtar, June 2011, J. Geophys. Res.-Atmos., 118, 6212-6232, doi:10.1002/Jgrd.50534, 2013.

Ansmann, A., Tesche, M., Althausen, D., Muller, D., Seifert, P., Freudenthaler, V., Heese, B., Wiegner, M., Pisani, G., Knippertz, P., and Dubovik, O.: Influence of Saharan dust on cloud glaciation in southern Morocco during the Saharan Mineral Dust Experiment, J. Geophys. Res.-Atmos., 113, D04210, doi:10.1029/2007jd008785, 2008.

Ansmann, A., Tesche, M., Knippertz, P., Bierwirth, E., Althausen, D., Muller, D., and Schulz, O.: Vertical profiling of convective dust plumes in southern Morocco during SAMUM, Tellus B, 61, 340-353, doi:10.1111/j.1600-0889.2008.00384.x, 2009.

Ansmann, A., Petzold, A., Kandler, K., Tegen, I., Wendisch, M., Müller, D., Weinzierl, B., Müller, T., and Heintzenberg, J.: Saharan Mineral Dust Experiments SAMUM-1 and SAMUM-2: what have we learned?, Tellus B, 63, 403-429, doi:10.1111/j.16000889.2011.00555.x, 2011.

Ansmann, A., Seifert, P., Tesche, M., and Wandinger, U.: Profiling of fine and coarse particle mass: case studies of Saharan dust and Eyjafjallajökull/Grimsvötn volcanic plumes, Atmos. Chem. Phys., 12, 9399-9415, doi:10.5194/acp-12-9399-2012, 2012.

Banks, J. R. and Brindley, H. E.: Evaluation of MSG-SEVIRI mineral dust retrieval products over Africa and the Middle East, Remote Sens. Environ., 128, 58-73, doi:10.1016/j.rse.2012.07.017, 2013.

Banks, J. R., Brindley, H. E., Flamant, C., Garay, M. J., Hsu, N. C., Kalashnikov, O. V., Kluser, L., and Sayer, A. M.: Intercomparison of satellite dust retrieval products over the west African Sahara during the Fennec campaign in June 2011, Remote Sens. Environ., 136, 99-116, doi:10.1016/j.rse.2013.05.003, 2013.

Bauer, S. E., Balkanski, Y., Schulz, M., Hauglustaine, D. A., and Dentener, F.: Global modeling of heterogeneous chemistry on mineral aerosol surfaces: Influence on tropospheric ozone chemistry and comparison to observations, J. Geophys. Res.-Atmos., 109, D02304, doi:10.1029/2003jd003868, 2004.

Baumgardner, D., Jonsson, H., Dawson, W., O’Connor, D., and Newton, R.: The cloud, aerosol and precipitation spectrometer: a new instrument for cloud investigations, Atmos. Res., 59, 251264, 2001.

Bian, H. S. and Zender, C. S.: Mineral dust and global tropospheric chemistry: Relative roles of photolysis and heterogeneous uptake, J. Geophys. Res.-Atmos., 108, 4672, doi:10.1029/2002jd003143, 2003.

Birch, C. E., Parker, D. J., Marsham, J. H., and Devine, G. M.: The effect of orography and surface albedo on stratification in the summertime Saharan boundary layer: Dynamics and implications for dust transport, J. Geophys. Res.-Atmos., 117, D05105, doi:10.1029/2011jd015965, 2012.

Blyth, A. M., Cooper, W. A., and Jensen, J. B.: A Study of the Source of Entrained Air in Montana Cumuli, J. Atmos. Sci., 45, 3944-3964, doi:10.1175/15200469(1988)045<3944:Asotso>2.0.Co;2, 1988.

Brindley, H., Knippertz, P., Ryder, C., and Ashpole, I.: A critical evaluation of the ability of the Spinning Enhanced Visible and Infrared Imager (SEVIRI) thermal infrared red-green-blue rendering to identify dust events: Theoretical analysis, J. Geophys. Res.-Atmos., 117, D07201, doi:10.1029/2011jd017326, 2012.

Brindley, H. E. and Russell, J. E.: An assessment of Saharan dust loading and the corresponding cloud-free longwave direct radia- 
tive effect from geostationary satellite observations, J. Geophys. Res.-Atmos., 114, D23201, doi:10.1029/2008jd011635, 2009.

Brooke, J. K.: Airborne Observations of the Physical and Optical Properties of Atmospheric Aerosol, PhD, School of Earth and Environment, University of Leeds, UK, 2014.

Campanelli, M., Estelles, V., Smyth, T., Tomasi, C., MartinezLozano, M. P., Claxton, B., Muller, P., Pappalardo, G., Pietruczuk, A., Shanklin, J., Colwell, S., Wrench, C., Lupi, A., Mazzola, M., Lanconelli, C., Vitale, V., Congeduti, F., Dionisi, D., Cardillo, F., Cacciani, M., Casasanta, G., and Nakajima, T.: Monitoring of Eyjafjallajokull volcanic aerosol by the new European Skynet Radiometers (ESR) network, Atmos. Environ., 48, 33-45, doi:10.1016/j.atmosenv.2011.09.070, 2012.

Caquineau, S., Magonthier, M. C., Gaudichet, A., and Gomes, L.: An improved procedure for the X-ray diffraction analysis of lowmass atmospheric dust samples, Eur. J. Mineral., 9, 157-166, 1997.

Caquineau, S., Gaudichet, A., Gomes, L., and Legrand, M.: Mineralogy of Saharan dust transported over northwestern tropical Atlantic Ocean in relation to source regions, J. Geophys. Res.Atmos., 107, 4251, doi:10.1029/2000jd000247, 2002.

Chang, R. Y. W., Sullivan, R. C., and Abbatt, J. P. D.: Initial uptake of ozone on Saharan dust at atmospheric relative humidities, Geophys. Res. Lett., 32, L14815, doi:10.1029/2005g1023317, 2005.

Chauvin, F., Roehrig, R., and Lafore, J. P.: Intraseasonal Variability of the Saharan Heat Low and Its Link with Midlatitudes, J. Climate, 23, 2544-2561, doi:10.1175/2010jcli3093.1, 2010.

Chazette, P., Dabas, A., Sanak, J., Lardier, M., and Royer, P.: French airborne lidar measurements for Eyjafjallajökull ash plume survey, Atmos. Chem. Phys., 12, 7059-7072, doi:10.5194/acp-127059-2012, 2012.

Cotton, R., Osborne, S., Ulanowski, Z., Hirst, E., Kaye, P. H., and Greenaway, R. S.: The Ability of the Small Ice Detector (SID-2) to Characterize Cloud Particle and Aerosol Morphologies Obtained during Flights of the FAAM BAe146 Research Aircraft, J. Atmos. Ocean. Tech., 27, 290-303, doi:10.1175/2009jtecha1282.1, 2010.

Cuesta, J., Edouart, D., Mimouni, M., Flamant, P. H., Loth, C., Gibert, F., Marnas, F., Bouklila, A., Kharef, M., Ouchene, B., Kadi, M., and Flamant, C.: Multiplatform observations of the seasonal evolution of the Saharan atmospheric boundary layer in Tamanrasset, Algeria, in the framework of the African Monsoon Multidisciplinary Analysis field campaign conducted in 2006, J. Geophys. Res.-Atmos., 113, D00c07, doi:10.1029/2007jd009417, 2008.

Cuesta, J., Marsham, J. H., Parker, D. J., and Flamant, C.: Dynamical mechanisms controlling the vertical redistribution of dust and the thermodynamic structure of the West Saharan atmospheric boundary layer during summer, Atmos. Sci. Lett., 10, 34-42, doi:10.1002/As1.207, 2009.

de Reus, M., Dentener, F., Thomas, A., Borrmann, S., Strom, J., and Lelieveld, J.: Airborne observations of dust aerosol over the North Atlantic Ocean during ACE 2: Indications for heterogeneous ozone destruction, J. Geophys. Res.-Atmos., 105, 1526315275, doi:10.1029/2000jd900164, 2000.

de Reus, M., Fischer, H., Sander, R., Gros, V., Kormann, R., Salisbury, G., Van Dingenen, R., Williams, J., Zöllner, M., and Lelieveld, J.: Observations and model calculations of trace gas scavenging in a dense Saharan dust plume during MINATROC, Atmos. Chem. Phys., 5, 1787-1803, doi:10.5194/acp-5-17872005, 2005.

de Villiers, R. A., Ancellet, G., Pelon, J., Quennehen, B., Schwarzenboeck, A., Gayet, J. F., and Law, K. S.: Airborne measurements of aerosol optical properties related to early spring transport of mid-latitude sources into the Arctic, Atmos. Chem. Phys., 10, 5011-5030, doi:10.5194/acp-10-5011-2010, 2010.

Dubovik, O. and King, M. D.: A flexible inversion algorithm for retrieval of aerosol optical properties from Sun and sky radiance measurements, J. Geophys. Res.-Atmos., 105, 20673-20696, doi:10.1029/2000jd900282, 2000.

Dubovik, O., Holben, B., Eck, T. F., Smirnov, A., Kaufman, Y. J., King, M. D., Tanre, D., and Slutsker, I.: Variability of absorption and optical properties of key aerosol types observed in worldwide locations, J. Atmos. Sci., 59, 590-608, doi:10.1175/15200469(2002)059<0590:Voaaop>2.0.Co;2, 2002.

Dubovik, O., Sinyuk, A., Lapyonok, T., Holben, B. N., Mishchenko, M., Yang, P., Eck, T. F., Volten, H., Munoz, O., Veihelmann, B., van der Zande, W. J., Leon, J. F., Sorokin, M., and Slutsker, I.: Application of spheroid models to account for aerosol particle nonsphericity in remote sensing of desert dust, J. Geophys. Res.Atmos., 111, D11208, doi:10.1029/2005jd006619, 2006.

Dunion, J. P. and Velden, C. S.: The impact of the Saharan air layer on Atlantic tropical cyclone activity, B. Am. Meteorol. Soc., 85, 353-365, doi:10.1175/Bams-85-3-353, 2004.

Engelstaedter, S., Tegen, I., and Washington, R.: North African dust emissions and transport, Earth-Sci. Rev., 79, 73-100, doi:10.1016/j.earscirev.2006.06.004, 2006.

Engelstaedter, S., Washington, R., Flamant, C., Parker, D. J., Allen, C. J. T., and Todd, M. C.: The Saharan heat low and moisture transport pathways in the central Sahara - multi-aircraft observations and Africa-LAM evaluation, J. Geophys. Res.-Atmos., 120, 4417-4442, doi:10.1002/2015JD023123, 2015.

Estellés, V., Campanelli, M., Smyth, T. J., Utrillas, M. P., and Martínez-Lozano, J. A.: Evaluation of the new ESR network software for the retrieval of direct sun products from CIMEL CE318 and PREDE POM01 sun-sky radiometers, Atmos. Chem. Phys., 12, 11619-11630, doi:10.5194/acp-12-11619-2012, 2012a.

Estellés, V., Campanelli, M., Utrillas, M. P., Expósito, F., and Martínez-Lozano, J. A.: Comparison of AERONET and SKYRAD4.2 inversion products retrieved from a Cimel CE318 sunphotometer, Atmos. Meas. Tech., 5, 569-579, doi:10.5194/amt-5-569-2012, 2012b.

Evan, A. T., Vimont, D. J., Heidinger, A. K., Kossin, J. P., and Bennartz, R.: The Role of Aerosols in the Evolution of Tropical North Atlantic Ocean Temperature Anomalies, Science, 324, 778-781, doi:10.1126/science.1167404, 2009.

Evan, A. T., Foltz, G. R., Zhang, D. X., and Vimont, D. J.: Influence of African dust on ocean-atmosphere variability in the tropical Atlantic, Nat. Geosci., 4, 762-765, doi:10.1038/Ngeo1276, 2011.

Evan, A. T., Flamant, C., Fiedler, S., and Doherty, S.: An analysis of aeolian dust in climate models, Geophys. Res. Lett., 41, 59966001, doi:10.1002/2014GL060545, 2014.

Flamant, C., Chaboureau, J. P., Parker, D. J., Taylor, C. A., Cammas, J. P., Bock, O., Timouk, F., and Pelon, J.: Airborne observations of the impact of a convective system on the planetary boundary layer thermodynamics and aerosol distribution in the inter- 
tropical discontinuity region of the West African Monsoon, Q. J. Roy. Meteor. Soc., 133, 1175-1189, doi:10.1002/Qj.97, 2007.

Formenti, P., Rajot, J. L., Desboeufs, K., Saïd, F., Grand, N., Chevaillier, S., and Schmechtig, C.: Airborne observations of mineral dust over western Africa in the summer Monsoon season: spatial and vertical variability of physico-chemical and optical properties, Atmos. Chem. Phys., 11, 6387-6410, doi:10.5194/acp-11-6387-2011, 2011a.

Formenti, P., Schütz, L., Balkanski, Y., Desboeufs, K., Ebert, M., Kandler, K., Petzold, A., Scheuvens, D., Weinbruch, S., and Zhang, D.: Recent progress in understanding physical and chemical properties of African and Asian mineral dust, Atmos. Chem. Phys., 11, 8231-8256, doi:10.5194/acp-11-8231-2011, $2011 \mathrm{~b}$.

Formenti, P., Caquineau, S., Desboeufs, K., Klaver, A., Chevaillier, S., Journet, E., and Rajot, J. L.: Mapping the physicochemical properties of mineral dust in western Africa: mineralogical composition, Atmos. Chem. Phys., 14, 10663-10686, doi:10.5194/acp-14-10663-2014, 2014.

Forster, P., Ramaswamy, V., Artaxo, P., Berntsen, T., Betts, R., Fahey, D. W., Haywood, J. M., Lean, J., Lowe, D. C., Myhre, G., Nganga, J., Prinn, R., Raga, G., Schulz, M., and Van Dorland, R.: Changes in Atmospheric Constituents and in Radiative Forcing, in: Climate Change 2007: The Physical Science Basis, in: Contribution of Working Group I to the Fourth Assessment Report of the Intergovernmental Panel on Climate Change, edited by: Solomon, S., Qin, D., Manning, M., Chen, Z., Marquis, M., Averyt, K. B., Tignor, M., and Miller, H. L., Cambridge University Press, Cambridge, UK, 2007.

García, O. E., Díaz, J. P., Expósito, F. J., Díaz, A. M., Dubovik, O., Derimian, Y., Dubuisson, P., and Roger, J.-C.: Shortwave radiative forcing and efficiency of key aerosol types using AERONET data, Atmos. Chem. Phys., 12, 5129-5145, doi:10.5194/acp-125129-2012, 2012.

Garcia-Carreras, L., Marsham, J. H., Parker, D. J., Bain, C. L., Milton, S., Saci, A., Salah-Ferroudj, M., Ouchene, B., and Washington, R.: The impact of convective cold pool outflows on model biases in the Sahara, Geophys. Res. Lett., 40, 1647-1652, doi:10.1002/Grl.50239, 2013.

Garcia-Carreras, L., Parker, D. J., Marsham, J. H., Rosenberg, P. D., Brooks, I. M., Lock, A. P., Marenco, F., McQuaid, J. B., and Hobby, M.: The Turbulent Structure and Diurnal Growth of the Saharan Atmospheric Boundary Layer, J. Atmos. Sci., 72, 693 713, doi:10.1175/Jas-D-13-0384.1, 2015.

Grassian, V. H.: Chemical reactions of nitrogen oxides on the surface of oxide, carbonate, soot, and mineral dust particles: Implications for the chemical balance of the troposphere, J. Phys. Chem. A, 106, 860-877, doi:10.1021/Jp012139h, 2002.

Gross, S., Tesche, M., Freudenthaler, V., Toledano, C., Wiegner, M., Ansmann, A., Althausen, D., and Seefeldner, M.: Characterization of Saharan dust, marine aerosols and mixtures of biomassburning aerosols and dust by means of multi-wavelength depolarization and Raman lidar measurements during SAMUM 2, Tellus B, 63, 706-724, doi:10.1111/j.1600-0889.2011.00556.x, 2011.

Hanisch, F. and Crowley, J. N.: Ozone decomposition on Saharan dust: an experimental investigation, Atmos. Chem. Phys., 3, 119 130, doi:10.5194/acp-3-119-2003, 2003.

Hashimoto, M., Nakajima, T., Dubovik, O., Campanelli, M., Che, H., Khatri, P., Takamura, T., and Pandithurai, G.: Development of a new data-processing method for SKYNET sky radiometer ob- servations, Atmos. Meas. Tech., 5, 2723-2737, doi:10.5194/amt5-2723-2012, 2012.

Haywood, J. M., Francis, P., Osborne, S., Glew, M., Loeb, N., Highwood, E., Tanre, D., Myhre, G., Formenti, P., and Hirst, E.: Radiative properties and direct radiative effect of Saharan dust measured by the C-130 aircraft during SHADE: 1 . Solar spectrum, J. Geophys. Res.-Atmos., 108, 8577, doi:10.1029/2002jd002687, 2003.

Haywood, J. M., Pelon, J., Formenti, P., Bharmal, N., Brooks, M., Capes, G., Chazette, P., Chou, C., Christopher, S., Coe, H., Cuesta, J., Derimian, Y., Desboeufs, K., Greed, G., Harrison, M., Heese, B., Highwood, E. J., Johnson, B., Mallet, M., Marticorena, B., Marsham, J. H., Milton, S., Myhre, G., Osborne, S. R., Parker, D. J., Rajot, J. L., Schulz, M., Slingo, A., Tanre, D., and Tulet, P.: Overview of the Dust and Biomass-burning Experiment and African Monsoon Multidisciplinary Analysis Special Observing Period-0, J. Geophys. Res.-Atmos., 113, D00c17, doi:10.1029/2008jd010077, 2008.

Haywood, J. M., Johnson, B. T., Osborne, S. R., Baran, A. J., Brooks, M., Milton, S. F., Mulcahy, J., Walters, D., Allan, R. P., Klaver, A., Formenti, P., Brindley, H. E., Christopher, S., and Gupta, P.: Motivation, rationale and key results from the GERBILS Saharan dust measurement campaign, Q. J. Roy. Meteor. Soc., 137, 1106-1116, doi:10.1002/Qj.797, 2011 a.

Haywood, J. M., Johnson, B. T., Osborne, S. R., Mulcahy, J., Brooks, M. E., Harrison, M. A. J., Milton, S. F., and Brindley, H. E.: Observations and modelling of the solar and terrestrial radiative effects of Saharan dust: a radiative closure case-study over oceans during the GERBILS campaign, Q. J. Roy. Meteor. Soc., 137, 1211-1226, doi:10.1002/Qj.770, 2011b.

Heim, M., Mullins, B. J., Umhauer, H., and Kasper, G.: Performance evaluation of three optical particle counters with an efficient "multimodal" calibration method, J. Aerosol Sci., 39, 1019-1031, doi:10.1016/j.jaerosci.2008.07.006, 2008.

Heintzenberg, J.: The SAMUM-1 experiment over Southern Morocco: overview and introduction, Tellus B, 61, 2-11, doi:10.1111/j.1600-0889.2008.00403.x, 2009.

Highwood, E. J., Northway, M. J., McMeeking, G. R., Morgan, W. T., Liu, D., Osborne, S., Bower, K., Coe, H., Ryder, C., and Williams, P.: Aerosol scattering and absorption during the EUCAARI-LONGREX flights of the Facility for Airborne Atmospheric Measurements (FAAM) BAe-146: can measurements and models agree?, Atmos. Chem. Phys., 12, 7251-7267, doi:10.5194/acp-12-7251-2012, 2012.

Hobby, M., Gascoyne, M., Marsham, J. H., Bart, M., Allen, C., Engelstaedter, S., Fadel, D. M., Gandega, A., Lane, R., McQuaid, J. B., Ouchene, B., Ouladichir, A., Parker, D. J., Rosenberg, P., Ferroudj, M. S., Saci, A., Seddik, F., Todd, M., Walker D., and Washington, R.: The Fennec Automatic Weather Station (AWS) Network: Monitoring the Saharan Climate System, J. Atmos. Ocean. Tech., 30, 709-724, doi:10.1175/Jtech-D-1200037.1, 2013

Hsu, N. C., Tsay, S. C., King, M. D., and Herman, J. R.: Aerosol properties over bright-reflecting source regions, IEEE T. Geosci. Remote, 42, 557-569, doi:10.1109/Tgrs.2004.824067, 2004.

Huang, Q., Marsham, J. H., Parker, D. J., Tian, W. S., and Grams, C. M.: Simulations of the effects of surface heat flux anomalies on stratification, convective growth, and vertical transport within the 
Saharan boundary layer, J. Geophys. Res.-Atmos., 115, D05201, doi:10.1029/2009jd012689, 2010.

Huneeus, N., Schulz, M., Balkanski, Y., Griesfeller, J., Prospero, J., Kinne, S., Bauer, S., Boucher, O., Chin, M., Dentener, F., Diehl, T., Easter, R., Fillmore, D., Ghan, S., Ginoux, P., Grini, A., Horowitz, L., Koch, D., Krol, M. C., Landing, W., Liu, X., Mahowald, N., Miller, R., Morcrette, J.-J., Myhre, G., Penner, J., Perlwitz, J., Stier, P., Takemura, T., and Zender, C. S.: Global dust model intercomparison in AeroCom phase I, Atmos. Chem. Phys., 11, 7781-7816, doi:10.5194/acp-11-7781-2011, 2011.

Israelevich, P. L., Ganor, E., Levin, Z., and Joseph, J. H.: Annual variations of physical properties of desert dust over Israel, J. Geophys. Res.-Atmos., 108, 4381, doi:10.1029/2002jd003163, 2003.

Jenkins, G. S., Pratt, A. S., and Heymsfield, A.: Possible linkages between Saharan dust and tropical cyclone rain band invigoration in the eastern Atlantic during NAMMA-06, Geophys. Res. Lett., 35, L08815, doi:10.1029/2008g1034072, 2008.

Jickells, T. D., An, Z. S., Andersen, K. K., Baker, A. R., Bergametti, G., Brooks, N., Cao, J. J., Boyd, P. W., Duce, R. A., Hunter, K. A., Kawahata, H., Kubilay, N., laRoche, J., Liss, P. S., Mahowald, N., Prospero, J. M., Ridgwell, A. J., Tegen, I., and Torres, R.: Global iron connections between desert dust, ocean biogeochemistry, and climate, Science, 308, 67-71, 2005.

Johnson, B., Turnbull, K., Brown, P., Burgess, R., Dorsey, J., Baran, A. J., Webster, H., Haywood, J., Cotton, R., Ulanowski, Z., Hesse, E., Woolley, A., and Rosenberg, P.: In situ observations of volcanic ash clouds from the FAAM aircraft during the eruption of Eyjafjallajokull in 2010, J. Geophys. Res.-Atmos., 117, D00u24, doi:10.1029/2011jd016760, 2012.

Journet, E., Balkanski, Y., and Harrison, S. P.: A new data set of soil mineralogy for dust-cycle modeling, Atmos. Chem. Phys., 14, 3801-3816, doi:10.5194/acp-14-3801-2014, 2014.

Kandler, K., Benker, N., Bundke, U., Cuevas, E., Ebert, M., Knippertz, P., Rodriguez, S., Schutz, L., and Weinbruch, S.: Chemical composition and complex refractive index of Saharan Mineral Dust at Izana, Tenerife (Spain) derived by electron microscopy, Atmos. Environ., 41, 8058-8074, doi:10.1016/j.atmosenv.2007.06.047, 2007.

Kanitz, T., Seifert, P., Ansmann, A., Engelmann, R., Althausen, D., Casiccia, C., and Rohwer, E. G.: Contrasting the impact of aerosols at northern and southern midlatitudes on heterogeneous ice formation, Geophys. Res. Lett., 38, L17802, doi:10.1029/2011g1048532, 2011.

Kim, D., Chin, M., Yu, H. B., Diehl, T., Tan, Q., Kahn, R. A., Tsigaridis, K., Bauer, S. E., Takemura, T., Pozzoli, L., Bellouin, N., Schulz, M., Peyridieu, S., Chedin, A., and Koffi, B.: Sources, sinks, and transatlantic transport of North African dust aerosol: A multimodel analysis and comparison with remote sensing data, J. Geophys. Res.-Atmos., 119, 6259-6277, doi:10.1002/2013jd021099, 2014.

Kinne, S., Lohmann, U., Feichter, J., Schulz, M., Timmreck, C., Ghan, S., Easter, R., Chin, M., Ginoux, P., Takemura, T., Tegen, I., Koch, D., Herzog, M., Penner, J., Pitari, G., Holben, B., Eck, T., Smirnov, A., Dubovik, O., Slutsker, I., Tanre, D., Torres, O., Mishchenko, M., Geogdzhayev, I., Chu, D. A., and Kaufman, Y.: Monthly averages of aerosol properties: A global comparison among models, satellite data, and AERONET ground data, J. Geophys. Res.-Atmos., 108, 4634, doi:10.1029/2001jd001253, 2003.
Knippertz, P., Deutscher, C., Kandler, K., Muller, T., Schulz, O., and Schutz, L.: Dust mobilization due to density currents in the Atlas region: Observations from the Saharan Mineral Dust Experiment 2006 field campaign, J. Geophys. Res.-Atmos., 112, D21109, doi:10.1029/2007jd008774, 2007.

Knollenberg, R. G.: The optical array: An alternative to scattering or extinction for airborne particle size determination, J. Appl. Meteorol., 9, 86-103, doi:10.1175/15200450(1970)009<0086:TOAAAT>2.0.CO;2, 1970.

Kocha, C., Flamant, C., Berckmens, J., Fink, A., Garcia-Carreras, L., Knippertz, P., Lafore, J.-P., Marnas, F., Marsham, J. H., Parker, D. J., Rosenberg, P., Ryder, C. L., Tulet, P., and Washington, R.: How can a dusty cold pool change the diurnal evolution of the Saharan Boundary Layer?, EGU April 2013, Vienna, EGU2013-9774, 2013.

Koehler, K. A., Kreidenweis, S. M., DeMott, P. J., Petters, M. D., Prenni, A. J., and Carrico, C. M.: Hygroscopicity and cloud droplet activation of mineral dust aerosol, Geophys. Res. Lett., 36, L08805, doi:10.1029/2009g1037348, 2009.

Kok, J. F., Mahowald, N. M., Fratini, G., Gillies, J. A., Ishizuka, M., Leys, J. F., Mikami, M., Park, M.-S., Park, S.-U., Van Pelt, R. S., and Zobeck, T. M.: An improved dust emission model - Part 1: Model description and comparison against measurements, Atmos. Chem. Phys., 14, 13023-13041, doi:10.5194/acp14-13023-2014, 2014.

Lacis, A. A. and Mishchenko, M. I.: Climate forcing, climate sensitivity, and climate response: A radiative modeling perspective on atmospheric aerosols, Dahl. Ws. Env., 17, 11-42, 1995.

Lance, S., Medina, J., Smith, J. N., and Nenes, A.: Mapping the operation of the DMT Continuous Flow CCN counter, Aerosol. Sci. Tech., 40, 242-254, doi:10.1080/02786820500543290, 2006.

Lavaysse, C., Flamant, C., Janicot, S., Parker, D. J., Lafore, J. P., Sultan, B., and Pelon, J.: Seasonal evolution of the West African heat low: a climatological perspective, Clim. Dynam., 33, 313330, doi:10.1007/s00382-009-0553-4, 2009.

Legrand, M., Pietras, C., Brogniez, G., Haeffelin, M., Abuhassan, N. K., and Sicard, M.: A high-accuracy multiwavelength radiometer for in situ measurements in the thermal infrared. Part I: Characterization of the instrument, J. Atmos. Ocean. Tech., 17, 1203-1214, doi:10.1175/15200426(2000)017<1203:Ahamrf>2.0.Co;2, 2000.

Lensky, I. M. and Rosenfeld, D.: Clouds-Aerosols-Precipitation Satellite Analysis Tool (CAPSAT), Atmos. Chem. Phys., 8, 6739-6753, doi:10.5194/acp-8-6739-2008, 2008.

Liu, P. S. K., Leaitch, W. R., Strapp, J. W., and Wasey, M. A.: Response of Particle Measuring Systems Airborne Asasp and Pcasp to Nacl and Latex-Particles, Aerosol. Sci. Tech., 16, 8395, doi:10.1080/02786829208959539, 1992.

Mahowald, N., Albani, S., Kok, J. F., Engelstaeder, S., Scanza, R., Ward, D. S., and Flanner, M. G.: The size distribution of desert dust aerosols and its impact on the Earth system, Aeolian. Res., 15, 53-71, doi:10.1016/j.aeolia.2013.09.002, 2014.

Marenco, F., Johnson, B., Turnbull, K., Newman, S., Haywood, J., Webster, H., and Ricketts, H.: Airborne lidar observations of the 2010 Eyjafjallajokull volcanic ash plume, J. Geophys. Res.Atmos., 116, D00u05, doi:10.1029/2011jd016396, 2011.

Marenco, F.: Nadir airborne lidar observations of deep aerosol layers, Atmos. Meas. Tech., 6, 2055-2064, doi:10.5194/amt-62055-2013, 2013. 
Marenco, F., Amiridis, V., Marinou, E., Tsekeri, A., and Pelon, J.: Airborne verification of CALIPSO products over the Amazon: a case study of daytime observations in a complex atmospheric scene, Atmos. Chem. Phys., 14, 11871-11881, doi:10.5194/acp14-11871-2014, 2014.

Marsham, J. H., Parker, D. J., Grams, C. M., Johnson, B. T., Grey, W. M. F., and Ross, A. N.: Observations of mesoscale and boundary-layer scale circulations affecting dust transport and uplift over the Sahara, Atmos. Chem. Phys., 8, 6979-6993, doi:10.5194/acp-8-6979-2008, 2008a.

Marsham, J. H., Parker, D. J., Grams, C. M., Taylor, C. M., and Haywood, J. M.: Uplift of Saharan dust south of the intertropical discontinuity, J. Geophys. Res.-Atmos., 113, D21102, doi:10.1029/2008jd009844, 2008b.

Marsham, J. H., Knippertz, P., Dixon, N. S., Parker, D. J., and Lister, G. M. S.: The importance of the representation of deep convection for modeled dust-generating winds over West Africa during summer, Geophys. Res. Lett., 38, L16803, doi:10.1029/2011gl048368, 2011.

Marsham, J. H., Dixon, N. S., Garcia-Carreras, L., Lister, G. M. S., Parker, D. J., Knippertz, P., and Birch, C. E.: The role of moist convection in the West African monsoon system: Insights from continental-scale convection-permitting simulations, Geophys. Res. Lett., 40, 1843-1849, doi:10.1002/Grl.50347, $2013 \mathrm{a}$.

Marsham, J. H., Hobby, M., Allen, C. J. T., Banks, J. R., Bart, M., Brooks, B. J., Cavazos-Guerra, C., Engelstaedter, S., Gascoyne, M., Lima, A. R., Martins, J. V., McQuaid, J. B., O’Leary, A., Ouchene, B., Ouladichir, A., Parker, D. J., Saci, A., SalahFerroudj, M., Todd, M. C., and Washington, R.: Meteorology and dust in the central Sahara: Observations from Fennec supersite-1 during the June 2011 Intensive Observation Period, J. Geophys. Res.-Atmos., 118, 4069-4089, doi:10.1002/Jgrd.50211, 2013 b.

McConnell, C. L., Highwood, E. J., Coe, H., Formenti, P., Anderson, B., Osborne, S., Nava, S., Desboeufs, K., Chen, G., and Harrison, M. A. J.: Seasonal variations of the physical and optical characteristics of Saharan dust: Results from the Dust Outflow and Deposition to the Ocean (DODO) experiment, J. Geophys. Res.-Atmos., 113, D14s05, doi:10.1029/2007jd009606, 2008.

Messager, C., Parker, D. J., Reitebuch, O., Agusti-Panareda, A., Taylor, C. M., and Cuesta, J.: Structure and dynamics of the Saharan atmospheric boundary layer during the West African monsoon onset: observations and analyses from the research flights of 14 and 17 July 2006, Q. J. Roy. Meteor. Soc., 136, 107-124, doi:10.1002/qj.469, 2010.

Müller, D., Ansmann, A., Freudenthaler, V., Kandler, K., Toledano, C., Hiebsch, A., Gasteiger, J., Esselborn, M., Tesche, M., Heese, B., Althausen, D., Weinzierl, B., Petzold, A., and von Hoyningen-Huene, W.: Mineral dust observed with AERONET Sun photometer, Raman lidar, and in situ instruments during SAMUM 2006: Shape-dependent particle properties, J. Geophys. Res.-Atmos., 115, D11207, doi:10.1029/2009jd012523, 2010a.

Müller, D., Weinzierl, B., Petzold, A., Kandler, K., Ansmann, A., Müller, T., Tesche, M., Freudenthaler, V., Esselborn, M., Heese, B., Althausen, D., Schladitz, A., Otto, S., and Knippertz, P.: Mineral dust observed with AERONET Sun photometer, Raman lidar, and in situ instruments during SAMUM 2006: Shapeindependent particle properties, J. Geophys. Res.-Atmos., 115, D07202, doi:10.1029/2009jd012520, 2010b.
Müller, D., Lee, K. H., Gasteiger, J., Tesche, M., Weinzierl, B., Kandler, K., Müller, T., Toledano, C., Otto, S., Althausen, D., and Ansmann, A.: Comparison of optical and microphysical properties of pure Saharan mineral dust observed with AERONET Sun photometer, Raman lidar, and in situ instruments during SAMUM 2006, J. Geophys. Res.-Atmos., 117, D07211, doi:10.1029/2011jd016825, 2012.

Nakajima, T., Tonna, G., Rao, R. Z., Boi, P., Kaufman, Y., and Holben, B.: Use of sky brightness measurements from ground for remote sensing of particulate polydispersions, Appl. Optics, 35, 2672-2686, doi:10.1364/Ao.35.002672, 1996.

Newman, S. M., Clarisse, L., Hurtmans, D., Marenco, F., Johnson, B., Turnbull, K., Havemann, S., Baran, A. J., O’Sullivan, D. and Haywood, J.: A case study of observations of volcanic ash from the Eyjafjallajokull eruption: 2. Airborne and satellite radiative measurements, J. Geophys. Res.-Atmos., 117, D00u13, doi:10.1029/2011jd016780, 2012.

Omar, A. H., Winker, D. M., Kittaka, C., Vaughan, M. A., Liu, Z. Y., Hu, Y. X., Trepte, C. R., Rogers, R. R., Ferrare, R. A., Lee, K. P., Kuehn, R. E., and Hostetler, C. A.: The CALIPSO Automated Aerosol Classification and Lidar Ratio Selection Algorithm, J. Atmos. Ocean. Tech., 26, 1994-2014, doi:10.1175/2009jtecha1231.1, 2009.

Osborne, S. R., Baran, A. J., Johnson, B. T., Haywood, J. M., Hesse, E., and Newman, S.: Short-wave and long-wave radiative properties of Saharan dust aerosol, Q. J. Roy. Meteor. Soc., 137, 11491167, doi:10.1002/Qj.771, 2011.

Paluch, I. R.: Entrainment Mechanism in Colorado $\mathrm{Cu}-$ muli, J. Atmos. Sci., 36, 2467-2478, doi:10.1175/15200469(1979)036<2467: Temicc>2.0.Co;2, 1979.

Pappas, V., Ryder, C. L., Highwood, E. J., and Young, S.: Comparison of Fennec airborne in-situ dust measurements with CALIOP spaceborne lidar retrievals of extinction, Remote Sens. Environ., in prep., 2015.

Petersen, G. N. and Renfrew, I. A.: Aircraft-based observations of air-sea fluxes over Denmark Strait and the Irminger Sea during high wind speed conditions, Q. J. Roy. Meteor. Soc., 135, 2030 2045, doi:10.1002/Qj.355, 2009.

Preissler, J., Wagner, F., Pereira, S. N., and Guerrero-Rascado, J. L.: Multi-instrumental observation of an exceptionally strong Saharan dust outbreak over Portugal, J. Geophys. Res.-Atmos., 116, D24204, doi:10.1029/2011jd016527, 2011.

Raymond, D. J. and Blyth, A. M.: Precipitation Development in a New-Mexico Thunderstorm, Q. J. Roy. Meteor. Soc., 115, 13971423, doi:10.1002/qj.49711549011, 1989.

Redelsperger, J. L., Thorncroft, C. D., Diedhiou, A., Lebel, T., Parker, D. J., and Polcher, J.: African monsoon multidisciplinary analysis - An international research project and field campaign, B. Am. Meteorol. Soc., 87, 1739-1746, doi:10.1175/Bams-8712-1739, 2006.

Reid, J. S., Jonsson, H. H., Maring, H. B., Smirnov, A., Savoie, D. L., Cliff, S. S., Reid, E. A., Livingston, J. M., Meier, M. M., Dubovik, O., and Tsay, S. C.: Comparison of size and morphological measurements of coarse mode dust particles from Africa, J. Geophys. Res.-Atmos., 108, 8593, doi:10.1029/2002jd002485, 2003.

Reid, J. S., Brooks, B., Crahan, K. K., Hegg, D. A., Eck, T. F., O'Neill, N., de Leeuw, G., Reid, E. A., and Anderson, K. D.: Reconciliation of coarse mode sea-salt aerosol parti- 
cle size measurements and parameterizations at a subtropical ocean receptor site, J. Geophys. Res.-Atmos., 111, D02202, doi:10.1029/2005jd006200, 2006.

Reid, J. S., Reid, E. A., Walker, A., Piketh, S., Cliff, S., Al Mandoos, A., Tsay, S. C., and Eck, T. F.: Dynamics of southwest Asian dust particle size characteristics with implications for global dust research, J. Geophys. Res.-Atmos., 113, D14212, doi:10.1029/2007jd009752, 2008.

Renfrew, I. A., Moore, G. W. K., Kristjánsson, J. E., Ólafsso, N. H., Gray, S. L., Petersen, G. N., Bovis, K., Brown, P., For, e. I., Haine, T. W. N., Hay, C., Irvine, E. A., Oghuishi, T., Outte, n. S. D., Pickart, R., Shapiro, M. A., Sproson, D., Swinbank, R., Wooley, A., and Zhang, S.: The Greenland flow distortion experiment, B. Am. Meteorol. Soc., 89, 1307-1324, doi:10.1175/2008bams2508.1, 2008.

Roberts, G. C. and Nenes, A.: A continuous-flow streamwise thermal-gradient $\mathrm{CCN}$ chamber for atmospheric measurements, Aerosol. Sci. Tech., 39, 206-221, doi:10.1080/027868290913988, 2005.

Rodwell, M. J. and Jung, T.: Understanding the local and global impacts of model physics changes: An aerosol example, Q. J. Roy. Meteor. Soc., 134, 1479-1497, doi:10.1002/Qj.298, 2008.

Rose, D., Gunthe, S. S., Mikhailov, E., Frank, G. P., Dusek, U., Andreae, M. O., and Pöschl, U.: Calibration and measurement uncertainties of a continuous-flow cloud condensation nuclei counter (DMT-CCNC): CCN activation of ammonium sulfate and sodium chloride aerosol particles in theory and experiment, Atmos. Chem. Phys., 8, 1153-1179, doi:10.5194/acp-8-11532008, 2008.

Rosenberg, P. D., Dean, A. R., Williams, P. I., Dorsey, J. R., Minikin, A., Pickering, M. A., and Petzold, A.: Particle sizing calibration with refractive index correction for light scattering optical particle counters and impacts upon PCASP and CDP data collected during the Fennec campaign, Atmos. Meas. Tech., 5, 1147-1163, doi:10.5194/amt-5-1147-2012, 2012.

Rosenberg, P. D., Parker, D. J., Ryder, C. L., Marsham, J. H., Garcia-Carreras, L., Dorsey, J. R., Brooks, I. M., Dean, A. R., Crosier, J., McQuaid, J. B., and Washington, R.: Quantifying particle size and turbulent scale dependence of dust flux in the Sahara using aircraft measurements, J. Geophys. Res.-Atmos., 119, 7577-7598, doi:10.1002/2013jd021255, 2014.

Ryder, C. L., Highwood, E. J., Lai, T. M., Sodemann, H., and Marsham, J. H.: Impact of atmospheric transport on the evolution of microphysical and optical properties of Saharan dust, Geophys. Res. Lett., 40, 2433-2438, doi:10.1002/Grl.50482, 2013a.

Ryder, C. L., Highwood, E. J., Rosenberg, P. D., Trembath, J., Brooke, J. K., Bart, M., Dean, A., Crosier, J., Dorsey, J., Brindley, H., Banks, J., Marsham, J. H., McQuaid, J. B., Sodemann, H., and Washington, R.: Optical properties of Saharan dust aerosol and contribution from the coarse mode as measured during the Fennec 2011 aircraft campaign, Atmos. Chem. Phys., 13, 303325, doi:10.5194/acp-13-303-2013, 2013b.

Sassen, K., DeMott, P. J., Prospero, J. M., and Poellot, M. R.: Saharan dust storms and indirect aerosol effects on clouds: CRYSTAL-FACE results, Geophys. Res. Lett., 30, 1633, doi:10.1029/2003g1017371, 2003.

Schepanski, K., Tegen, I., Laurent, B., Heinold, B., and Macke, A.: A new Saharan dust source activation frequency map de- rived from MSG-SEVIRI IR-channels, Geophys. Res. Lett., 34, L18803, doi:10.1029/2007g1030168, 2007.

Schepanski, K., Tegen, I., and Macke, A.: Saharan dust transport and deposition towards the tropical northern Atlantic, Atmos. Chem. Phys., 9, 1173-1189, doi:10.5194/acp-9-1173-2009, 2009.

Schepanski, K., Flamant, C., Chaboureau, J. P., Kocha, C., Banks, J. R., Brindley, H. E., Lavaysse, C., Marnas, F., Pelon, J., and Tulet, P.: Characterization of dust emission from alluvial sources using aircraft observations and high-resolution modeling, J. Geophys. Res.-Atmos., 118, 7237-7259, doi:10.1002/Jgrd.50538, 2013.

Scheuvens, D., Schutz, L., Kandler, K., Ebert, M., and Weinbruch, S.: Bulk composition of northern African dust and its source sediments - A compilation, Earth-Sci. Rev., 116, 170194, doi:10.1016/j.earscirev.2012.08.005, 2013.

Schuster, G. L., Vaughan, M., MacDonnell, D., Su, W., Winker, D., Dubovik, O., Lapyonok, T., and Trepte, C.: Comparison of CALIPSO aerosol optical depth retrievals to AERONET measurements, and a climatology for the lidar ratio of dust, Atmos. Chem. Phys., 12, 7431-7452, doi:10.5194/acp-12-7431-2012, 2012.

Sodemann, H., Lai, M., Marenco, F., Ryder, C. L., Flamant, C., Knippertz, P., Rosenberg, P., Bart, M., and McQuaid, J. B.: Lagrangian dust model simulations for a case of moist convective dust emission and transport in the western Sahara region during Fennec/LADUNEX, J. Geophys. Res.-Atmos., 120, 6117-6144, doi:10.1002/2015JD023283, 2015.

Sternberg, R.: Into the Cauldron: A Meteorological Adventure, in: EGU GeoCinema, available at: http://fennec.ouce.ox.ac.uk/ movie.html (last access: 23 July 2015), 2013.

Stohl, A., Forster, C., Frank, A., Seibert, P., and Wotawa, G.: Technical note: The Lagrangian particle dispersion model FLEXPART version 6.2, Atmos. Chem. Phys., 5, 2461-2474, doi:10.5194/acp-5-2461-2005, 2005.

Sultan, B. and Janicot, S.: The West African monsoon dynamics. Part II: The "preonset" and "onset" of the summer monsoon, J. Climate, 16, 3407-3427, doi:10.1175/15200442(2003)016<3407:Twamdp>2.0.Co;2, 2003.

Sun, D. L., Lau, W. K. M., Kafatos, M., Boybeyi, Z., Leptoukh, G., Yang, C. W., and Yang, R. X.: Numerical Simulations of the Impacts of the Saharan Air Layer on Atlantic Tropical Cyclone Development, J. Climate, 22, 6230-6250, doi:10.1175/2009jcli2738.1, 2009.

Tesche, M., Ansmann, A., Muller, D., Althausen, D., Mattis, I., Heese, B., Freudenthaler, V., Wiegner, M., Esselborn, M., Pisani, G., and Knippertz, P.: Vertical profiling of Saharan dust with Raman lidars and airborne HSRL in southern Morocco during SAMUM, Tellus B, 61, 144-164, doi:10.1111/j.16000889.2008.00390.x, 2009.

Thorncroft, C. D., Parker, D. J., Burton, R. R., Diop, M., Ayers, J. H., Barjat, H., Devereau, S., Diongue, A., Dumelow, R., Kindred, D. R., Price, N. M., Saloum, M., Taylor, C. M., and Tompkins, A. M.: The JET2000 project: Aircraft observations of the African easterly jet and African easterly waves, B. Am. Meteorol. Soc., 84, 337-351, 2003.

Todd, M. C., Allen, C. J. T., Bart, M., Bechir, M., Bentefouet, J., Brooks, B. J., Cavazos-Guerra, C., Clovis, T., Deyane, S., Dieh, M., Engelstaedter, S., Flamant, C., Garcia-Carreras, L., Gandega, A., Gascoyne, M., Hobby, M., Kocha, C., Lavaysse, C., 
Marsham, J. H., Martins, J. V., McQuaid, J. B., Ngamini, J. B., Parker, D. J., Podvin, T., Rocha-Lima, A., Traore, S., Wang, Y., and Washington, R.: Meteorological and dust aerosol conditions over the western Saharan region observed at Fennec Supersite-2 during the intensive observation period in June 2011, J. Geophys. Res.-Atmos., 118, 8426-8447, doi:10.1002/Jgrd.50470, 2013.

Tompkins, A. M., Cardinali, C., Morcrette, J. J., and Rodwell, M.: Influence of aerosol climatology on forecasts of the African Easterly Jet, Geophys. Res. Lett., 32, L10801, doi:10.1029/2004g1022189, 2005.

Trembath, J.: Airborne CCN Measurements, SAES, University of Manchester, UK, 2012.

Trembath, J., Bart, M., and Brooke, J.: FAAM Technical Note: Efficiencies of modified Rosemount housings for sampling aerosol on a fast atmospheric research aircraft, Facility for Airborne Atmospheric Measurements, FAAM, Cranfield, UK, http://www.faam.ac.uk/index.php/faam-documents/ science-instruments (last access: 23 July 2015), 2012.

Tulet, P., Crahan-Kaku, K., Leriche, M., Aouizerats, B., and Crumeyrolle, S.: Mixing of dust aerosols into a mesoscale convective system Generation, filtering and possible feedbacks on ice anvils, Atmos. Res., 96, 302-314, doi:10.1016/j.atmosres.2009.09.011, 2010.

Turnbull, K., Johnson, B., Marenco, F., Haywood, J. M., Minikin, A., Weinzierl, B., Schlager, H., Schumann, U., Leadbetter, S., and Woolley, A.: A case study of observations of volcanic ash from the Eyjafjallajokull eruption: 1. In situ airborne observations, J. Geophys. Res.-Atmos., 117, D00U12, doi:10.1029/2011jd016688, 2012.

Twohy, C. H., Kreidenweis, S. M., Eidhammer, T., Browell, E. V., Heymsfield, A. J., Bansemer, A. R., Anderson, B. E., Chen, G., Ismail, S., DeMott, P. J., and Van den Heever, S. C.: Saharan dust particles nucleate droplets in eastern Atlantic clouds, Geophys. Res. Lett., 36, L01807, doi:10.1029/2008gl035846, 2009.

Veihelmann, B., Konert, M., and van der Zande, W. J.: Size distribution of mineral aerosol: using light-scattering models in laser particle sizing, Appl. Optics, 45, 6022-6029, doi:10.1364/Ao.45.006022, 2006.
Washington, R., Todd, M. C., Engelstaedter, S., Mbainayel, S., and Mitchell, F.: Dust and the low-level circulation over the Bodele Depression, Chad: Observations from BoDEx 2005, J. Geophys. Res.-Atmos., 111, D03201, doi:10.1029/2005jd006502, 2006.

Washington, R., Flamant, C., Parker, D. J., Marsham, J. H., McQuaid, J. B., Brindley, H., Todd, M., Highwood, E. J., Ryder, C. L., Chaboureau, J.-P., Kocha, C., Bechir, M., and Saci, A.: Fennec - The Saharan Climate System, CLIVAR Exchanges, 17, 31-32, 2012.

Weinzierl, B., Petzold, A., Esselborn, M., Wirth, M., Rasp, K., Kandler, K., Schütz, L., Koepke, P., and Fiebig, M.: Airborne measurements of dust layer properties, particle size distribution and mixing state of Saharan dust during SAMUM 2006, Tellus B, 61, 96-117, doi:10.1111/j.1600-0889.2008.00392.x, 2009.

Wendisch, M., Coe, H., Baumgardner, D., Brenguier, J.-L., Dreiling, V., Fiebig, M., Formenti, P., Herman, J. R., Kramer, M., Levin, Z., Maser, R., Matieu, E., Nacass, P., Noone, K., Osborne, S., Schneider, S., Schutz, L., Schwarzenboeck, A., Stratmann, F., and Wilson, J. C.: Aircraft particle inlets: State-ofthe-art and future needs, B. Am. Meteorol. Soc., 85, 89-91, doi:10.1175/BAMS-85-1-89, 2004.

Wilson, J. C., Lafleur, B. G., Hilbert, H., Seebaugh, W. R., Fox, J., Gesler, D. W., Brock, C. A., Huebert, B. J., and Mullen, J.: Function and performance of a low turbulence inlet for sampling supermicron particles from aircraft platforms, Aerosol Sci. Tech., 38, 790-802, doi:10.1080/027868290500841, 2004.

Wilson, S. H. S., Atkinson, N. C., and Smith, J. A.: The development of an airborne infrared interferometer for meteorological sounding studies, J. Atmos. Ocean. Tech., 16, 1912-1927, doi:10.1175/1520-0426(1999)016<1912:Tdoaai>2.0.Co;2, 1999.

Zipser, E. J., Twohy, C. H., Tsay, S. C., Thornhill, K. L., Tanelli, S., Ross, R., Krishnamurti, T. N., Ji, Q., Jenkins, G., Ismail, S., Hsu, N. C., Hood, R., Heymsfield, G. M., Heymsfield, A., Halverson, J., Goodman, H. M., Ferrare, R., Dunion, J. P., Douglas, M., Cifelli, R., Chen, G., Browell, E. V., and Anderson, B.: The Saharan Air Layer and the Fate of African Easterly Waves, B. Am. Meteorol. Soc., 90, 1137-1156, doi:10.1175/2009bams2728.1, 2009. 